\title{
Home or home-like hospital birth for low-risk nulliparae : does it matter?
}

Citation for published version (APA):

Hendrix, M. J. C. (2010). Home or home-like hospital birth for low-risk nulliparae : does it matter? [Doctoral Thesis, Maastricht University]. Datawyse / Universitaire Pers Maastricht. https://doi.org/10.26481/dis.20100616mh

Document status and date:

Published: 01/01/2010

DOI:

10.26481/dis.20100616mh

Document Version:

Publisher's PDF, also known as Version of record

\section{Please check the document version of this publication:}

- A submitted manuscript is the version of the article upon submission and before peer-review. There can be important differences between the submitted version and the official published version of record.

People interested in the research are advised to contact the author for the final version of the publication, or visit the DOI to the publisher's website.

- The final author version and the galley proof are versions of the publication after peer review.

- The final published version features the final layout of the paper including the volume, issue and page numbers.

Link to publication

\footnotetext{
General rights rights.

- You may freely distribute the URL identifying the publication in the public portal. please follow below link for the End User Agreement:

www.umlib.nl/taverne-license

Take down policy

If you believe that this document breaches copyright please contact us at:

repository@maastrichtuniversity.nl

providing details and we will investigate your claim.
}

Copyright and moral rights for the publications made accessible in the public portal are retained by the authors and/or other copyright owners and it is a condition of accessing publications that users recognise and abide by the legal requirements associated with these

- Users may download and print one copy of any publication from the public portal for the purpose of private study or research.

- You may not further distribute the material or use it for any profit-making activity or commercial gain

If the publication is distributed under the terms of Article $25 \mathrm{fa}$ of the Dutch Copyright Act, indicated by the "Taverne" license above, 


\section{Home or home-like hospital birth for low-risk nulliparae:}

does it matter? 
The studies described in this thesis were performed within GROW- School for Ocology and Development Biology and within CAPHRI School for Public Health and Primary Care.

Cover design: Bart Ploemen

Layout: Marijke Hendrix

Printed by: Datawyse, Universitaire Pers Maastricht

(C) Copyright M.J.C. Hendrix, Maastricht 2010

Universitaire Pers Maastricht

ISBN 978-90-5278-945-3 


\title{
Home or home-like hospital birth for low-risk nulliparae:
}

\author{
does it matter?
}

\author{
PROEFSCHRIFT \\ ter verkrijging van de graad van doctor \\ aan de Universiteit Maastricht, \\ op gezag van de Rector Magnificus \\ Prof. mr. G.P.M.F. Mols
}

volgens het besluit van het College van Decanen,

in het openbaar te verdedigen

op woensdag 16 juni 2010 om 16.00 uur

door

Maria Johanna Catharina Hendrix

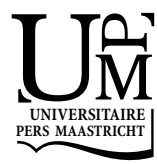




\section{Promotores}

Prof. dr. J.G. Nijhuis

Prof. dr. J.L. Severens

\section{Copromotor}

Dr. M.I. Pavlova

\section{Beoordelingscommissie}

Prof. dr. J.F.M. Metsemakers (voorzitter)

Prof. dr. S.E. Buitendijk (Universiteit van Amsterdam)

Prof. dr. G.G.M. Essed

Prof. dr. W. Groot

Dr. A. de Jonge (Vrije Universiteit Amsterdam)

The studies described in this thesis were supported by grants from the Profileringsfonds (PF198), Maastricht University Medical Centre. 


\section{Contents}

$\begin{array}{lll}\text { Chapter } 1 \text { General introduction } & 7\end{array}$

Chapter 2 Why women do not accept randomization for place of birth: 19 feasibility of a RCT in the Netherlands.

Chapter 3 The choice of obstetric care in the Netherlands: implications for policy and management.

Chapter 4 Differences in preferences for obstetric care between nulliparae and their partners in the Netherlands, using the discrete-choice experiment.

Chapter 5 Operative deliveries in low-risk pregnancies in the Netherlands: primary versus secondary care.

Chapter 6 Differences in referrals in low-risk pregnancies in the Netherlands: home birth versus home-like hospital birth.

Chapter 7 Cost analysis of the Dutch obstetric system: home birth compared to short-stay hospital birth - a prospective nonrandomised controlled study.

Chapter 8 General discussion

Chapter 9 Summary

Chapter 10 Samenvatting

Dankwoord

Curriculum Vitae

List of publications 

Chapter 1

General introduction 


\section{Chapter 1}

\section{Introduction}

In contrast to most other high-income countries, the organization of the Dutch obstetric care is unique. In the Netherlands, low-risk pregnant women have the possibility of choosing between a home birth and a home-like hospital birth, supervised by their own primary caregiver, a midwife or a general practitioner. In the latter case (i.e. a home-like hospital birth), the woman can choose for a birth in the hospital under supervision of her own midwife. When no complications occur, the woman can be discharged within a couple of hours of giving birth. In the literature, the term "short-stay hospital birth" is used as well ". Both terms, "home-like hospital birth" and "short-stay hospital birth" will be used interchangeably in this thesis and refer to a hospital birth under the supervision of a primary caregiver (midwife or GP).

Annually, about $30 \%$ of all Dutch women who expecting a child give birth at home and another $10 \%$ in a home-like hospital environment. The remaining $60 \%$ give birth at a hospital under supervision of the obstetrician (secondary care). However, the organization of the Dutch obstetric care became increasingly a subject for discussion because of several developments in the last decade, such as high perinatal mortality ${ }^{1,2}$, negative perceptions of birth experiences with the obstetric care ${ }^{3-5}$ and high intervention and referral rates ${ }^{6-8}$. In particular, women with a first ongoing pregnancy (nulliparae) are known to have high intervention and referral rates during birth ${ }^{6-8}$ and negative feelings about their experiences three years after giving birth ${ }^{3}$.

This thesis presents studies which have been conducted to compare and analyse several aspects of home births versus home-like hospital births for low-risk nulliparae. First, this thesis will give background information about the Dutch obstetric care givers and the developments in the Dutch obstetric care will be given, as well as an explanation of the research carried out for this thesis.

\section{Obstetric caregivers in the Netherlands}

Maternity care in the Netherlands is divided into primary care for low-risk pregnant women and secondary care for women with an increased risk of medical problems. At the primary care level, most of the obstetric care is provided by independent midwives (i.e. private practice). Some general practitioners attend women during their pregnancy and delivery as well (in about $5 \%$ of all cases) ${ }^{9,10}$. When complications occur during pregnancy or birth, the midwife has to refer the

1 The term home-like birth is a common term in other international countries. However, in these countries 'home-like' refers to the home-like interior of the maternity room, but the obstetrician is still responsible for the obstetric care. 


\section{General introduction}

woman to an obstetrician for secondary care, further assessment or treatment. If the complications cannot be treated, the obstetrician continues the care for the pregnant woman. Otherwise, the obstetrician may refer the woman back to the midwife. The need for collaboration between midwives and obstetricians has been specified in the Obstetric Manual (Verloskundig Vademecum) ${ }^{11}$. This manual can in fact be described as a clinical guideline and includes a list of obstetric indications for referral from primary care to secondary care, based on the evidence or consensus.

The number of registered midwives in the Netherlands has largely increased during the last decade ${ }^{12}$. In 1998 , there were a total of 1,416 registered midwives, while in 2008 , this number increased to 2,315 registered midwives. In 1998 , about $85 \%$ of the midwives worked in a private practice (individual or group practice). The other $15 \%$ of the midwives worked in the hospital maternity wards. In 2008, the number of midwives working in maternity wards increased. Of all midwives, $73 \%$ of the Dutch midwives worked in a private practice and $27 \%$ worked in the hospital ${ }^{12}$. This increase was in accordance with the advice of the 'Steering Group for the Modernization of Obstetrics' [Stuurgroep Modernisering Verloskunde] regarding continued presence of a clinical midwife on the maternity wards in the hospital ${ }^{13}$.

\section{Developments in the home birth rate}

In the Netherlands, planned home births are more common than in other highincome countries. However, the home birth rate decreased from $68.5 \%$ in 1965 to $35 \%$ at the end of the last century, and then to $29 \%$ in $2008{ }^{7}$. This decline can be explained to a certain extent by the introduction of the home-like hospital birth in the 1970's, although other factors also played an important role (e.g. delayed motherhood, social perceptions about technology development and risks during birth). The introduction of home-like hospital births provided Dutch women with a choice between a home birth and a birth in the hospital under the supervision of a midwife. In the case of a home-like hospital birth, assuming no complications occur, a woman could be discharged out of the hospital within a couple of hours after giving birth. Women with low-risk pregnancies are free to decide where to give birth, at home or in a home-like hospital setting, both attended by their midwife or general practitioner. However, when a woman prefers to give birth in a home-like hospital setting, she has to rent a maternity room in the hospital. For this rent, the woman has to pay a fee of $€ 350.00$ out-of-pocket (if these costs are not covered by her health insurance).

In the last decades an increase in the referral rate to obstetricians during childbirth was observed, particularly for nulliparae, both in planned home births and planned home-like hospital births ${ }^{6-8}$. In $1988,37 \%$ of all pregnant women were 


\section{Chapter 1}

referred to the obstetrician, where $18.4 \%$ were referred during pregnancy and $18.5 \%$ during labour. In $2004,51.4 \%$ of all pregnant women were referred to the obstetrician, where $27.4 \%$ were referred during pregnancy and $23.5 \%$ during labour ${ }^{8}$. Nulliparous women are known to be referred to the obstetrician more often than parous women ${ }^{14-18}$. Of all nulliparae in 2006 , only $19 \%$ gave birth at home and $10.8 \%$ had a home-like hospital birth ${ }^{19}$.

Obviously, the precise referral rates depend on the denominator used (e.g. all deliveries, or all deliveries starting in primary care, etc). Therefore, these referral rates led to debates among midwives, obstetricians and also policy makers. Tables 1 and 2 give an insight into the referral rates of low-risk nulliparae in 2006 and 2007, and it is easy to see what the effect is, if another denominator is used. Of all nulliparae in $2006,23.5 \%$ gave birth in primary care (at home or in a homelike hospital setting) and $76.5 \%$ gave birth in secondary care. In $2007,23.0 \%$ of all nulliparae gave birth in primary care. The referral rates during delivery were $18.0 \%$ in 2006 and $16.9 \%$ in 2007 , respectively.

Of all nulliparae who started their prenatal care in primary care the referral rates during delivery were $22.6 \%$ in 2006 and $21.3 \%$ in 2007 . In 2006, of all low-risk nulliparae who started their delivery in primary care $43.4 \%$ were referred to secondary care during delivery. In 2007 , this referral rate was $42.4 \%$.

Table 1: Referral rates from primary care to secondary care of nulliparae in 2006.

\begin{tabular}{|c|c|c|c|}
\hline & $\begin{array}{l}\text { All nulliparae } \\
\mathrm{N}=79.748(100 \%)\end{array}$ & $\begin{array}{l}\text { All nulliparae who } \\
\text { started their prenatal } \\
\text { care in primary care }\end{array}$ & $\begin{array}{l}\text { All nulliparae who } \\
\text { started their delivery } \\
\text { in primary care }\end{array}$ \\
\hline Primary care & 63.425 (79.5\%) & $63.425(100 \%)$ & \\
\hline Secondary care & $16.323(20.5 \%)$ & & \\
\hline $\begin{array}{l}\text { Referral during pregnancy to } \\
\text { secondary care }\end{array}$ & $30.335(38.0 \%)$ & $30.335(47.8 \%)$ & \\
\hline Start delivery in primary care & $33.090(41.5 \%)$ & $33.090(52.2 \%)$ & $33.090(100 \%)$ \\
\hline Start delivery in secondary care & $46.658(58.5 \%)$ & & \\
\hline Referral during delivery & $14.361(18.0 \%)$ & $14.361(22.6 \%)$ & $14.361(43.4 \%)$ \\
\hline Delivery in primary care & $18.729(23.5 \%)$ & $18.729(29.5 \%)$ & $18.729(56.6 \%)$ \\
\hline Delivery in secondary care & $61.019(76.5 \%)$ & & \\
\hline
\end{tabular}




\section{General introduction}

Table 2: Referral rates from primary care to secondary care of nulliparae in 2007.

\begin{tabular}{llll}
\hline & $\begin{array}{l}\text { All nulliparae } \\
\mathrm{N}=78.950(100 \%)\end{array}$ & $\begin{array}{l}\text { All nulliparae who } \\
\text { started their prenatal } \\
\text { care in primary care } \\
\mathrm{N}=62.829(100 \%)\end{array}$ & $\begin{array}{l}\text { All nulliparae who } \\
\text { started their deliv- } \\
\text { ery in primary care } \\
\mathrm{N}=31.538(100 \%)\end{array}$ \\
\hline $\begin{array}{l}\text { Primary care } \\
\text { Secondary care }\end{array}$ & $\begin{array}{l}62.829(79.6 \%) \\
16.121(20.4 \%)\end{array}$ & $62.829(100 \%)$ & \\
Referral during pregnancy to & $31.291(39.6 \%)$ & $31.291(49.8 \%)$ & \\
secondary care & & & $31.538(100 \%)$ \\
Start delivery in primary care & $31.538(39.9 \%)$ & $31.538(50.2 \%)$ & $13.377(42.4 \%)$ \\
Start delivery in secondary care & $47.412(60.1 \%)$ & & $18.161(57.6 \%)$ \\
Referral during delivery & $13.377(16.9 \%)$ & $13.377(21.3 \%)$ & \\
& $18.161(23.0 \%)$ & $18.161(28.9 \%)$ & \\
Delivery in primary care & $60.789(77.0 \%)$ & & \\
Delivery in secondary care & & & \\
\hline
\end{tabular}

A referral during birth has been shown to lead to more negative perceptions of birth experiences compared to not being referred ${ }^{3,5,20,21}$. A recent Dutch study showed that $23 \%$ of all nulliparae were, three years after giving birth of their first child, unhappy or very unhappy with their delivery. However, if women had delivered at home, they were very satisfied. In that case, $96 \%$ still felt satisfied 3 years after giving birth. A referral to the hospital seemed to be an important factor for a negative recall of the birth experience ${ }^{3}$.

The Dutch obstetric care has a well-established system of promoting home and home-like hospital birth and is therefore recommended as an ideal setting for a randomised controlled trial (RCT) comparing home birth versus home-like hospital birth that would assess perinatal outcomes and maternal safety and satisfaction ${ }^{22}$. A crucial question is whether pregnant women are prepared to participate in such a randomised trial. A RCT comparing different intended places of birth has never been conducted in the Netherlands, let alone elsewhere in the world. The focus of this thesis is the critical comparison of home versus home-like hospital birth.

\section{Preferences for place of birth}

In the Netherlands, where no complications occur during pregnancy and birth, the choice of the place of birth is made by the pregnant woman. This choice is often based on the preferences of the pregnant women. As a consequence, a discussion of Dutch obstetric care often refers to preferences and choices of low-risk 


\section{Chapter 1}

women as to the place of birth. Many studies indicate possible factors which weigh upon a woman's choice for obstetric care, like woman's socio-demographic characteristics, attributes of obstetric care, and attitudes towards childbirth $4,5,15,17,23-31$. These studies also showed that women's choices are influenced by social and cultural factors and are reinforced by own beliefs and experiences, the perceptions and experiences of significant others (partner, family and obstetric care providers) and the organization of obstetric care in the Netherlands. It is still not known whether these choices of obstetric care by low-risk pregnant women are due to the preferences for a specific place of birth or due to a combination of preferences for obstetric care, socio-demographic factors and attitudes that jointly result in a given choice of obstetric care.

During the last decade, the influence of partners during pregnancy and the child birth process has become factor in the decision-making process ${ }^{32}$. A Swedish study shows that women who are dissatisfied with the support they receive from their partner were at an increased risk of negative experiences with their birth ${ }^{33}$. However, it is unknown whether there are differences in preferences between low-risk pregnant women and their partners regarding the obstetric care. The preferences of pregnant women and their partners for obstetric care and the place of birth are analysed in this thesis.

\section{Referral rates, intervention during birth, costs of obstetric care}

Perinatal outcomes are an important subject of discussion in the Netherlands. They provide information about the quality of obstetric care and give women better information upon which to base their choice of place of birth. Recently, PERISTAT-II, a European study comparing health care outcomes of mothers and babies in 25 EU-countries and Norway, showed that the Netherlands had one of the highest perinatal mortality rates in Europe ${ }^{1,2}$. The analysis that followed implied that this was due to the organization of the Dutch obstetric care system and the inherent risks of a home birth. These critics of the Dutch system suggest that the high referral rate, especially for nulliparae, leads to the conclusion that adequate risk selection of low-risk pregnant women is not feasible anymore ${ }^{34}$. However, the safety of home births has been confirmed in several (inter)national studies ${ }^{35,36}$ and is therefore not part of this thesis. Previous (inter)national studies show also that women who started their delivery at home had a lower chance for operative deliveries, like vaginal operative deliveries and caesarean sections, than women who start their delivery in the hospital ${ }^{15-18,37}$. However, such evidence related to the place of birth was limited because of the differences in maternity care systems among the locations in where the studies were carried out. Thus, a comparative study on the planned place of birth (primary care or secondary care) and 


\section{General introduction}

incidence of operative deliveries among women with a low-risk pregnancy at the onset of delivery is still lacking.

As mentioned before, the referral rate for nulliparae in the Netherlands has increased for the last twenty years ${ }^{6-8}$. The differences in referral rates between home births and home-like hospital births have not been investigated in a prospective study. It is also unclear whether there are differences between home and home-like hospital births regarding operative deliveries and the consequences for the costs of obstetric care. However, as safety is comparable between home and home-like hospital birth, the costs of a home birth can be expected to be lower. These issues are tackled in this thesis.

Given this background information, we can conclude that Dutch obstetric care seems to have some important advantages, like safe home births and low intervention rates during birth. However, there are also some concerns, like high perinatal mortality, dissatisfaction with the obstetric care and high referral rates to secondary care level during birth.

So far, most studies on home births have focused on outcomes such as mortality and morbidity ${ }^{1,2,15,16,18,36,37}$ or on attitudes towards home births ${ }^{4,5,15,17,23-31}$. In most of these studies, the data are based on retrospective sources ${ }^{1,2,8,34}$, on studies conducted in the last century ${ }^{14,15,25,26,28-31}$, or conducted in other countries ${ }^{4,5,16,18,37}$. A prospective study about the differences between home births and home-like hospital births, especially for low-risk nulliparae, regarding preferences, referral rates and operative deliveries and the costs of primary care has, to our knowledge not been conducted so far. Research on these subjects provides important information about the quality of obstetric care. This information will be useful for care givers, health insurers and policy makers. In other high-income countries, almost all deliveries take place in the hospital. What will the future of Dutch obstetric care be? Does the current Dutch obstetric care perform adequately, especially for nulliparae?

\section{Aim of the study}

The aim of this study is to investigate the differences amongst low-risk pregnant women with regard to place of birth, as well as the effectiveness and efficiency of care. To achieve this aim, the following research questions have been formulated:

- Why are nulliparae not willing to participate in a randomised controlled trial comparing home births and home-like hospital births? (chapter 2).

- What are the preferences of nulliparae regarding the place of birth? (chapter 3).

- Are there differences in preferences between nulliparae and their partners with regard to place of birth? (chapter 4). 


\section{Chapter 1}

- What are the differences in operative deliveries between low-risk pregnancies in primary and secondary care? (chapter 5).

- Are there differences in referral and intervention rates between nulliparae planning to give birth at home and women planning to give birth in the hospital? (chapter 6).

- What are the total costs of home births and home-like hospital births for lowrisk nulliparae? (chapter 7 ).

In chapter 8, the main results of these studies and their possible implications are discussed.

\section{Materials}

The studies presented in this thesis are based on retrospective and prospective data. The retrospective data in this study were derived from the Netherlands Perinatal Registry (LVR-1 and LVR-2) and contained data about births in 2003. Data were included from women who were considered low-risk at the start of delivery and for whom data have been recorded about their planned place of birth $(n=107.667)$.

A prospective study was conducted to investigate the differences between lowrisk nulliparae preferring a home birth and such women who prefer a home-like hospital birth. One hundred midwives from across the Netherlands were involved in the recruitment of the study population. Women who were expected to give birth to their first child (nulliparae), and their partners were eligible to participate in the cohort study. All women had a low-risk pregnancy (no medical complications or risk factors) and had to understand the Dutch language sufficiently to read and fill out the questionnaires. Eligible pregnant women and their partners received the study information at the first prenatal visit (8-10th week of pregnancy). When they decided to participate they gave informed consent. Recruitment was carried out between March 2007 and August 2007. In this period, 529 women and 372 partners gave informed consent.

The data in this prospective study were collected using three questionnaires, a cost diary, and birth registration forms. The first questionnaire was sent out immediately after the woman and her partner gave informed consent (around the 16 th week of pregnancy). This questionnaire consisted of questions regarding the preferences of the women and their partners regarding place of birth, pregnancy and the information given by the midwife. In addition to those questions, some questions about the socio-demographic and psychological characteristics of the respondent were included. At a gestation age of 32 weeks, the respondents received the second questionnaire. The topic of this questionnaire was the differences in preferences during pregnancy and birth. Six weeks after giving birth, 


\section{General introduction}

questionnaire 3 was sent out. This questionnaire contained questions about the experiences of the place of birth and the birth in general.

Cost diaries completed by the respondents were used to determine the volume of contacts with health care providers (e.g. midwife, GP, obstetrician) and the use of medication. The women were asked to fill in these diaries weekly. After the woman gave birth, the midwife was asked to send the birth registration form. In case of a hospital birth, the birth registration form of the hospital was also reclaimed.

In Figure 1, an overview of the follow-up is presented of the women who were included in the prospective study.

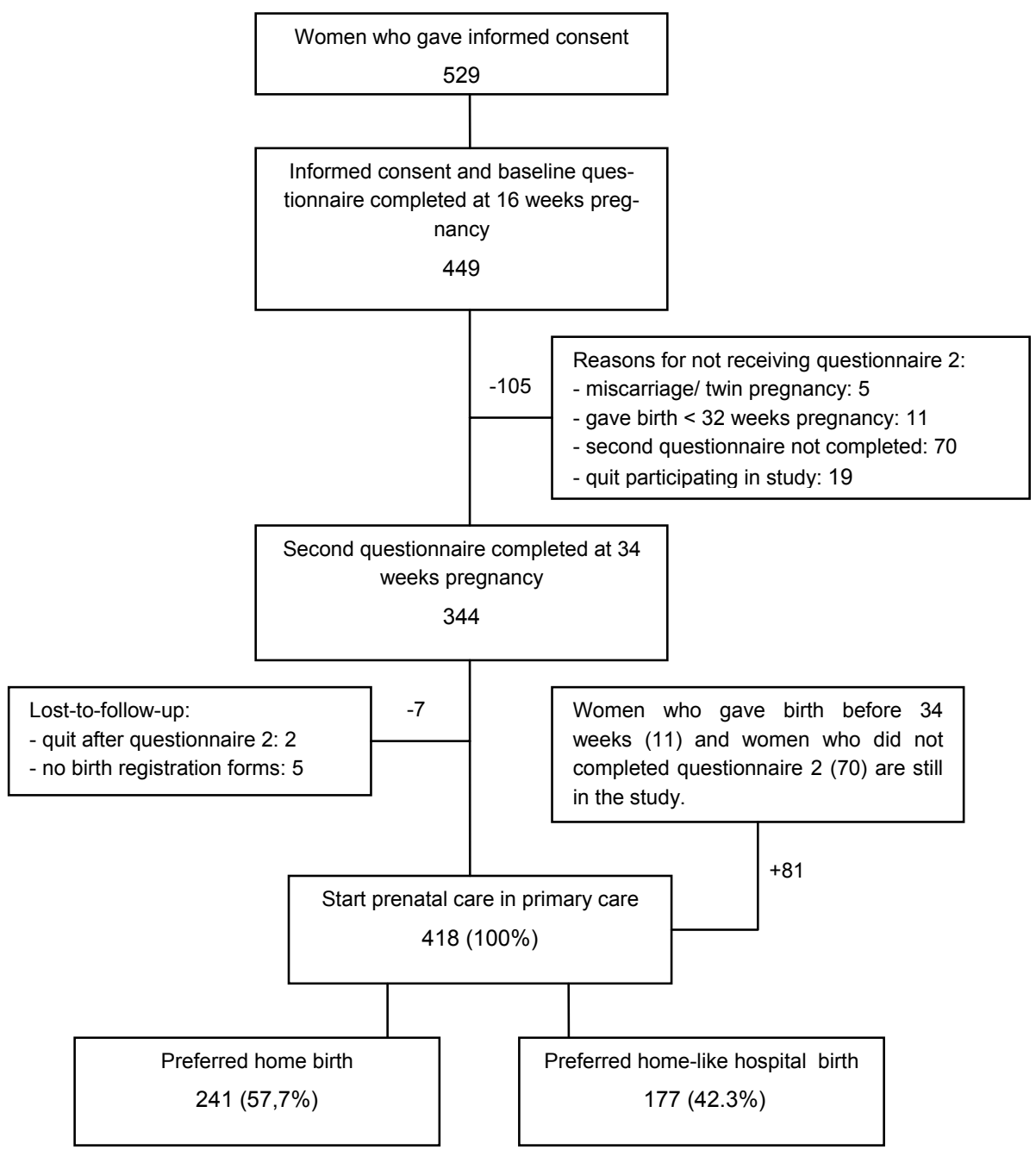

Figure 1: Flowchart of the women in the prospective study 


\section{Chapter 1}

\section{References}

1 Buitendijk SE, Nijhuis JG. Hoge perinatale sterfte in Nederland in vergelijking tot de rest van Europa. Ned Tijdschr Geneeskd 2004; 148: 1855-60.

2 Mohangoo AD, Nijhuis JG, Buitendijk SE, Ravelli ACJ, Hukkelhoven CWPM, Rijninks-van Driel GC, Tamminga P. Hoge perinatale sterfte in Nederland vergeleken met andere Europese landen: de Peristat-II-studie. Ned Tijdschr Geneeskd 2008;152 : 2718-27.

3 Rijnders M, Baston H, Schonbeck Y, van der Pal, K, Prins, M, Green J, Buitendijk S. Perinatal factors related to positive or negative recall of birth experience in women 3 years post partum in The Netherlands. Birth. 2008; 35: 107-16.

4 Christiaens W, Bracke P. Place of birth and satisfaction with childbirth in Belgium and Netherlands. Midwifery 2009; 25: e11-e19.

5 Christiaens W, Gouwy A, Bracke P. Does a referral from home to hospital affect satisfaction with childbirth? A cross-national comparison. BMC Health Services Research 2007; 7: 109.

6 Anthony S, Amelink-Verburg MP, Jacobusse GW, van der Pal- de Bruin KM. De thuisbevalling in Nederland 1995-2002. Leiden: Stichting Perinatale Registratie Nederland en TNO Kwaliteit van Leven, 2005.

7 Centraal Bureau voor de Statistiek, 2009.

8 Amelink-Verburg MP, Rijnders MEB, Buitendijk SE. A trend analysis in referrals during pregnancy and labour in Dutch midwifery care 1988-2004. BJOG 2009; 116: 923-32.

9 Coffie DSV, Wiegers TA, Schellevis FG. Verloskunde uit de eerste lijn. Verschuiving in taakopvatting van huisartsen. Medisch Contact 2003; 58: 803-4.

10 Wiegers TA. Steeds minder huisartsen verloskundig actief. Huisarts en Wetenschap 2003; 46: 432-4.

11 College voor Zorgverzekeringen. Verloskundig Vademecum 2003. Diemen: College voor Zorgverzekeringen, 2003.

12 Hingstman L, Kenens RJ. Cijfers uit de registratie van verloskundige: peiling 2008. Utrecht: Nivel, 2009.

13 Stuurgroep Modernisering Verloskunde. Eindrapportage Stuurgroep Modernisering Verloskunde. Bilthoven: Stuurgroep modernisering verloskunde, 2000.

14 Berghs G, Spanjaards E, Driessen L, et al. Neonatal neurological outcome after low-risk pregnancies. Eur J Obstet Gynecol 1995; 62: 167-71.

15 Wiegers TA, Keirse MJ, Zee van der J, Berghs GA. Outcome of planned home and planned hospital births in low risk pregnancies: Prospective study in midwifery practices in the Netherlands. BMJ 1996; 313: 1309-13.

16 Janssen PA, Lee SK, Ryan E, et al. Outcomes of planned home births versus planned hospital births after regulation of midwifery in British Columbia. Can Med Assoc J 2002; 166: 315-23.

17 Van der Hulst LAM, van Teijlingen ER, Bonsel GJ, Eskes M, Bleker OP. Does a pregnant's woman intended place of birth influence her attitudes toward and occurrence of obstetric interventions? Birth 2004; 31: 28-33.

18 Johnson KC, Daviss BA. Outcomes of planned home births with certified professional midwives: Large prospective study in North America. BMJ 2005; 330: 1416.

19 Stichting Perinatale Registratie Nederland. Perinatale Zorg in Nederland 2006. Utrecht: Stichting Perinatale Registratie Nederland, 2008.

20 Wiegers TA, van der Zee J, Keirse MJ. Transfer from home to hospital: what is its effect on the experience of childbirth? Birth 1998; 25: 19-24.

21 Kleiverda G, Steen AM, Andersen I, Treffers PE, Everaerd W. Confinement in nulliparous women in the Netherlands: subjective experiences related to actual events and post-partum well-being. J Reprod Infant Psychol 1991; 9: 195-213.

22 Dowswell T, Thornton JG, Hewison J, Lilford RJ, Raisler J, Macfarlane A, et al. Should there be a trial of home versus hospital delivery in the United Kingdom? BMJ 1996; 312: 753-7.

23 Anthony S, Buitendijk SE, Offerhaus PM, Dommelen P, Pal-de Bruin KM. Maternal factors and the probability of a planned home birth. BJOG 2005; 112: 748-53. 


\section{General introduction}

24 Kind E. Thuis of in het ziekenhuis? Welke reden zijn voor de cliënt bepalend voor de keuze? Tijdschrift voor Verloskundigen 2000; 25: 110-15.

25 Hingstman L, Foets M, Ritcco JA. Meningen van de consumenten: thuis of in het ziekenhuis bevallen. Tijdschrift voor Verloskundigen 1993; 18: 66-74.

26 Kleiverda G, Steen AM, Andersen I. Place of delivery in the Netherlands: maternal motives and background variables related to preference for home or hospital confinement. Eur J Obstet Gynecol Reprod Biol 1990; 36: 1-9.

27 Van der Hulst LAM, van Teijlingen ER, Bonsel GJ, Eskes M, birnie E, Bleker OP. Dutch women's decision-making in pregnancy and labour as seen through the eyes of their midwives. Midwifery 2007; 23: 279-86.

28 Wiegers TA. Home or hospital birth: a prospective study of midwifery care in the Netherlands. Eur J Obstet Gynecol Reprod Biol 1998; 79: 139-41.

29 Wiegers TA, van der Zee J, Keirse MJNC. Maternity care in the Netherlands: the changing home birth rate. Birth 1998; $25: 190-7$.

30 Wiegers TA, van der Zee J, Kerssens JJ, Keirse MJNC. Variation in home-birth rates between midwifery practices in the Netherlands. Midwifery 2000; 16: 96-104.

31 Wiegers TA, van der Zee J, Kerssens JJ, Keirse MJNC. Home birth or short-stay hospital birth in a low risk population in the Netherlands. Soc Sci Med 1998; 46: 1505-11.

32 Capogna G, Camorcia M, Stirparo S. Expectant fathers' experience during labor with or without epidural analgesia. International Journal of Obstetric Anesthesia 2007; 16: 110-5.

33 Waldenström U, Hildingsson I, Rubertsson C, Rådestad I. A negative birth experience: prevalence and risk factors in a national sample. Birth. 2004; 31: 17-27.

34 Steer P. Editor's choice. How safe is home birth? BJOG 2008;115:i-ii.

35 Olsen O. Meta-analysis of the safety of home birth. Birth 1997; 24: 4-13.

36 de Jonge A, van der Goes BY, Ravelli ACJ, Amelink-Verburg MP, Mol BW, Nijhuis JG, et al. Perinatal mortality and morbidity in a nationwide cohort of 529688 low-risk planned home and hospital births. BJOG 2009; DOI:10.1111/j.1471-0528.2009.02175.x.

37 Ackermann-Liebrich U, Voegeli T, Gunter-Witt K, et al. Home versus hospital deliveries: Follow up study of matched pairs for procedures and outcome. BMJ 1996; 313: 1313-8. 



\section{Chapter 2 \\ Why women do not accept randomisation for place of birth: feasibility of a RCT in the Netherlands}

M.J.C Hendrix, M.W.P Van Horck, D. Moreta, F.H.M. Nieman, M.J Nieuwenhuijze, J.L. Severens and J.G. Nijhuis

BJOG 2009; 116: 537-4 


\section{Chapter 2}

\section{Abstract}

Objective The purpose of this study was to investigate why low-risk nulliparae were not willing to participate in a randomised controlled trial of place of birth.

Methods A questionnaire for 107 nulliparae who were willing to participate in a cohort study on place of birth, but at an earlier stage in their pregnancy declined to participate in a RCT of place of birth. This questionnaire included 12 items on a 4-point Likert scale but was not subjected to formal validation.

Main outcome measure Reasons why nulliparae did not accept randomisation of place of birth.

Results The most important reason why women refused participation in the trial was that they had already chosen their place of birth before they were asked to participate at 12 weeks pregnancy. From their answers, it became clear that pregnant women strongly value their autonomy of choice. The decision not to participate in the trial was not influenced by the information given by the midwife and the additional written information.

Conclusions Factors that prevent randomisation for place of birth are difficult to influence. There is a need to explore why there is such certainty of view amongst women having their first child. Until we have an understanding of why women select information to make these choices and why women are reluctant to participate in trials that challenge choice, it may well be impossible to mount a trial of place of birth. 


\section{Introduction}

With increasing interest in home birth there is a continuing debate about the need for a randomised controlled trial (RCT) comparing home birth versus hospital birth that would assess perinatal outcomes and maternal safety and satisfaction. An attempt at a trial in Britain recommended the Netherlands as the ideal setting for this type of RCT because the Dutch obstetric system has a well-established system that promotes home or home-like births ${ }^{1}$. Compared with other western countries, the Dutch obstetric system is unique: women, who have a low-risk pregnancy, are free to choose between a home birth (30\% of all deliveries) and a home-like short-stay hospital birth ( $12 \%$ of all deliveries). In both cases the birth is supervised by a registered independent midwife.

A study of place of birth is of interest as the process of childbirth is influenced by both biological and emotional factors, such as feelings of security and confidence, which are related to the place of birth ${ }^{2}$.

We designed a randomised controlled trial to investigate differences in interventions, satisfaction, referrals to the obstetrician and costs between home birth and home-like short-stay hospital birth. Low-risk nulliparous women were to be randomly allocated to giving birth at home or at a hospital, in both cases assisted by a registered independent midwife. They would be studied from the first trimester of the pregnancy until 6 weeks after delivery. Outcome variables of interest included expectations and experiences of pregnant women and their partners, indications for referral to specialist care and clinical interventions.

A crucial question was whether pregnant women would be prepared to participate in such a randomised trial, given the UK experience. Therefore, we conducted a pilot study in 2003. One hundred nulliparous women were given a hypothetical scenario of being randomly allocated to either a home birth or a short-stay hospital birth. Sixty women $(60 \%)$ answered this question and thirty women indicated that they would certainly be willing to participate. Based on this result a power calculation was performed; the trial was registered at Clinical Trials (registration number NCT00237601) and accepted by the medical ethical committee. Funding was raised and recruitment started in March 2006.

The trial was conducted in different parts of the Netherlands. Thirty-five midwives in 14 primary care midwifery practices participated in the trial by recruiting pregnant women. The midwives gave information about the trial during the first prenatal visit, usually between 8-10 weeks of pregnancy. Only nulliparous women were eligible to participate. Inclusion was possible up till the 18 week of pregnancy. A week after this prenatal visit these women were contacted by the researcher to ask if they wanted to participate in this trial. During this contact, more information about the study was given to the women and their questions were answered. When a pregnant woman declined to participate in the trial, the reason for this was asked and noted and the woman was asked to participate in a nonrandom- 


\section{Chapter 2}

ised cohort study. Participants were free to choose their place of birth, and data for both groups would be analysed separately. The reasons for nonparticipation in the trial or in cohort study at all were registered by the researcher.

After an inclusion period of 6 months during which all nulliparous women were asked to participate in the trial, only one woman had given informed consent for randomisation. Another 115 women declined the RCT but were willing to participate in the cohort study.

Given this striking discrepancy with our own expectations based on the results of the pilot study, several questions arose: why do pregnant women decline to be randomly allocate to either home birth or home-like short-stay hospital birth, which factors influence their decision and which is most decisive? We decided to perform a questionnaire study explore these questions.

\section{Methods}

A newly constructed, self administered postal questionnaire was developed. The study population was all nulliparous women who had declined participation in the trial but had agreed to participate in the cohort study $(n=115)$. Women who had given birth before the questionnaire was sent out were excluded $(n=8)$. The gestational age of women who were sent this questionnaire was between 9 and 34 weeks, 1 and 20 weeks after they declined participation in the trial.

The questionnaire was based on the reasons women had given by telephone and reasons found in previous studies of Verheggen et al ${ }^{3,4}$. Twelve items were included on a 4-point Likert scale containing statements respondents could agree or disagree with (Table 2). The statements referred to motivations for not participating in medical research in general and to possible motivations for not participating in this trial in particular. Underlying ideas that had emerged were feelings of autonomy in decision- making, fear of over-medicalisation or undermedicalisation in relation to the participation in the trial, or indifference with regard to medical research in general.

We asked to indicate to what extent they agreed or disagreed with the statements. To try to determine the content validity of the questionnaire the participants were also asked to write down their motivation in their own words, if this had not already been worded in the precoded, closed items in the questionnaire. The questionnaire was sent to 107 participants. The results were analysed using SPSS 12.0 (SPSS inc., Chicago, IL, USA). 


\section{Results}

Of the 107 participants, 84 women (79\%) returned the questionnaire. Twenty-one $(19 \%)$ did not return the questionnaire. Two women $(2 \%)$ had a spontaneous miscarriage (Figure 1). The demographic characteristics are summarised in Table 1.

Declining participation in the trial appeared to be based on four propositions (Table 2, proposition 1, 2, 3 and 5). The most important was that they had already chosen the place of birth before they were asked to participate in the trial. In more than $64.3 \%$ of the cases respondents agreed very much with that proposition. $60.7 \%$ of respondents agreed very much with the proposition: 'I hold on to my own choice on where I wish to give birth, researchers should not meddle in this'. Another important proposition was the fear of over-medicalisation: 'I do not wish to run the risk of receiving a treatment I do not want' $(46.4 \%$ agreed with this proposition strongly).

Also the fact that they were pregnant with their first child was an important reason for the respondents (Table 2, proposition 3).

The unwillingness of women to participate in the trial did not appear to be influenced by the oral and written information given by the midwives and a member of the research team. Eighty percent of the respondents indicated that the written information was clear enough. The purpose of medical research was clear for the respondents, and women stated that they were not against participation in medical research in general. No woman gave additional reason(s) for refusing participation that had not already been noted in the closed items of the questionnaire.

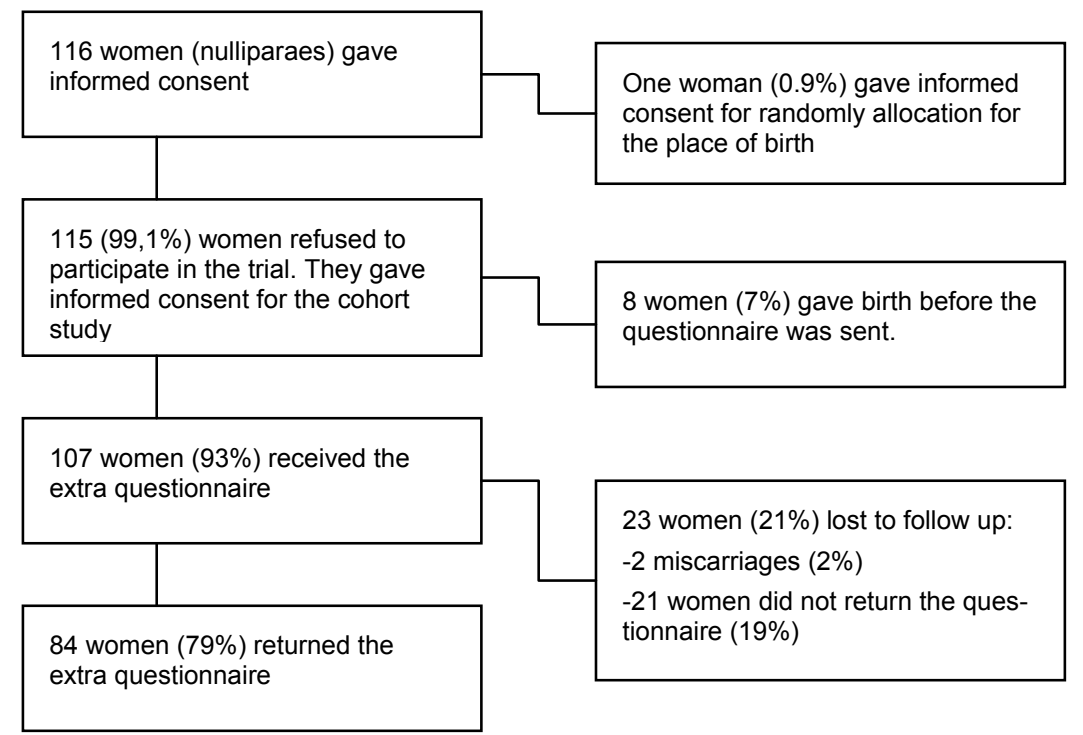

Figure 1: Follow up of the study population 


\section{Chapter 2}

Table 1: Characteristics of women in study $(n=84)$

\begin{tabular}{|c|c|c|}
\hline Basic characteristics & $\mathrm{N}(\%)$ & Mean (SD) \\
\hline Mean gestational age (weeks) & & $15(4.1)$ \\
\hline $\begin{array}{l}\text { Age (years) } \\
<25 \\
25-35 \\
>35 \\
\text { Unknown }\end{array}$ & $\begin{array}{l}14(16.8) \\
66(78.4) \\
1(1.2) \\
3(3.6)\end{array}$ & $28(3.8)$ \\
\hline $\begin{array}{l}\text { Length (metres) } \\
\quad<1.65 \\
1.65-1.75 \\
>1.75 \\
\text { Unknown }\end{array}$ & $\begin{array}{l}16(19.0) \\
45(53.6) \\
15(17.9) \\
8(9.5)\end{array}$ & $1.70(0.06)$ \\
\hline $\begin{array}{l}\text { Weight }(\mathrm{kg}) \\
<60 \\
60-75 \\
>75 \\
\text { Unknown }\end{array}$ & $\begin{array}{l}16(19.0) \\
4148.8) \\
18(21.5) \\
9(10.7)\end{array}$ & $68.9(12.9)$ \\
\hline $\begin{array}{l}\text { Nationality } \\
\text { Dutch } \\
\text { Other } \\
\text { Unknown }\end{array}$ & $\begin{array}{l}78(92.9) \\
3(3.6) \\
3(3.6)\end{array}$ & \\
\hline $\begin{array}{l}\text { Employment } \\
\text { Employment } \\
\text { Unemployment } \\
\text { Unknown }\end{array}$ & $\begin{array}{l}65(77.4) \\
11(13.1) \\
8(9.5)\end{array}$ & \\
\hline $\begin{array}{l}\text { Household income (monthly) } \\
<1000 \text { euro } \\
100-1500 \text { euro } \\
1500-2000 \text { euro } \\
2000-2500 \text { euro } \\
2500-3000 \text { euro } \\
>3000 \text { euro } \\
\text { No information } \\
\text { Unknown }\end{array}$ & $\begin{array}{l}3(3.6) \\
3(3.6) \\
5(6.0) \\
18(21.4) \\
21(25.0) \\
17(20.2) \\
14(16.7) \\
3(3.6)\end{array}$ & \\
\hline $\begin{array}{l}\text { Marital State } \\
\text { Married } \\
\text { Living together } \\
\text { Single } \\
\text { Unknown }\end{array}$ & $\begin{array}{l}30(36.1) \\
48(57.1) \\
1(1.2) \\
5(6.0)\end{array}$ & \\
\hline $\begin{array}{l}\text { Chosen place of birth } \\
\text { Home birth } \\
\text { Short-stay hospital birth } \\
\text { Hospital birth } \\
\text { No idea } \\
\text { Unknown }\end{array}$ & $\begin{array}{l}47(56) \\
30(35.7) \\
2(2.4) \\
2(2.4) \\
3(3.6)\end{array}$ & \\
\hline
\end{tabular}




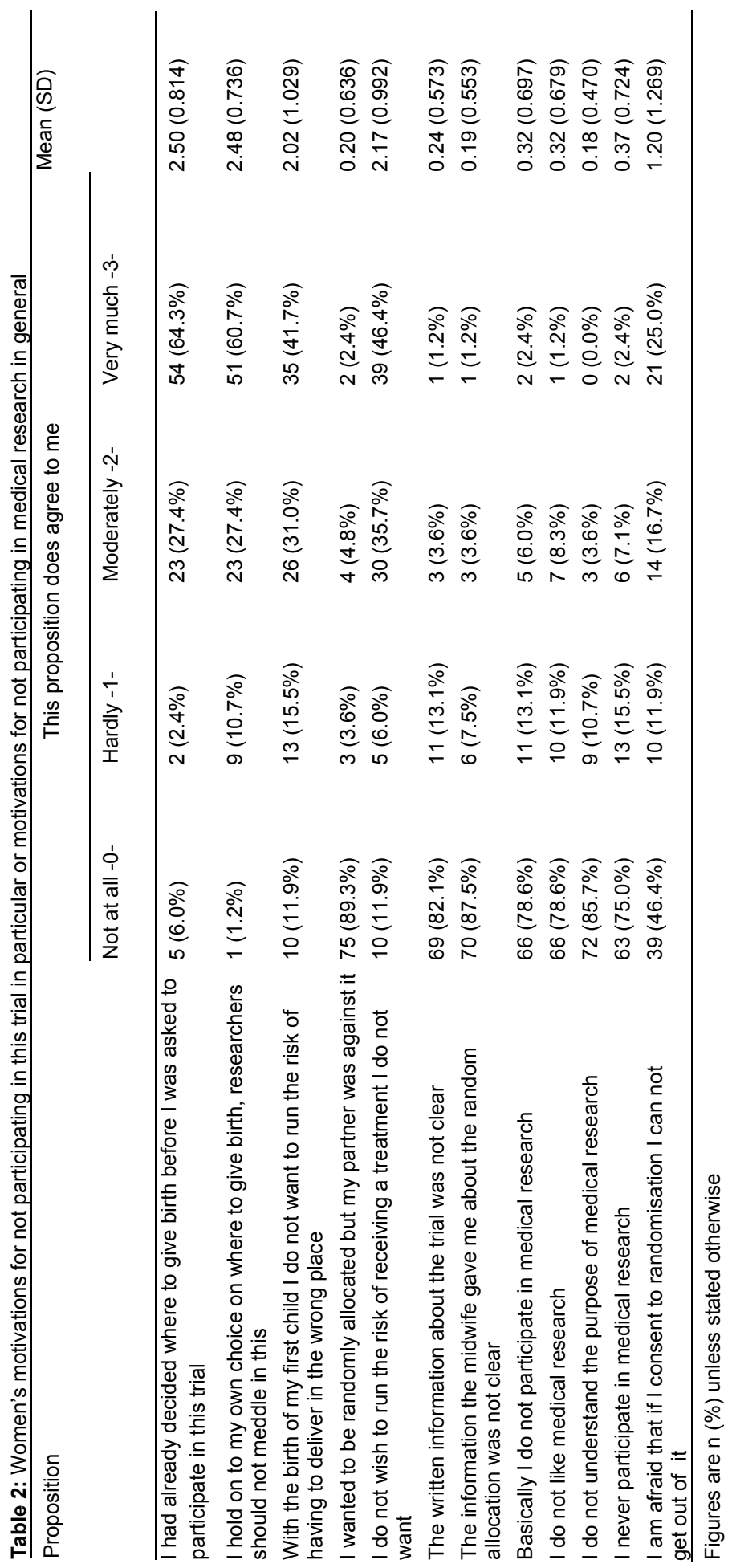




\section{Chapter 2}

\section{Discussion}

The most important reason for pregnant women to decline randomisation was that they highly value their autonomy. Women want to decide themselves about the place of birth. It is their opinion that researchers should not be meddling in this decision. The fact that women highly value their autonomy in these matters is a factor that cannot easily be manipulated or influenced and has to be respected. The questionnaire used in this study was an ad hoc questionnaire, newly constructed for this occasion. The researcher had registered the reasons women gave for their trial refusal. These reasons were used to construct items in the questionnaire in combination with some general questions from literature and the respondents had the opportunity to give their own opinion about the refusal.

We acknowledge that no formal analysis of the overall validity of the questionnaire has been undertaken, although we have examined content validity to some extent. It was felt that the timing of seeking women's views was important and this precluded the necessary pilot phase of such a questionnaire that would have provided data for validation. We are aware that this may have influenced the conclusions of our study. Disadvantages of not validating the questionnaire can be found in the external and internal validity. It is important to know if the questionnaire measures what it should measure (internal validity) and if the results are valid for the total population (external validity). Usually the validating process includes results from psychometric techniques like item analysis, correlational analysis of items, factor analysis, reliability coefficients (Cronbach's alpha) and scale construction(s) ${ }^{5-6}$. Especially the external validity of this questionnaire can be discussed. It is difficult to say whether the results of this study are applicable to all nulliparous women.

The time that women were asked to participate in this trial might play a role in the results. The women were informed during the first visit to their midwife. At that moment, most of the women were 8-10 weeks pregnant. Previous research shows that an early choice in these matters is highly correlated with the final choice ${ }^{7}$. The exact time when low-risk women decide where to give birth is unknown and difficult to determine. Women may choose their place of birth before they get pregnant.

It is unclear whether women stay with their first decision for the place of birth. It is possible that this is a dynamic process where women may move from one decision to another. It is interesting to investigate this decision-making process of pregnant women for the place of birth during pregnancy.

There is an increasing awareness that women should participate actively in decision-making, and there is evidence that properly informed women are more likely to adhere to treatment. Clear communication with women and their relatives is decisive. Random allocation of a treatment is a key feature that women have to understand prior to giving informed consent for a trial ${ }^{8}$. From our results we can 
conclude that the provision of the information seemed to have no effect on the decision to not participate in the randomisation. In this case more information or other methods of communication would probably not have changed their mind.

The provision of clear and accurate patient information is important, but this alone will not ensure consistent interpretation of concepts such as randomisation. Women may need to discuss the purpose of randomisation to understand them fully enough to give informed consent ${ }^{9}$. Other studies, in oncology care, showed that one of the main reasons for accepting trial entry is 'trust in the doctor', implying that the act of communication has a greater influence on the decision than the written word ${ }^{10}$. Randomised clinical trials pose particular problems, and the concept of randomisation raises many issues for both health care professionals and women ${ }^{11}$. It is possible that midwives participating in the trial did not fully support randomisation, although we do not know this. This might have influenced their communication with eligible women and may have had an impact on the women's decision to participate. However, eligible women who received information about the trial were also contacted by a member of the research team. They further explained the study protocol and its purpose. We therefore assume that the aim of the trial and the randomisation were sufficiently explained.

Randomisation in itself is not always understood by both women and the general public ${ }^{12}$. A series of studies showed that participants in a randomised trial did not find randomisation itself acceptable, nor did they find it acceptable that a clinician would not know which treatment was best ${ }^{13-14}$. Clear explanation of the concept and the purpose of the randomisation is fundamental to ensure properly educated consent to clinical trial participation. The purpose of our randomised trial was to compare two common 'standard' settings. In the Netherlands, both home births and home-like short-stay hospital births are common choices for a delivery supervised by a registered midwife. We had therefore expected that a RCT for home birth or home-like short-stay hospital birth would be feasible.

This assumption was tested in a pilot study in 2003 , before the trial actual started. One of the advantages of conducting a pilot study is that it might give advance warning about where the main research project could fail ${ }^{15}$. The result of our pilot study was promising, $50 \%$ indicated willingness to participate, and our power analysis was based on these results. However, when the trial actually started, only one woman out of the first 116 candidates accepted randomisation. The reason for this unexpected and almost unanimous refusal might be that when it comes to a hypothetical scenario, people prefer to give the socially most acceptable answer, while when dealing with real-life decisions they answer truthfully. Finally, nulliparous women are preparing for the unknown and might therefore be more reluctant to let others decide on the place of delivery. 


\section{Chapter 2}

\section{Conclusion}

The decision not to participate in a trial that randomly allocates nulliparous women to either a home birth or a home-like short-stay hospital birth may be explicable by the fact that women have already decided on their place of birth before their first visit with their midwife. These women highly value their autonomy of choice and do not want others to make these decisions for them, and these factors are difficult to influence.

Health care professionals must acknowledge that women value and deserve autonomy of choice, but such choice is only valid if it is based on reliable information about the risk-benefit ratios of their choice. Without such information, choice is not really meaningful because it is not properly informed. Given the repeated publication on the uncertainties of safety of home and home-like hospital births, ${ }^{16-}$ ${ }^{19}$ there is a need to explore why there is such certainty of view amongst women having their first child. Until we have an understanding of why women select information to make these choices and why women are reluctant to participate in trials that challenge choice, it may well be impossible to mount a trial of place of birth. 


\section{Randomisation for place of birth}

\section{References}

1 Dowswell T, Thornton JG, Hewison J, Lilford RJ, Raisler J,Macfarlane A, et al. Should there be a trial of home versus hospital delivery in the United Kingdom? BMJ 1996; 312: 753-7.

2 Wiegers TA. Home or hospital birth. A prospective study of midwifery care in The Netherlands. Thesis, University of Leiden, Leiden, 1997.

3 Verheggen FW, Jonkers R, Kok G. Patients' perceptions on informed consent and the quality of information disclosure in clinical trials. Patient Educ Couns 1996; 29: 137-53.

4 Verheggen FW, Nieman F, Jonkers R. Determinants of patient participation in clinical studies requiring informed consent: why patients enter a clinical trial. Patient Educ Couns 1998; 35: 11125.

5 Bouter LM, Van Dongen MCJM, Zielhuis GA. Epidemiologisch onderzoek Opzet en interpretatie. Houten, the Netherlands: Bohn Stafleu van Loghum, 2005.

6 Borsboom D, Mellenbergh GJ, van Heerden J. The concept of validity. Psychol Rev 2004; 111: 1061-71.

7 Howell-White S. Choosing a birth attendant: the influence of a woman's childbirth definition. Soc Sci Med 1997; 45: 925-36.

8 Jenkins V, Fallowfield L, Cox A. The preferences of 600 patients for different descriptions of randomisation. Br J Cancer 2005; 92: 807-10.

9 Featherstone K, Donovan JL. Random allocation or allocation at random? Patients' perspectives of participation in a randomised controlled trial. BMJ 1998; 317: 1177-80.

10 Jenkins V, Fallowfield L. Reasons for accepting or declining to participate in randomized clinical trials for cancer therapy. Br J Cancer 2000; 82: 1783-8.

11 Jenkins V, Leach L, Fallowfield L, Nicholls K, Newsham A. Describing randomisation: patients' and the public's preferences compared with clinicians' practice. Br J Cancer 2002; 87: 854-8.

12 Corbett F, Oldham J, Lilford R. Offering patients entry in clinical trials: preliminary study of the views of prospective participants. J Med Ethics 1996; 22: 227-31.

13 Kerr C, Robinson E, Stevens A, Braunholtz D, Edwards S, Lilford R. Randomisation in trials: do potential trial participants understand it and find it acceptable? J Med Ethics 2004; 30: 80-4.

14 Robinson EJ, Kerr C, Stevens A, Lilford R, Braunholtz D, Edwards S. Lay conceptions of the ethical and scientific justifications for random allocation in clinical trials. Soc Sci Med 2004; 58 : 811-24.

15 Van Teijlingen ER, Hundley V. The importance of pilot studies. Soc Res Update 2001.

16 Hodnett ED, Downe S, Edwards N, Walsh D. Home-like versus conventional institutional settings for birth (review). Cochrane Database Syst Rev 2005;CD000012. DOI: 10.1002/14651858. CD000012. pub2.

17 Wiegers TA. Home or hospital birth: a prospective study of midwifery care in the Netherlands. Eur J Obstet Gynecol Reprod Biol 1998; 79: 139-41.

18 Mori R, Dougherty M, Whittle M. An estimation of intrapartum-related perinatal mortality for booked home births in England and Wales between 1994 and 2003. BJOG 2008; 115: 554-9.

19 Olsen O, Jewell MD. Home versus hospital birth (review). Cochrane Database Syst Rev 1998;CD000352. DOI: 10.1002/14651858. CD000352. 



\section{Chapter 3}

\section{The choice of obstetric care by low-risk pregnant women in the Netherlands: implications for policy and management}

M.I. Pavlova, M.J.C. Hendrix, E. Nouwens, J.G. Nijhuis and G.G. van Merode

Health Policy 2009; 93: 27-34 


\section{Chapter 3}

\section{Abstract}

Background In the Netherlands, pregnant women at low risk of complications during pregnancy, have the opportunity to choose freely between giving birth at home or in a hospital maternity unit. This study analyses how various attributes of obstetric care, socio-economic characteristics and attitudes influence the decisions that these women make with regard to obstetric care.

Methods The method of discrete-choice experiment was applied in the process of data collection and analysis. The data were collected among low-risk nulliparous pregnant women.

Results The analysis suggests that there are strong preferences among some Dutch women for a home birth. Nevertheless, the absence of a medical painrelief treatment might provide incentives for some women to opt for a birth in a hospital, especially at the end of their pregnancy.

Conclusions If the attractiveness of home birth should be preserved in the Netherlands, specific attention should be paid on the approach to pain during a home birth. Efforts could also be made in offering a domestic atmosphere during hospital births to improve hospital-based obstetric care in view of women's preferences. 


\section{Introduction}

In the Netherlands, pregnant women at low risk of complications during pregnancy, have the opportunity to choose freely between giving birth at home or in a hospital maternity unit. In both cases, the birth is attended by a primary care provider (most often a registered midwife and rarely a GP). In case of a high-risk pregnancy or complications during birth, the woman is referred to an obstetrician and the birth always takes place in a hospital ${ }^{1-3}$. The home birth rate in the Netherlands slightly decreased during the last decade (from $35 \%$ to $29 \%$ ) ${ }^{4}$, but it remains uniquely high compared to other industrialised countries ${ }^{5-7}$. The literature explains this high home birth rate by the specific combination of social, cultural, political and organisational factors largely in favour of the social model of obstetric care for low-risk pregnant women (opposite to the technocratic model that prevails in other countries) ${ }^{8-12}$.

The discussions on home birth and obstetric care in the Netherlands often refer to the preferences of Dutch women for place of birth and attributes of obstetric care ${ }^{8,13,14}$. There is also ample empirical evidence on this topic (e.g. ${ }^{1,3,14-25}$ ). The research hitherto predominantly uses data on attitudes, experiences, and past utilisation of obstetric care by low-risk pregnant women. Based on these data, possible determinants of women's choices of obstetric care are revealed. The choice determinants concern the attributes of obstetric care, women's sociodemographic characteristics (incl. health status), and women's attitudes towards childbirth. Determinants related to attitudes frequently emerge as highly important compared to the other two categories. The overall conclusion is that women's attitudes towards childbirth are socially and culturally determined, and are reinforced by own believes and experience, the perceptions and experience of the significant others (partners, family, friends and obstetric care providers), and the organization of obstetric care in the Netherlands ${ }^{1,3,14-25}$.

However, the role of place of birth in the choice of obstetric care is not yet explicitly examined in the literature. It remains unclear from previous research whether the choice of obstetric care by low-risk pregnant women is due to preferences for a specific birth place (home or hospital) per se, or due to the specific combination of preferences for obstetric care, socio-demographic status and attitudes that jointly result in a given choice of obstetric care. The investigation of this question is the core objective of our paper.

The answers to this question cannot be obtained by analysing data on the actual choice of obstetric care. This is mainly due to a lack of variation in some attributes of obstetric care (e.g. low-risk pregnant women in the Netherlands are supervised by a primary care provider), or due to co-variation between some attributes (e.g. medical pain-relief treatment is not possible during a home birth, and obstetricians do not attend home births). There are also problems related to selfselection and generalisation when actual behaviour is analysed ${ }^{26}$. 


\section{Chapter 3}

Therefore, following the methodological recommendations in recent publications reporting similar analysis in other countries ${ }^{27,28}$, we apply the method of discretechoice experiment. The discrete-choice experiment is a stated preference technique that relies on respondents' choices between hypothetical profiles to infer information about individual preferences and decision-making ${ }^{29,30}$. After this introductory section, the paper presents the design of our discrete-choice experiment, as well as the process of data collection and analysis. This is followed by the study results, their discussion and conclusions.

\section{Methods}

\section{Preparation of the discrete-choice experiment}

The method of discrete-choice experiment is extensively discussed in the literature ${ }^{29,30}$. In our discrete-choice experiment, the commodity obstetric care was presented to the respondents in form of alternative profiles that contained combinations of attributes of obstetric care (see table 1 and appendix A). Attributes and attribute levels that appeared important to pregnant women in previous research ${ }^{27,28}$, and were also relevant to the Dutch context, were included in the analysis. We kept the number of attributes and their levels at a minimum to assure the feasibility of data collection.

We drew an orthogonal main-effect fractional factorial design from all possible profiles $\left(2^{6}=64\right)$, to reduce them to a manageable number. Thus, eight profiles were included in the study. One profile that represented a potentially realistic situation was selected to be the basis profile. The rest of the profiles were used as alternative profiles. Seven choice-sets were defined where each choice-set contained the basis profile and one alternative profile (see table 1).

Some alternative profiles included in the study were purely hypothetical. Although it was possible to design the discrete-choice experiment based on the actual covariation between the attributes, this would not allow analysing the effect of each attribute on the respondents' decision-making and the role of place of birth in the choice of obstetric care. Therefore, we omitted the correlations between the attributes of obstetric care that exist in practice.

\section{Data collection procedure}

The research setting consisted of midwives' practices in the city of Maastricht, the Netherlands. All three midwives' practices in the city were included in the study. For a period of one week in May 2004, all nulliparous (first-time expectant) pregnant women who came for a consultation at a given practice, were asked to participate in the study. The participation in the study required only filling in a ques- 
tionnaire (in the presence of a researcher). We included only nulliparous pregnant women to assure that the respondents did not have previous experience with obstetric care that might lead to a bias in their responses ${ }^{31}$. There were no other inclusion criteria applied. Of all 80 women who were asked to participate, 78 women filled in the questionnaire and 2 women refused to participate. Thus, the sample included low-risk pregnant women, who were actually confronted with decisions regarding childbirth, but who did not have previous experience with obstetric care. The questionnaire included seven discrete-choice questions based on the seven choice-sets (see table 1). One of the discrete-choice questions is presented in appendix $B$ as an example. The rest of the discrete-choice questions were formulated in an analogous fashion based on table 1. To assure that the respondents understood the meaning of the attributes and their levels, information shown in appendix A was included in the questionnaire and was discussed with the respondents prior to the discrete-choice experiment.

In addition to the discrete-choice questions, the respondents were also presented with questions about their socio-demographic status and the provisional choice of place of birth that each respondent had made prior to our study (i.e. when asked by a midwife during the consultations). The place of birth selected by the respondents prior to our study was taken as an indicator of the overall respondents' attitude towards the place of birth. Questions for collecting qualitative data on who, what and how had influenced the provisional choice of place of birth were also included. Prior approval by an ethical committee was unnecessary due to the non-intervention character of the survey.

\section{Model specification and method of data analysis}

In general, the analysis of discrete-choice data is based on the assumption that respondents derive a distinctive utility from each attribute level and choose the profile that they associate with the highest level of total utility ${ }^{29,30}$. Thus, to analyse our discrete-choice data, we assume that when pregnant women were confronted with a discrete-choice task, they evaluated the utility levels associated with the two profiles of obstetric care in that task. They chose the alternative profile over the basis profile only when the utility level associated with the alternative profile was higher than the utility level associated with the basis profile. 


\section{Chapter 3}

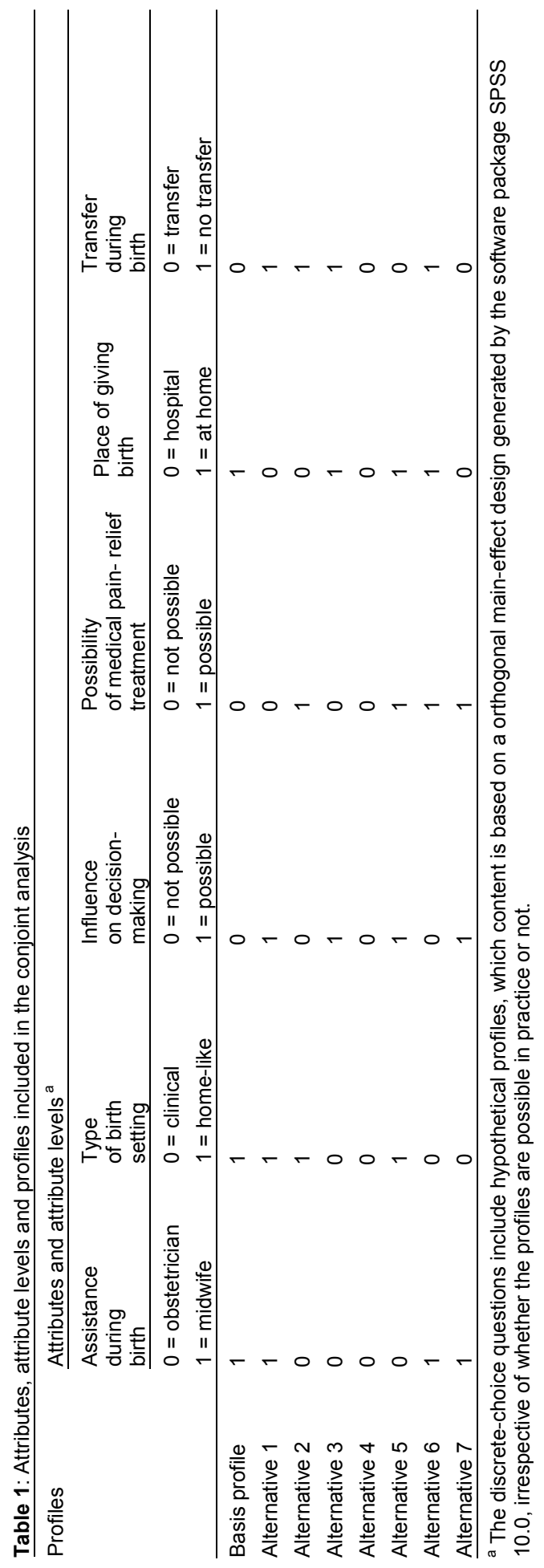




\section{Choice of obstetric care}

This decision-making process can be presented by the following binary choice model:

$\Delta U^{\text {Alternative-Basis }}=\sum_{k}^{n} \Delta x_{k}^{\text {Alternative-Basis }}+\sum_{k}^{n} \sum_{l}^{j} \Delta x_{k}^{\text {Alternative-Basis }} z_{l}+\sum_{k}^{n} \Delta x_{k}^{\text {Alternative-Basis }} y+\mu+\varepsilon$

\begin{tabular}{l|l} 
Choice of profile $=$ & $\begin{array}{l}0 \text { (basis profile is selected) when } \Delta \mathrm{U}^{\text {Alternative }- \text { Basis }} \leq 0 \\
1 \text { (alternative profile is selected) when } \Delta U^{\text {Alternative-Basis }}>0\end{array}$
\end{tabular}

where $\Delta U^{\text {Alternative-Basis }}$ is the latent utility difference when shifting from the basis to alternative profile, $\Delta x^{\text {Alternative-Basis }}$ is the difference between the levels of a given attribute in the basis and alternative profile, $\Delta x^{\text {Alternative-Basis }} z$ is the interaction between the difference in one attribute and a socio-demographic feature (age, country of birth, education, gestation age, family income, travel time from home to the nearest hospital), $\Delta x^{\text {Alternative-Basis }} y$ is the interaction between the difference in one attribute and the attitude towards the place of birth, $n$ denotes the number of attributes, $j$ denotes the number of socio-demographic features, $\varepsilon$ is an error term that presents variations between respondents, $\mu$ is an error term that presents variations within the choices of each respondent, and Choice of profile is the observed variable.

To parameterise the model, we used binary probit regression with random effects (software package LIMDEP 7.0). Choice of profile was the dependent variable. Initially, we included all attribute differences and all interactions (see the model above) as independent variables. Then, we reduced the model using a backward stepwise procedure where statistically insignificant independent variables were systematically removed from the model (for which $\mathrm{p}>0.10$ ). The aim was to obtain a reduced model that contains only statistically significant independent variables.

\section{Results}

\section{Socio-demographic characteristics and provisional choice of place of birth}

Totally, 78 out of 80 pregnant women completed the questionnaire resulting in a response rate of $98 \%$. The descriptive statistics of the socio-demographic variables are presented in table 2 . The majority of the women in the sample $(91 \%)$ were born in the Netherlands. On average, they were 30 years old, had a gross monthly family income of 3000 Euro, had a high education level, and lived 10 min away from a hospital. The gestation age was on average 30-weeks pregnancy. The strength of association between the socio-demographic variables was relatively low (Spearman's rho < 0.5). Therefore, all of them were included in the analysis. 


\section{Chapter 3}

Table 2: Socio-demographic variables included in the conjoint analysis

\begin{tabular}{ll}
\hline Socio- demographic variables & $\begin{array}{c}\text { Number } \\
\text { (Valid } \%)\end{array}$ \\
\hline Age & $38(48.7 \%)$ \\
$0=\leq 30$ years & $40(51.3 \%)$ \\
$1=>30$ years & \\
Gestation age & $45(57.7 \%)$ \\
$0=\leq 30$ weeks pregnancy & $33(42.3 \%)$ \\
$1=>30$ weeks pregnancy & \\
Country of origin & $7(9.0 \%)$ \\
$0=$ born in another country & $71(91.0 \%)$ \\
$1=$ born in the Netherlands & \\
Education & $28(35.9 \%)$ \\
$0=$ up to high-school degree ${ }^{a}$ & $50(64.1 \%)$ \\
$1=$ higher than high-school degree ${ }^{b}$ & $32(48.5 \%)$ \\
Familiy income & $34(51.5 \%)$ \\
$0=\leq 3000$ euro & \\
$1=>3000$ euro & $53(67.9 \%)$ \\
Distance to nearest hospital in minutes & $25(32.1 \%)$ \\
$0=\leq 10$ minutes & \\
$1=>10$ minutes & $34(43.6 \%)$ \\
\hline Attitude towards the place of birth & $44(56.4 \%)$ \\
\hline Provisional choice of place of birth made by the respondents prior to the study & \\
$0=$ had chosen for a birth at home & \\
$1=$ had chosen for a birth in a hospital & \\
\hline a high-school degree is equal to HAVO/VWO/Gymnasium; ${ }^{b}$ higher than high-school degree includes \\
HBO/WO
\end{tabular}

Table 2 indicates also the provisional choice of place of birth made by respondents prior to our study. All respondents had made such choice. The respondents were almost evenly divided between the two birth options, home birth and birth in a hospital maternity unit. The additional qualitative data collected in the study indicated that respondents who had chosen to deliver at home, most frequently indicated that they had made this choice because they would prefer to deliver in a natural setting. Their pregnancy was progressing without any complications and if necessary, they could always be transferred to a hospital. Women who opted for a birth in a hospital maternity unit, referred to the proximity of the obstetrician and the safety of the hospital setting as an explanation of their choice. All respondents had decided on the place of birth together with their partners. However, family members, midwives, and friends had also influenced this decision. The type of information received during the prenatal checkups also appeared to have a significant influence on the women's choice. Respondents had significantly more often chosen the birth option for which they had received more information (chi-square test; $p<0.05$ ).

The strength of association between the provisional choice of place of birth and the socio-demographic characteristics was also examined. A significant level of 
association (Spearman's rho $>0.5$ ) was found in case of income and travel time to the nearest hospital. Respondents with a high family income and those, who lived far from a hospital, had significantly more often chosen for a birth in a hospital maternity unit. Due to this strong association, income and distance from a hospital had to be excluded from further analysis.

\section{Results of the discrete-choice experiment}

The results of the discrete-choice experiment are presented in table 3. Only three attributes of obstetric care have statistically significant main effects (see main effects in table 3), namely 'type of birth setting', 'possibility of medical pain-relief treatment' and 'place of giving birth'. This means that in our study, only these three attributes were important determinants of the choice of obstetric care at a sample level irrespective of the respondents' socio-demographic characteristics and provisional choice of place of birth. The rest of the attributes, i.e. 'assistance during birth', 'influence on decision making' and 'transfer during birth', appeared statistically significant only for some groups of respondents.

To identify the preferences for attributes of obstetric care in our sample, we look at the directions and magnitudes of their main effects and the effects of their interactions (keeping in mind the model and the coding of model variables in table 3).

With regard to attribute 'type of birth setting', its main effect is negative, which indicates that the pregnant women in our sample preferred to give birth in a setting with a domestic atmosphere. The interaction of attribute 'type of birth setting' with provisional choice of place of birth has a positive effect but the magnitude of this effect is lower than the main attribute effect. This indicates that the sample was in favour of domestic atmosphere during birth but these preferences were less strong for respondents who had chosen for a birth in a hospital maternity unit prior to our study, compared to those who had opted for a home birth.

With regard to attribute 'possibility for a medical pain-relief treatment', both its main effect and the effect of its interaction with gestation age are positive. Consequently, pregnant women in our sample preferred to have a possibility to receive a medical pain-relief treatment during birth. The possibility of a medical pain-relief treatment was however, more important to women who were more than 30 weeks pregnant.

For attribute 'place of giving birth', its main effect is negative, which suggests preferences among respondents for a home birth irrespective of the respondents' socio-demographic characteristics and provisional choice of place of birth. However, the interaction of attribute 'place of birth' with the provisional choice of place of birth has a positive effect and the magnitude of this effect is higher than the main attribute effect. Consequently, a significant group of respondents who prior to our study had provisionally chosen for a birth in a hospital maternity unit, chose 


\section{Chapter 3}

for a hospital birth also in the discrete-choice experiment. Attributes 'assistance during birth' and 'influence on decision making' appeared important only for pregnant women with a higher than high-school degree. This group of respondents more often preferred to be assisted by a midwife and to have an influence on the decision-making process compared to women with a lower education level. The last attribute 'transfer during birth' appeared important to respondents, who had chosen for a birth in a hospital maternity unit prior to our study. For this group of respondents it was more important not to be transferred during birth compared to the rest of respondents.

The bottom part of table 3 presents additional data and results from the regression analysis, which can be used to evaluate the adequacy and goodness of fit of the analytical model. Specifically, the table presents the value of the correlation $\rho$ between the two error terms in the model (i.e. the error due to differences between respondents and the error due to variations within a respondent). This value is significant, which suggests that the application of a regression model with random effects (that accounts for both types of errors) is suitable. Furthermore, the table presents the chi-square value from the likelihood ratio test and the McFadden's pseudo R-square, also called likelihood ratio index (see 32 for definitions). The significance of the chi-square value and the magnitude of McFadden's pseudo R-square indicate that overall the model fit is good. This is also supported by the high percent of correct predictions of the value of the dependent variable based on the regression model. 
Choice of obstetric care

Table 3: Results of the discrete-choice experiment (binary regression, reduced model)

$\begin{array}{ll}\text { Choice of profile (dependent variable) } & =0 \text { (if the basis profile is selected) } \\ & =1 \text { (if an alternative profile is selected) }\end{array}$

Independent variable

Regressioncoefficient

Value estimated (Se)

Main attribute effects

Difference in type of birth setting

$1=$ clinical instead of domestic

$-1.322^{b}$

$0=$ domestic in both profiles

Difference in possibility of medical pain-relief treatment

$1=$ possible instead of not possible

$0.595^{b}$

$0=$ not possible in both profiles

Difference in place of giving birth

$1=$ in a hospital instead of at home

$-0.959^{b}$

$0=$ at home in both profiles

Interactions

Difference in assistance during birth $\times$ education level

$1=$ obstetrician instead of midwife $\times$ higher than high-school $-0.847^{\mathrm{b}}$

$0=$ other interaction groups

Difference in influence on decision-making $\times$ education level

$1=$ possible to influence instead of not possible $\times$ higher

than high-school

$0.974^{b}$

$0=$ other interaction groups

Difference in possibility of medical pain-relief treatment $\times$ gestation age

$1=$ possible instead of not possible $\times$ more than 30

weeks pregnancy

$0=$ other interaction groups

Difference in type of birth setting $\times$ provisional choice of place of birth

$1=$ clinical instead of domestic $\times$ prefer birth in a hospital

$0=$ other interaction groups

Difference in place of giving birth $\times$ provisional choice of place of birth

$1=$ in a hospital instead of at home $\times$ prefer birth in a hospital

$0.974^{b}$

$0.544^{b}$

$0=$ other interaction groups

Difference in transfer during birth $\times$ provisional choice of place of birth

$1=$ no transfer instead of transfer $\times$ prefer birth in a

hospital

$0.419^{b}$

$0=$ other interaction groups

Additional data and results

Number of observations

Number of respondents

539

78

Log likelihood

$0.509 \mathrm{~b}$

$-226.580$

Chi-square d

$61.885 \mathrm{~b}$

McFadden Pseudo R-square e

0.265

Correct predictions of Choice of profile $=0$ (basis profile) $\quad 74.8 \%$

Correct predictions of Choice of profile $=1$ (alternative profile)

$75.7 \%$

${ }^{a}$ Binary probit regression with random effects. The statistically insignificant variables are excluded from the model following a backward stepwise procedure to obtain a reduced model where all variables are statistically significant.; ${ }^{b} p \leq 0.10 ;{ }^{c} \rho$ is the correlation between the error terms (i.e. between the error due to differences between respondents, and the error due to variations within a respondent). It measures the extent to which observations of the same respondent are correlated. Its statistical significance suggests that the regression model with random effects is suitable; ${ }^{d}$ Likelihood ratio test . The statistical significance of the chi-square value indicates that the independent variables are significant predictors of the dependent variable; e Likelihood ratio index. It indicates the goodness-of-fit of the model. A value in this range indicates a good 


\section{Chapter 3}

\section{Discussion}

\section{Validity and limitations of the study results}

The regression results presented in table 3 suggest a good model fit and adequacy of the analytical model. As expected, respondents who had chosen for a birth in a hospital maternity unit prior to the study, appeared to have preferences for a hospital birth also in the discrete-choice experiment. Moreover, for these respondents, it was less important to give birth in a domestic atmosphere but it was more important not to be transferred during birth compared to respondents who had chosen for a home birth. This also complies with prior expectations and previous findings ${ }^{1,3,14-25}$.

Our results correspond to previous findings as well. As in previous research ${ }^{5,19,25}$, we also found out that low-risk pregnant women in the Netherlands (in our study, nulliparae) are in favour of a medical pain-relieve treatment during birth and that their preferences are divided between giving birth at home and in a hospital maternity unit. We observed this division in preferences based on the provisional choice of place of birth made by respondents prior to our study, and based on the results of the discrete-choice experiment.

Similar to previous research results ${ }^{18,19}$, pregnant women in our sample explained their preferences for a birth in a hospital maternity unit primarily by the issue of safety, while preferences for a home birth were primarily explained by the possibility of a natural birth environment. We also found out that the choice of place of birth had been influenced by the significant others (e.g. partners, family members, friends and midwives) as well as by the type of prenatal information received. These results were obtained based on the qualitative data collected in our study.

The analysis of the discrete-choice data suggested significant differences in the choice of obstetric care with regard to education, gestation age and attitudes towards the place of birth (indicated by the provisional choice of place of birth made by the respondents prior to our study). Based on the strength of association between the provisional choice of place of birth and the socio-demographic features, we also found significant associations with regard to income and travel time to the nearest hospital. The effect of all variables mentioned above on the choice of obstetric care in the Netherlands is reported and discussed by others as well ${ }^{1,3,14-25}$.

The comparability of our results with preliminary expectations and previous findings is an indication of the theoretical and convergent validity of our results. Moreover, the socio-demographic characteristics of our sample (see table 2) appeared comparable to the national statistics, except for education. Roughly estimated, in the Netherlands, the gross primary income per family per month is on average 3200 Euro, there are about $10 \%$ foreigners in the country and most women give birth to their first child when they are between 25 to 35 years old ${ }^{4}$. 
With regard to education however, the group of women with higher than a highschool degree, was overrepresented in our sample. However, we accounted in the analysis for the effect of education, as well as for other socio-demographic features. The above considerations indicate a possibility for generalisations in our study but only with regard to first time expectant mothers since this was the criterion for the inclusion of respondents.

Our study has however, some limitations related to methodology. Only a limited number of attributes and attribute levels were used in the discrete-choice experiment to assure the feasibility of data collection. This means that the results of our discrete-choice experiment can be interpreted only in relative terms considering the specific attributes and attribute levels.

Despite this limitation, the method of discrete-choice experiment appeared to be an adequate research technique for this study, because it allowed us to take into account the combined effect of multiple choice-determinants on the decisionmaking process. Moreover, the discrete-choice experiment allowed us to study the attractiveness of potentially feasible as well as purely hypothetical alternatives of obstetric care. These were important methodological advantages given the research question that we aimed to investigate.

Yet, concerns can be raised that the inclusion of purely hypothetical profiles might affect the validity of the choices made by the respondents in a discretechoice experiment. Although, the results of our discrete-choice experiment appeared consistent with prior expectations and previous research results, this issue requires further investigation.

\section{Overall discussion and conclusions}

The method of discrete-choice experiment was applied in our study to investigate whether the choice of obstetric care by low-risk pregnant women in the Netherlands is due to preferences for a specific birth place (home or hospital maternity unit) per se, or due to the specific combination of preferences for obstetric care, socio-demographic status and attitudes that jointly result in a given choice of obstetric care. To answer this question, we collected data among a sample of low-risk first time expectant mothers.

The findings of our study suggest that the choice of obstetric care by this group of women is multidimensional. Overall, this choice appeared to be influenced by some attributes of obstetric care, namely birth-setting, possibility of a medical pain-relief treatment and place of birth. However, there are also significant variations in how this choice is made. The variations are related to both sociodemographic features (specifically, education level and gestation age) and attitude towards the place of birth (represented in out analysis by the provisional choice of place of birth made by the respondents prior to our study). 


\section{Chapter 3}

With regard to place of birth, our results suggest that this attribute is on its own an important determinant of the choice of obstetric care by low-risk first time expectant mothers irrespective of other attributes of obstetric care. Our results indicate that there are strong preferences among some Dutch women for a home birth apart from other features of obstetric care and apart from their sociodemographic and attitude-related characteristics. As suggested by previous research (e.g. ${ }^{2,8,10,11}$ ), the roots of these preferences can be found in the core Dutch perceptions of pregnancy as a normal physiological process and birth as a lowtech family event. These social perceptions are also confirmed by the continuous government support for the home birth option, the specific organisation of Dutch obstetric care focused on the prevention of unnecessary interventions, and the empirical evidence on the safety of the home birth option ${ }^{2,6,33-35}$. However, shifts within the Dutch social perceptions (specifically, more positive views on the involvement of medical technology during pregnancy and birth ${ }^{12}$ ) might be a reason in future more women to prefer a birth in a hospital maternity unit.

We also found out strong preferences for medical pain-relief treatments (also among women who had chosen to give birth at home and especially among those with an advanced pregnancy). This suggests that the lack of possibility to receive a medical pain-relief treatment during a home birth might provide incentives for some women to opt for a birth in a hospital maternity unit, even when they would prefer to give birth at home, and especially at the end of their pregnancy. If the attractiveness of the home birth option should be preserved in the Netherlands, the prenatal counselling should be especially focused on the fear of pain during birth and non-medical pain-relief options during birth.

The content of information that low-risk pregnant women receive during their prenatal consultations, also deserves a special attention. According to our results based on the qualitative data collected in the study, this information appears to influence the choice of place of birth. Perhaps, the content of this information could be standardised at a national level with the objective to offer the low-risk pregnant women a comprehensive and balanced description of both birth options. This can empower the low-risk pregnant women to make an informed and objective choice that best corresponds to their preferences.

With regard to birth in a hospital maternity unit, our study suggests that this choice is not determined by women's preferences to be specifically supervised by an obstetrician during birth. This choice is mostly due to women's preferences not to be transferred during birth in case of complications. Simultaneously, in a hospital, the medical pain-relief treatment is a feasible option (which correspondents to the overall women's preferences) although the woman should be referred to an obstetrician to be able to receive such treatment. In view of our findings, the organisation of Dutch obstetric care for low-risk pregnant women, who prefer to give birth in a hospital maternity unit, appears adequate. Yet, as indicated by our results, efforts could be made in offering a domestic atmosphere at the maternity 
Choice of obstetric care

hospital units that resembles the home environment. This could help to improve hospital-based obstetric care in view of women's preferences. 


\section{Chapter 3}

\section{References}

1 Anthony S, Buitendijk SE, Offerhaus PM, Dommelen P, Pal-de Bruin KM. Maternal factors and the probability of a planned home birth. BJOG 2005; 112: 748-53.

2 Benoit C, Wrede S, Bourgeault I, Sandall J, De Vries R, van Teijlingen ER. Understanding the social organisation of maternity care systems: midwifery as a touchstone. Sociology of Health \& IIIness 2005; 27: 722-37.

3 van der Hulst LAM, van Teijlingen ER, Bonsel GJ, Eskes M, Bleker OP. Does a pregnant woman's intended place of birth influence her attitudes toward and occurrence of obstetric interventions? Birth 2004; 31: 28-33.

4 CBS. Minder thuisbevallingen. http://www.cbs.nl; 2009.

5 Anthony S. The Dutch perinatal and neonatal registers: application in perinatal epidemiology. Leiden: De Bink; 2005.

6 Bellanger MM, Or Z. What can we learn from a cross-country comparison of the costs of child delivery?. Health Econ 2008; 17(S1): S47-S57.

7 de Vries RG. The wrap of evidence-based medicine: lessons from Dutch maternity care. International Journal of Health Services 2004; 34: 595-623.

8 de Vries RG. A pleasing birth: midwives and maternity care in the Netherlands. Philadelphia: Temple University Press; 2005.

9 de Vries R, Lemmens T. The social and cultural shaping of medical evidence: case studies from pharmaceutical research and obstetric science. Soc Sci Med 2006; 62: 2694-2706.

10 de Vries R, Salvesen H, Wiegers T, Williams AS. What (and why) do women want? The desires of women and the design of maternity care. In: de Vries R, Wrede S, van Teijlingen E, Benoit C. (eds.). Birth by Design: Maternity Care in a Social and Cultural Perspective. New York: Routledge; 2001.

11 van Teijlingen E, Wrede S, Benoit C, Sandall J, DeVries R. Born in the USA: exceptionalism in maternity care organisation among high-income countries. Sociological Research Online 2009; 14(1).

12 Smeenk A, ten Have H. Medicalization and obstetric care: an analysis of developments in Dutch midwifery. Medicine, Health Care and Philosophy 2003; 6: 153-65.

13 Nijhuis JG. De foetus verdient meer. Maastricht: Maastricht University; 2000.

14 Kind $\mathrm{E}$. Thuis of in het ziekenhuis? Welke reden zijn voor de cliënt bepalend voor de keuze? Tijdschrift voor Verloskundigen 2000; 25: 110-15.

15 Anthony S, Buitendijk SE, Offerhaus PM, Dommelen P, Pal-de Bruin KM. Maternal factors and the probability of a planned home birth. BJOG 2005; 112: 748-53.

16 Christiaens W, Bracke P. Place of birth and satisfaction with childbirth in Belgium and Netherlands. Midwifery 2009; 25: e11-e19.

17 Christiaens W, Gouwy A, Bracke P. Does a referral from home to hospital affect satisfaction with childbirth? A cross-national comparison. BMC Health Services Research 2007; 7: 109.

18 Hingstman L, Foets M, Ritcco JA. Meningen van de consumenten: thuis of in het ziekenhuis bevallen. Tijdschrift voor Verloskundigen 1993; 18: 66-74.

19 Kleiverda G, Steen AM, Andersen I. Place of delivery in the Netherlands: maternal motives and background variables related to preference for home or hospital confinement. Eur J Obstet Gynecol Reprod Biol 1990; 36: 1-9.

20 van der Hulst LAM, van Teijlingen ER, Bonsel GJ, Eskes M, birnie E, Bleker OP. Dutch women's decision-making in pregnancy and labour as seen through the eyes of their midwives. Midwifery 2007; 23: 279-86.

21 Wiegers TA. Home or hospital birth: a prospective study of midwifery care in the Netherlands. Eur J Obstet Gynecol Reprod Biol 1998; 79: 139-41.

22 Wiegers TA, Keirse MJNC, van der Zee J, Berg GAH. Outcomes of planned home and planned hospital births in low risk pregnancies: prospective study in midwifery practices in The Netherlands. BMJ 1996; 313: 1309-13. 


\section{Choice of obstetric care}

23 Wiegers TA, van der Zee J, Keirse MJNC. Maternity care in the Netherlands: the changing home birth rate. Birth 1998; 25: 190-7.

24 Wiegers TA, van der Zee J, Kerssens JJ, Keirse MJNC. Variation in home-birth rates between midwifery practices in the Netherlands. Midwifery 2000; 16: 96-104.

25 Wiegers TA, van der Zee J, Kerssens JJ, Keirse MJNC. Home birth or short-stay hospital birth in a low risk population in the Netherlands. Soc Sci Med 1998; 46: 1505-11.

26 Groot W, Maassen van den Brink H, Plug E. Money for health: the equivalent variation of cardiovascular diseases. Health Econ 2004; 13: 859-72.

27 Hundley V, Ryan M, Graham W. Assessing women's preferences for intrapartum care. Birth 2001; 28: 254-63.

28 Longworth L, Ratcliffe J, Boulton M. Investigating women's preferences for intrapartum care: home versus hospital births. Health and Social Care in the Community 2001; 9: 404-13.

29 Ryan M, Gerard K. Using discrete choice experiments to value health care programmes: current practice and future research reflections. Appl Health Econ Health Policy 2003; 2: 1-10.

30 Lancsar E, Louviere J. Conducting discrete choice experiments to inform healthcare decision making: a user's guide. PharmacoEconomics 2008; 26: 661-77.

31 Wiegers TA, van der Zee J, Keirse MJNC. Transfer from home to hospital: what is its effect on the experience of childbirth? Birth 1998; 25: 19-24.

32 Veall MR, Zimmermann KF. Evaluating Pseudo-R2's for binary probit models. Quality \& Quantity 1994; 28: 151-64.

33 Buitendijk SE. How safe are Dutch home births? In: Abraham-Van der Mark E (ed.) Successful home birth and midwifery: the Dutch model. Amsterdam: Het Spinhuis; 1996.

34 De Reu PAOM, Nijhuis JG, Oosterbaan HP, Eskes TKAB. Perinatal audit on avoidable mortality in a Dutch rural region: a retrospective study. Eur J Obstet Gynecol Reprod Biol 2000; 88: 65-9.

35 de Jonge A, van der Goes BY, Ravelli ACJ, Amelink-Verburg MP, Mol BW, Nijhuis JG, Bennebroek Gravenhorst J, Buitendijk SE. Perinatal mortality and morbidity in a nationwide cohort of 529688 low-risk planned home and hospital births. BJOG 2009: DOI: 10.1111/j.1471-0528.2009.02175.x. 


\section{Chapter 3}

Appendix A: Description of the attributes of obstetric care included in the study

Assistance during birth: This attribute indicates the provider of obstetric care that assists the pregnant women during birth. A distinction is made between a midwife (primary provider of obstetric care) and obstetrician (medical doctor specialised in the provision of obstetric services).

Type of birth setting: This attribute describes whether the setting of giving birth resembles a hospital or home environment. The attribute is presented by the levels clinical atmosphere (that resembles a hospital environment) and domestic atmosphere (that resembles a home environment).

Influence on decision-making: The attribute describes whether the pregnant women can influence the decisions that are taken during birth. There are two options: possible (the pregnant women can influence the decisions) and not possible (the pregnant women cannot influence the decisions).

Possibility of medical pain-relief treatment: Here, it is meant a medical treatment that is specifically aimed at pain-relief and that can be provided only by specialised medical personnel. The attribute has two levels: pain-relief (medical) treatment is possible and pain-relief (medical) treatment is not possible

Place of giving birth: This attribute presents the options of birth at home and birth in a hospital policlinic department.

Transfer during birth: The attribute indicates the need of transfer during birth if there are medical complications. Two attribute levels are considered: transfer, which indicates that a transfer might be necessary in case of complications, and no transfer, which indicates that transfer is not necessary in case of complications.

Appendix B: An example discrete-choice question included in the study

Which of the following profiles of obstetric care do you prefer? ${ }^{a}$

Profile A

Assistance during birth

Type of birth setting

Influence on decision-making

Possibility of medical pain-relief treatment

Place of giving birth

Transfer during birth
By a midwife

Domestic atmosphere

Not possible to influence

Pain-relief treatment not possible

At home

Transfer might be needed
Profile B

By an obstetrician

Domestic atmosphere

Not possible to influence

Pain-relief treatment possible

In a hospital

No transfer is needed

I prefer:

$\square$ profile A

$\square$ profile B

\footnotetext{
a Totally, 7 discrete-choice questions are included where profile $A$ is the basis profile and remains constant while profile B varies (see table 1). The discrete-choice questions include hypothetical profiles irrespective of whether the profiles are possible in practice or not.
} 


\section{Chapter 4}

\section{Differences in preferences for obstetric care between nulliparae and their partners in the Netherlands, using the discrete-choice experiment}

M.J.C. Hendrix, M.I. Pavlova, M.J. Nieuwenhuijze, J.L. Severens and J.G. Nijhuis

Submitted 


\section{Chapter 4}

\section{Abstract}

Background In the Netherlands, in low-risk pregnancies, the views of pregnant women and their partners on characteristics of obstetric care services are leading for the selection of place of birth. The aim of this study was to investigate whether there are differences between the decision-making process of pregnant women and their partners with regard to these attributes of obstetric care.

Methods This study was a prospective cohort study with low-risk nulliparae and their partners. A questionnaire, based on the method of discrete-choice experiment, was used to gather the data.

Results Possibility of influencing decision-making was, both for pregnant women $(n=321)$ and their partners $(n=212)$, the most important characteristic of the obstetric care. For women, a home-like birth setting was an important characteristic, while the partners found the possibility on pain-relief treatment during birth important.

Conclusions The results of this study suggest that women and their partners have clearly defined preferences for obstetric care. There are also some essential differences between the preferences of these two groups. The findings are important where policy issues related to aspects of maternity care service delivery are being considered. 


\section{Differences in preferences for obstetric care}

\section{Introduction}

In contrast to other high-income countries, planned home births are rather common in the Netherlands. Women with low-risk pregnancies are free to choose where to give birth, at home or in the hospital, both under supervision of a registered independent midwife. Between 2005-2008, 29\% of all Dutch births (multiparae en primiparae) took place at home ${ }^{1}$. Of all primiparae, $19 \%$ gave birth at home and $10.8 \%$ had a short-stay hospital birth supervised by midwives ${ }^{2}$. The choice of the place of birth has been reported in several Dutch studies ${ }^{3-7}$. A Dutch study by Wiegers et al $^{8}$ showed that for women at low-risk of obstetrical complications, the choice to give birth at home or in a hospital was based primarily on social factors, where the confidence of the family in home birth was the strongest factor for choosing a home birth.

The association between social support and health is well known ${ }^{9,10}$ and has been focused upon in studies of pregnant women's physical and emotional wellbeing ${ }^{11-14}$. A predictor of well-being during pregnancy is the support by the partner and social network ${ }^{13,15}$. The partner is usually highly valued as a source of support during pregnancy and birth. Previous studies have revealed that support by the partner was associated with a positive birth experience ${ }^{13-15}$ as well as leading to less need for pain relief during birth ${ }^{16}$. Partners also influence the decisionmaking process regarding place of birth ${ }^{17,18}$. A Dutch study showed that in $60 \%$ of the cases, partners were involved in this decision-making process ${ }^{17}$. Despite the involvement of the partners in the decision-making process, the preferences of partners for obstetric care and place of birth has not been studied yet. However, given the influence of partners in the decision-making process ${ }^{17-20}$, it is interesting to compare the preferences of pregnant women and their partners regarding birth. It is unclear whether there are differences in these preferences.

The comparison between the preferences of pregnant women and their partners regarding birth is also relevant to policy. In the Netherlands, the views of pregnant women and their partners about obstetric care services are important when choosing the place of birth. An insight in these preferences could indicate directions for improving primary obstetric care (i.e. midwifery care) received at home, as well as the primary and secondary obstetric care delivered at the hospital maternal units. Moreover, it is largely unknown how pregnant women and their partners perceive the out-of-pocket payment that is required in case of a shortstay hospital birth when there are no obstetrical complications. The impact of the out-of-pocket fee on the choice of place of birth in the Netherlands has never been investigated before and is part of this study.

The aim of this paper is to investigate the differences between the preferences of low-risk pregnant women and their partners for obstetric care and place of birth, and the extent to which these preferences are influenced by the attributes of obstetric care, socio-demographic factors and out-of-pocket payments. The 


\section{Chapter 4}

method of discrete-choice experiment was used to achieve the research aim. The discrete-choice experiment is a stated preference technique that is based upon the premise that all goods and services can be described by their characteristics (or attributes) ${ }^{21}$. In this study, the method of discrete-choice experiment was applied to assess the strength of the preferences of women and their partners several attributes of intrapartum care and how the respondents make trade-offs between these attributes ${ }^{21-23}$.

\section{Methods}

The discrete-choice experiment is a stated preference technique widely used in market research. This method has been described in details in previous studies ${ }^{21}$ ${ }^{28}$ and has been extensively applied in the areas of transport, environmental ${ }^{24}$ and health economics ${ }^{21,22}$ to assess preferences of consumers regarding services and goods. It also has been applied in the area of maternity services. The discretechoice experiment involves describing the characteristics of a service or good in terms of attributes and the levels within each attribute ${ }^{23,29}$.

The advantage of discrete-choice experiment over satisfaction surveys is that it takes account of respondents' preferences for individual aspects of care simultaneously. Asking respondents to choose between profiles means that they have to make trade-offs between attributes, they cannot have the best levels of all attributes. There is an opportunity cost to their choice; choosing an improvement in one attribute may mean that they get less of another attribute. Respondents' preferences provide data about the trade-offs that they are willing to make and this allows an overall satisfaction or utility score to be calculated for different ways of providing service ${ }^{30}$.

In this study, attributes and attribute levels that appeared important to pregnant women in previous research ${ }^{21,22,29}$, and were also relevant to the Dutch context, were included in the analysis. A monetary unit (i.e. out-of-pocket payments) was also included in the analysis. To assure the feasibility of the data collection, the number of attributes and attribute levels were kept at a minimum. Seven attributes with each two levels were selected. The attributes and their levels are listed in table 1.

We drew an orthogonal main-effect fractional factorial design from all possible profiles $\left(2^{7}=128\right)$, to reduce them to a manageable number. Thus, eight profiles were included in the study. One profile that represented a potentially realistic situation was selected to be the basis profile. The rest of the profiles were used as alternative profiles. Seven choice-sets were defined where each choice-set contained the basis profile and one alternative profile (see table 1). 


\section{Differences in preferences for obstetric care}

Some alternative profiles included in the study were purely hypothetical. Although it was possible to design the discrete-choice experiment based on the actual covariation between the attributes, this would not allow analysing the effect of each attribute on the respondents' decision-making and the role of place of birth in the choice of obstetric care. Therefore, we omitted the correlations between the attributes of obstetric care that exist in practice.

\section{Data collection}

Of all midwifery practices in the Dutch Midwifery Association Registration, 150 practices from across the Netherlands were selected at random and were invited to recruit the study population. Finally, 100 practices gave their agreement. Women with a first ongoing pregnancy (nulliparae) who were subscribed at these 100 practices, and their partners, were eligible to participate in the study. Also, they had to speak the Dutch language fluently. At the moment of inclusion (8-10 weeks pregnancy), the women participating in the study, were under the supervision of an independent midwife. The women had a low-risk pregnancy (low risk for medical complications). The eligible pregnant women and their partners received the information about the study at the first prenatal visit. When they decided to participate they gave informed consent. The recruitment of respondents was carried out between March 2007 and August 2007. Ethical approval was obtained by the Medical Ethical Committee Maastricht.

Data were collected using a self-administered postal questionnaire sent to the pregnant women and their partners at a gestation age of 32 weeks. Besides demographic questions (i.e. age, income, nationality), the questionnaire included seven discrete-choice questions based on the seven choice-sets (see table 1). One of the discrete-choice questions is presented in table 2 as an example. The rest of the discrete-choice questions were formulated in an analogous fashion. Each question consisted of two hypothetical situations based on all attributes. The respondents were asked to choose the situation that they prefer most. To assure that the respondents understood the meaning of the attributes and their levels, information on the definition of the attributes, was included in the questionnaire. 


\section{Chapter 4}

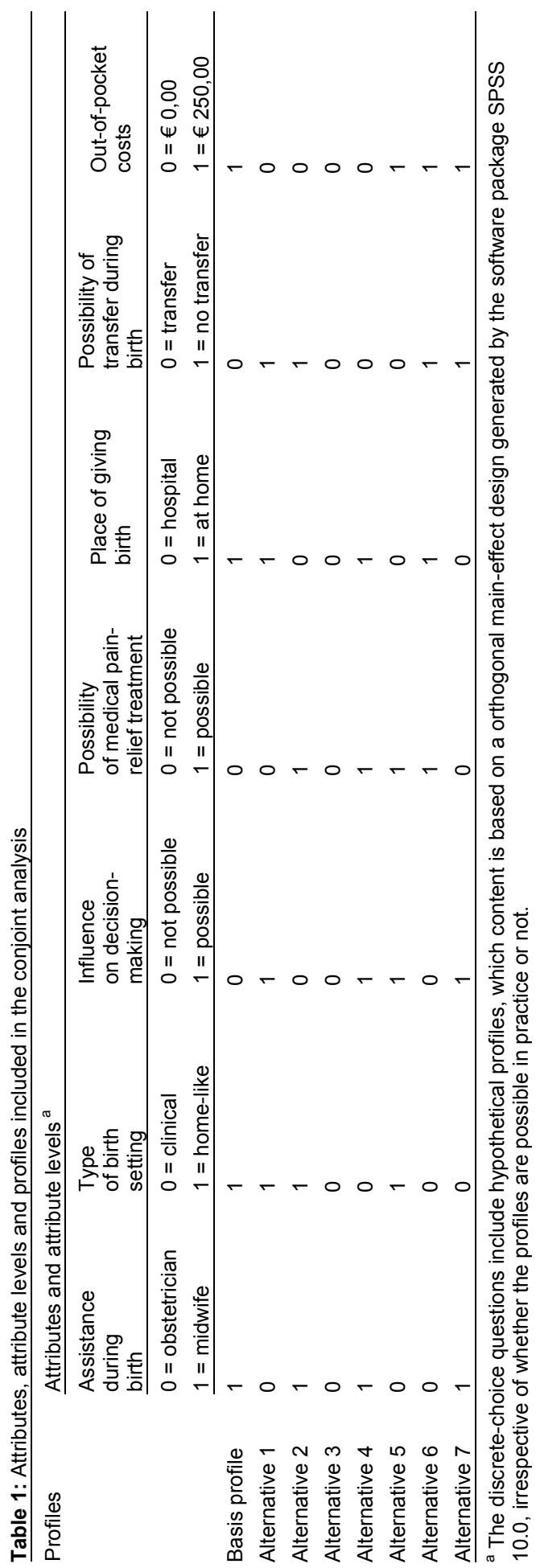




\section{Differences in preferences for obstetric care}

Table 2: Example of a discrete-choice question in the questionnaire

Which of the following profiles of obstetric care do you prefer? ${ }^{a}$

\begin{tabular}{lll} 
& Profile A & Profile B \\
Assistance during birth & By a midwife & By an obstetrician \\
Type of birth setting & Clinical setting \\
$\begin{array}{l}\text { Possibility of influencing decision- } \\
\text { making during birth }\end{array}$ & Not possible & Not possible \\
$\begin{array}{l}\text { Possibility of medical pain-relief } \\
\text { treatment }\end{array}$ & Not possible & Not possible \\
$\begin{array}{l}\text { Place of giving birth } \\
\text { Possibility of transfer during birth } \\
\text { Out-of-pocket costs }\end{array}$ & $\begin{array}{l}\text { At home } \\
\text { Transfer possible }\end{array}$ & $\begin{array}{l}\text { At the hospital } \\
\text { Transfer possible }\end{array}$ \\
I prefer: & Out-of pocket costs $(€ 250)$ & No out-of pocket costs $(€ 0)$ \\
\hline
\end{tabular}

\section{Data analysis}

In general, the analysis of discrete-choice data is based on the assumption that respondents derive a distinctive utility from each attribute level and choose the profile that they associate with the highest level of total utility ${ }^{31,32}$. In this study, we assume that when pregnant women and their partners were confronted with a discrete-choice task, they evaluated the utility levels associated with the two profiles of obstetric care in that task. They chose the alternative profile over the basis profile only when the total utility level associated with the alternative profile was higher than the total utility level associated with the basis profile. This decisionmaking process can be presented by the following binary choice model:

$$
\Delta U^{\text {Alternativ e-Basis }}=\sum_{k}^{n} \Delta x_{k}^{\text {Alternativ e-Basis }}+\sum_{k}^{n} \sum_{l}^{j} \Delta x_{k}^{\text {Alternativ e-Basis }} z_{l}+\mu+\varepsilon
$$

\begin{tabular}{l|l} 
Choice of profile $=$ & $\begin{array}{l}0 \text { (basis profile is selected) when } \Delta \mathrm{U}^{\text {Alternative -Basis }} \leq 0 \\
1 \text { (alternative profile is selected) when } \Delta \mathrm{U}^{\text {Alternative -Basis }>0}\end{array}$
\end{tabular}

where $\Delta U^{\text {Alternative-Basis }}$ is the latent utility difference when shifting from the basis to alternative profile, $\Delta x^{\text {Alternative-Basis }}$ is the difference between the levels of a given attribute in the basis and alternative profile, $\Delta x^{\text {Alternative-Basis }} z$ is the interaction between the difference in one attribute and a socio-demographic feature (namely, age, BMI, gestation age, country of origin, education, employment, marital state, family income, distance to nearest hospital in minutes, pregnancy course, way of 


\section{Chapter 4}

getting pregnant, provisional choice, first pregnancy), $n$ denotes the number of attributes, $j$ denotes the number of socio-demographic features, $\varepsilon$ is an error term that presents variations between respondents, $\mu$ is an error term that presents variations within the choices of each respondent, and Choice of profile is the observed variable.

The data collected in the discrete-choice experiment were analysed using a binary probit regression with random effects available in the statistics software package LIMDEP 7.0. This analysis was used because multiple observations were obtained from each respondent. Choice of profile in the discrete-choice questions was the dependent variable. Initially, for the main-effect model, only the attribute differences were included as independent variables. For the reduced model, all attribute differences and interactions were included as independent variables. Then, the model was reduced using a backward stepwise procedure where statistically insignificant independent variables $(p>0.10)$ were systematically removed from the model. The aim was to obtain a reduced model that contains only statistically significant independent variables.

Based on the regression results, it is possible to analyse whether the attributes were considered important in the hypothetical choice of obstetric care. If the coefficient of the attribute is significant at the $10 \%$ level, it could be assumed with relatively certainty $(90 \%)$ that respondents consider this attribute to be important. In addition to this, the magnitude of the coefficients makes it possible to determine the importance of one attribute relative to another in influencing overall utility. The larger the absolute value of the coefficient, the greater the impact of a unit change in the attribute on respondents' overall utility.

\section{Results}

In total, 449 women received the questionnaire. Of them, 321 women $(71.5 \%)$ returned the questionnaire with al least one discrete-choice question completed and were included in the analysis. Totally, 290 partners received the questionnaire. Of them, 212 partners $(73.1 \%)$ returned the questionnaire with at least one discrete-choice question completed.

The descriptive statistics of the socio-demographic variables of the pregnant women and their partners are presented in table 3. Given the socio-demographic variables, $56.7 \%$ of the women and $50.9 \%$ of the partners had chosen for a home birth prior to our study, while $43.3 \%$ of the women and $49.1 \%$ of the partners preferred a short-stay hospital birth. About $98 \%$ of the pregnant women and $97 \%$ of the partners were born in the Netherlands, while $2 \%$ and $3 \%$, respectively, were born in another country. In our study, $64.2 \%$ of all women and $61 \%$ of all 


\section{Differences in preferences for obstetric care}

partners had an education degree higher than high-school, which is very high compared to the national statistics ${ }^{1}$. Therefore, we account for the education level and other socio-demographic characteristics in our model.

Table 3: Socio-demographic variables of the study population included in the conjoint analysis. Numbers are percentages

\begin{tabular}{|c|c|c|}
\hline Socio- demographic variables & Women $(n=321)$ & Partners $(n=212)$ \\
\hline \multicolumn{3}{|l|}{ Age } \\
\hline $0=\leq 28$ years & 40.5 & 45.7 \\
\hline $1=>28$ years & 59.5 & 54.3 \\
\hline \multicolumn{3}{|l|}{ Body Mass Index (BMI) } \\
\hline $0=\geq 25$ & 29.5 & NA \\
\hline $1=<25$ & 70.5 & NA \\
\hline \multicolumn{3}{|l|}{ Gestation age } \\
\hline $0=\leq 34$ weeks pregnancy & 78.5 & 70.6 \\
\hline $1=>34$ weeks pregnancy & 21.5 & 29.4 \\
\hline \multicolumn{3}{|l|}{ Country of origin } \\
\hline $0=$ Born in another country & 1.9 & 2.8 \\
\hline $1=$ Born in the Netherlands & 98.1 & 97.2 \\
\hline \multicolumn{3}{|l|}{ Education } \\
\hline $0=$ up to high-school degree & 35.8 & 39.2 \\
\hline $1=$ higher than high-school degree & 64.2 & 60.8 \\
\hline \multicolumn{3}{|l|}{ Employment } \\
\hline $0=$ unemployment & 6.3 & NA \\
\hline 1 = employment & 93.7 & NA \\
\hline \multicolumn{3}{|l|}{ Marital state } \\
\hline $0=$ single & 1.3 & 0 \\
\hline $1=$ married $/$ cohabiting & 98.7 & 100 \\
\hline \multicolumn{3}{|l|}{ Familiy income } \\
\hline $0=\leq 2000$ euro & 9.2 & 21.2 \\
\hline $1=>2000$ euro & 90.8 & 78.8 \\
\hline \multicolumn{3}{|l|}{ Distance to nearest hospital in minutes } \\
\hline $0=\leq 10$ minutes & 30.0 & 32.9 \\
\hline $1=>10$ minutes & 70.0 & 67.1 \\
\hline \multicolumn{3}{|l|}{ Pregnancy course } \\
\hline $0=$ no & 16.7 & 19.4 \\
\hline $1=$ yes & 83.3 & 80.6 \\
\hline \multicolumn{3}{|l|}{ Way of getting pregnant } \\
\hline $0=$ with medical help & 8.4 & 8.5 \\
\hline 1 = spontaneous & 91.6 & 91.5 \\
\hline \multicolumn{3}{|l|}{ Provisional choice } \\
\hline $0=$ short-stay hospital birth & 43.3 & 49.1 \\
\hline 1 = home birth & 56.7 & 50.9 \\
\hline \multicolumn{3}{|l|}{ Primigravidae/ first child } \\
\hline $0=$ no & 13.9 & 0.6 \\
\hline $1=$ yes & 86.1 & 99.4 \\
\hline \multicolumn{3}{|l|}{ Previous experience with DCE } \\
\hline $0=$ no & 15.9 & 14.7 \\
\hline 1 = yes & 86.1 & 85.3 \\
\hline
\end{tabular}




\section{Chapter 4}

\section{Results of the discrete-choice experiment}

The results of the regression analysis that is carried out to analyse the data from the discrete-choice experiment are presented in table 4 (main effects model including only the attribute changes).

All attributes of obstetric care, except for the need of transfer during birth, are, for both women and their partners, significant in the main-effect model. This means that the respondents consider these attributes to be important for the choice of obstetric care. Given the coding of the independent variables (see table 1), the direction of the statistically significant regression coefficients in the main-effect model indicates that overall, the pregnant women in our sample prefer to be assisted by a midwife during birth, they prefer to give birth in a home-like birth setting, they also prefer to have an influence on the decision-making process and the possibility of pain-relief. Partners' preferences have the same direction. In addition to this, the women and their partners prefer no out-of pocket payments.

The larger the coefficient associated with a given attribute, the greater the impact of a unit change in that attribute on respondents' overall utility. For women, the possibility of influencing decision-making during birth has the largest coefficient (0.7492). Also the home-like birth setting has a relatively large coefficient (0.5442), followed by the place of giving birth (0.4363).

Comparing the results of the regression analysis of the women with the results of the partners, a difference can be seen. For partners the possibility of influencing on decision-making has the largest coefficient (0.5918), but the second attribute is possibility of pain relief $(0.5141)$. Compared to the women, this coefficient is much larger $(0.5141$ vs 0,3183$)$ for partners. For women, possibility of pain relief is fifth in the relative attribute ranking. Also the attribute 'out-of-pocket costs' is relatively more important for the partners than for the pregnant women $(-0.4264$ vs. -0.3715$)$.

Table 4: Results of discrete-choice experiment: pregnant women and partner; gestational age 32 weeks. Main effects model. Probit regression with random effects

\begin{tabular}{|c|c|c|}
\hline \multirow[t]{3}{*}{ Attributes } & \multicolumn{2}{|l|}{ Main effects model } \\
\hline & Women $(n=321)$ & Partner $(n=212)$ \\
\hline & Regression Coefficient (SE) & Regression Coefficient (SE) \\
\hline Assistance by the midwife & $0.3743^{*}(0.0772)$ & $0.2931^{*}(0.0894)$ \\
\hline Home-like birth setting & $0.5442^{*}(0.0747)$ & $0.2654^{*}(0.0888)$ \\
\hline $\begin{array}{l}\text { Possibility of influencing decision-making } \\
\text { during birth }\end{array}$ & $0.7492^{*}(0.0743)$ & $0.5918^{*}(0.0907)$ \\
\hline Possibility of pain relief & $0.3183^{*}(0.0753)$ & $0.5141^{*}(0.0818)$ \\
\hline Home birth & $0.4363^{*}(0.0544)$ & $0.2823^{*}(0.0682)$ \\
\hline Possibility of transfer during birth & $-0.0166(0.0681)$ & $-0.1397(0.0882)$ \\
\hline Out-of-pocket cost & $-0.3715^{*}(0.0734)$ & $-0.4264^{*}(0.0941)$ \\
\hline
\end{tabular}

A positive regression coefficient means a positive preference for the item listed in the table. Closer to 1 , the more important the item is; * $p$-value $<0,05$ 


\section{Differences in preferences for obstetric care}

Table 5 shows the results of the interactions between the socio-demographic characteristics of the pregnant women and the attributes, while Table 6 shows the same results for the partners. It can be seen from these tables how the attributes importance varies among specific subgroups based on the sociodemographic variables. For the partners, there are fewer differences identified among the subgroups compared to women. The attribute 'possibility of transfer during birth' was not significant on a sample level for the women, only as interactions with education and employment. For the partners this attribute is not significant at all, even not as an interaction with the socio- demographic characteristics. As indicated in table 5, for pregnant women with a higher than high-school degree 'the influence on decision-making', 'the possibility on pain-relief treatment', 'a home birth' and 'no need of transfer during birth' appear more important than for women with a lower education level.

Table 5: Results of discrete-choice experiment: pregnant women; gestational age 32 weeks. Probit regression with random effects

\begin{tabular}{|c|c|c|}
\hline Interaction terms & $\begin{array}{l}\text { Regression Coeffi- } \\
\text { cient }(\mathrm{Se})\end{array}$ & Explanation \\
\hline Age $\times \Delta$ Place of giving birth & $-0.3268^{* *}(0.1208)$ & $\begin{array}{l}\text { Women with a higher age than } 28 \text { years prefer } \\
\text { a short-stay hospital birth }\end{array}$ \\
\hline $\begin{array}{l}\text { Length } \mathrm{x} \Delta \text { Possibility of } \\
\text { Influencing decision-making }\end{array}$ & $-0.2916^{* *}(0.1052)$ & $\begin{array}{l}\text { Women with a length smaller than } 1.69 \text { metres } \\
\text { prefer to have influence on decision-making } \\
\text { process during birth more than women with a } \\
\text { length larger than } 1.69 \text { metres. }\end{array}$ \\
\hline $\begin{array}{l}\text { Weight } \mathrm{x} \Delta \text { Type of birth } \\
\text { setting }\end{array}$ & $-0.0010^{*}(0.0006)$ & $\begin{array}{l}\text { Women with a weight more than } 70 \text { kilograms } \\
\text { find the type of birth setting less important. }\end{array}$ \\
\hline $\begin{array}{l}\text { Gestation age } \times \Delta \text { Place of } \\
\text { giving birth }\end{array}$ & $0.3585^{\star *}(0.1193)$ & $\begin{array}{l}\text { Women with a gestation age more than } 34 \\
\text { weeks find a home birth more important than } \\
\text { women with a gestation age less than } 34 \text { weeks }\end{array}$ \\
\hline $\begin{array}{l}\text { Country of origin x } \Delta \text { Type of } \\
\text { birth setting }\end{array}$ & $-0.0012^{* *}(0.0006)$ & $\begin{array}{l}\text { Women with the Dutch nationality prefer a } \\
\text { clinical birth setting more than women with } \\
\text { another nationality. }\end{array}$ \\
\hline $\begin{array}{l}\text { Education } \times \Delta \text { Influence on } \\
\text { decision-making }\end{array}$ & $0.2682^{*}(0.1581)$ & $\begin{array}{l}\text { For women with a higher than high-school } \\
\text { degree the influence on decision-making ap- } \\
\text { pears to be more important than women with a } \\
\text { lower education level }\end{array}$ \\
\hline $\begin{array}{l}\text { Education } x \Delta \text { Possibility on } \\
\text { pain relief }\end{array}$ & $0.3402^{* *}(1105)$ & $\begin{array}{l}\text { For women with a higher than high-school } \\
\text { degree the possibility on pain relief appears to } \\
\text { be more important than women with a lower } \\
\text { education level }\end{array}$ \\
\hline $\begin{array}{l}\text { Education } \times \Delta \text { Place of giving } \\
\text { birth }\end{array}$ & $0.2962^{\star *}(0.1276)$ & $\begin{array}{l}\text { For women with a higher than high-school } \\
\text { degree a home birth appears to be more impor- } \\
\text { tant than women with a lower education level }\end{array}$ \\
\hline $\begin{array}{l}\text { Education } \times \Delta \text { Possibility of } \\
\text { transfer during birth }\end{array}$ & $0.2238^{*}(0.1353)$ & $\begin{array}{l}\text { For women with a higher than high-school } \\
\text { degree no need of transfer during birth appears } \\
\text { to be more important than women with a lower } \\
\text { education level }\end{array}$ \\
\hline $\begin{array}{l}\text { Employment } x \Delta \text { Assistence } \\
\text { during birth }\end{array}$ & $0.2883^{\star *}(0.0806)$ & $\begin{array}{l}\text { Women with an employment find assistance by } \\
\text { a midwife during birth more important than } \\
\text { women without an employment. }\end{array}$ \\
\hline
\end{tabular}




\section{Chapter 4}

\begin{tabular}{|c|c|c|}
\hline Interaction terms & $\begin{array}{l}\text { Regression Coeffi- } \\
\text { cient }(\mathrm{Se})\end{array}$ & Explanation \\
\hline $\begin{array}{l}\text { Employment } x \Delta \text { Possibility of } \\
\text { transfer during birth }\end{array}$ & $-0.9234^{* *}(0.2696)$ & $\begin{array}{l}\text { Women with an employment find not to be } \\
\text { transferred during birth more important than } \\
\text { women without an employment. }\end{array}$ \\
\hline $\begin{array}{l}\text { Employment x } \Delta \text { Out-of- } \\
\text { pocket costs }\end{array}$ & $-0.6057^{* *}(0.1203)$ & $\begin{array}{l}\text { Women with an employment find no out-of- } \\
\text { pocket costs more important than women } \\
\text { without an employment. }\end{array}$ \\
\hline $\begin{array}{l}\text { Familiy income } x \Delta \text { Out-of- } \\
\text { pocket costs }\end{array}$ & $-0.0003^{*}(0.0002)$ & $\begin{array}{l}\text { For women with a higher income level no out- } \\
\text { of-pocket costs appears to be more important } \\
\text { than women with a lower income level. }\end{array}$ \\
\hline $\begin{array}{l}\text { Pregnancy course } x \\
\text { Assistence during birth }\end{array}$ & $\Delta 0.0003^{*}(0.0002)$ & $\begin{array}{l}\text { Women with a pregnancy course find assis- } \\
\text { tance by a midwife during birth more important } \\
\text { than women without a pregnancy course. }\end{array}$ \\
\hline $\begin{array}{l}\text { Pregnancy course } x \\
\text { Possibility on pain relief }\end{array}$ & $\Delta-0.0004^{* *}(0.0001)$ & $\begin{array}{l}\text { Women with a pregnancy course find the } \\
\text { possibility on pain relief less important than } \\
\text { women without a pregnancy course. }\end{array}$ \\
\hline $\begin{array}{l}\text { Way of getting pregnant } \times \Delta \\
\text { Type of birth setting }\end{array}$ & $0.0006^{* *}(0.0001)$ & $\begin{array}{l}\text { Women with a spontaneous pregnancy prefer a } \\
\text { home-like birth setting more than women with- } \\
\text { out a spontaneous pregnancy. }\end{array}$ \\
\hline $\begin{array}{l}\text { Way of getting pregnant } \times \Delta \\
\text { Place of giving birth }\end{array}$ & $-0.0005^{\star *}(0.0002)$ & $\begin{array}{l}\text { Women with a spontaneous pregnancy prefer a } \\
\text { short-stay hospital birth more than women } \\
\text { without a spontaneous pregnancy. }\end{array}$ \\
\hline $\begin{array}{l}\text { Provisional choice } x \Delta \text { Out- } \\
\text { of-pocket costs }\end{array}$ & $0.4259^{* *}(0.1626)$ & $\begin{array}{l}\text { Women who chose for a home birth are willing } \\
\text { to pay any out-of-out pocket costs. }\end{array}$ \\
\hline $\begin{array}{l}\text { Previous DCE experience } \mathrm{x} \\
\Delta \text { Type of birth setting }\end{array}$ & $0.5176^{* *}(0.0843)$ & $\begin{array}{l}\text { Women who had previous DCE experience } \\
\text { prefer a home-like birth setting. }\end{array}$ \\
\hline $\begin{array}{l}\text { Previous DCE experience } x \\
\Delta \text { Place of giving birth }\end{array}$ & $-0.5754^{* *}(0.2429)$ & $\begin{array}{l}\text { Women who had previous DCE experience } \\
\text { prefer a short-stay hospital birth. }\end{array}$ \\
\hline
\end{tabular}

${ }^{* *}$ p-value $<0.05 ;{ }^{*} 0,05<p$-value $<0.1$

Table 6 shows that partners of women who are more than 34 weeks pregnant prefer a home birth. This is the same for the women (see table 5). Partners who prefer a short-stay hospital birth find the possibility of pain relief more important than partners who prefer a home birth.

Women with a gestation age above 34 weeks, as well as their partners, prefer to have a home birth. 
Table 6: Results of discrete-choice experiment: partners; gestational age 32 weeks. Probit regression with random effects

\begin{tabular}{|c|c|c|}
\hline Interaction terms & $\begin{array}{l}\text { Regression Coefficient } \\
(\mathrm{Se})\end{array}$ & Explanation \\
\hline $\begin{array}{l}\text { Gestation age } x \Delta \text { Type of } \\
\text { birth setting }\end{array}$ & $-0.0012^{*}(0.0007)$ & $\begin{array}{l}\text { Partners with women, who are more than } 34 \\
\text { weeks pregnant, find a clinical birth setting } \\
\text { more important. }\end{array}$ \\
\hline $\begin{array}{l}\text { Gestation age } \times \Delta \text { Place of } \\
\text { giving birth }\end{array}$ & $0.0009^{* *}(0.0003)$ & $\begin{array}{l}\text { Partners with women, who are more than } 34 \\
\text { weeks pregnant, prefer to have a home birth. }\end{array}$ \\
\hline $\begin{array}{l}\text { Provisional choice } x \Delta \text { Pos- } \\
\text { sibility of pain relief }\end{array}$ & $-0.0007^{* *}(0.0002)$ & $\begin{array}{l}\text { Partners who prefer a short-stay hospital birth } \\
\text { find the possibility of pain relief more important } \\
\text { than partners who prefer a home birth. }\end{array}$ \\
\hline $\begin{array}{l}\text { Previous DCE experiment } x \\
\Delta \text { Possibility of pain relief }\end{array}$ & $0.4251^{* *}(0.0991)$ & $\begin{array}{l}\text { Partners who had previous DCE experiment } \\
\text { find the possibility of pain relief more important }\end{array}$ \\
\hline $\begin{array}{l}\text { Previous DCE experiment } x \\
\Delta \text { Place of giving birth }\end{array}$ & $0.7749^{* *}(0.2677)$ & $\begin{array}{l}\text { Partners who had previous DCE experiment } \\
\text { prefer a home birth. }\end{array}$ \\
\hline
\end{tabular}

${ }^{* *}$ p-value $<0.05 ;{ }^{*} 0.05<p$-value $<0.1$

\section{Discussion}

In this study, the discrete-choice experiment was used to provide information about the attributes that are important to low-risk nulliparae and their partners in their choice for place of birth. Except the attribute 'possibility of transfer during birth', all attributes in the discrete-choice experiment appeared significantly important to low-risk nulliparae and their partners. The discrete-choice experiment showed that women and their partners value some attributes relatively higher than other attributes. It gave the possibility to investigate the preferences of women's and partners, not only for realistic combinations of attributes of obstetric care but also for hypothetical combinations of these attributes.

For women and their partners the possibility of influencing decision-making is the most important attribute when compared to the other attributes of obstetric care. This finding is consistent with other studies. These studies showed also that women seek control and participation in the process of decision-making. They should have, and feel, autonomy and control over the birthing process ${ }^{33.34}$. Influence on decision-making is known as an important dimension of childbirth satisfaction ${ }^{20,35}$.

The role and the influence of partners regarding the choice of place of birth has become more important ${ }^{17,18}$. Partners are more involved in the decision-making process regarding place of birth ${ }^{18}$. However, this influence is often exerted with limited, second-hand information on available birthing options. Themes identified in forming men's views and subsequently, men's influence on the choice of place of birth include available information, myths, time constraints, and risk perception $^{18}$. This highlights a need to acknowledge the importance of the man's role in childbirth decision-making by providing men with accurate, consistent information 


\section{Chapter 4}

delivered in an inclusive, men-focused way. This way, men can support their partners in making an informed choice about where their babies will be born.

Also the role of the partner during birth has been considered as important ${ }^{36}$. Making decisions during birth, particularly in relation to pain control, acquiring information to enable women to make decisions and performing practical activities (like back massage) describe the expectations of partners during birth.

For the partners, the pain-relief treatment is more important than a home-like birth setting and a home birth. The worst aspect of childbirth is witnessing their partner in pain. Feelings of frustration and helplessness were decreased by the use of pain relief. If the mother has no pain during delivery, the partner feels more helpful ${ }^{19}$. The helpfulness of the partner has been reported to be the most useful behaviour to the women. A Swedish study showed that fathers-to-be are more likely to express fear for the well-being of the woman than are the women themselves ${ }^{37}$. These differences are probably a consequence of the difference between being physically involved in the birthing process, in contrast to being a bystander.

The benefits of partner's attendance are mentioned by a number of studies, such as women reporting less pain and expressing a more positive attitude toward birth and pregnancy ${ }^{38-40}$. However, research revealed that professionals often see the partners just as a support for the woman, they are not included as equal partners and professionals have unclear roles for them. There is also little done to discover their (psychological) needs ${ }^{36}$. It is uncertain whether health care professionals give adequate information about the possible pain relief treatments. Given these results, it should be recommended to involve the partners more in the process of providing relevant information to expectant parents. It seems important for health care professionals to meet the partner's individually, design childbirth preparation from men's perspective, follow up interpretations of the content, discuss expectations with regard to the men's role, and assess their experiences during the birth process ${ }^{41,42}$. Research showed that partners need more information during pregnancy ${ }^{43}$. Partners get their information from a number of sources, i.e. books, internet and antenatal classes. However, the antenatal classes are mostly based on the needs of the pregnant women. Partners are not seen as equal partners during pregnancy, being invited only to special classes rather than the whole course of preparation for the birthing event.

The study achieved a high response rate of $76.6 \%$ for the women and $73.1 \%$ for the partners. However, some limitations in this study need to be considered.

An important limitation relates to the method of data collection. This study is a multicenter prospective cohort study. Therefore, possible selection bias cannot be completely excluded in our study.

In our sample, the percentage of women and partners with an origin other than the Dutch origin, is very small $(2.0 \%$ of the women and $3.0 \%$ of the partners). Of 


\section{Differences in preferences for obstetric care}

all women in the Netherlands, in $2008,90 \%$ was born in the Netherlands ${ }^{1}$. An explanation for this discrepancy can be that the women and their partners in this study had to speak the Dutch language fluently. In future studies, it is important to improve migrant participation and to compare their preferences to expectant parents with Dutch origin. This could provide a base for improving the primary obstetric care (i.e. midwifery care) received by the migrant population groups.

The percentage of high educated respondents is very high in this study population. Sixty-four percent of the women and $61 \%$ of the partners had a higher than high school education. However, in the interaction model we account for this by including education. The above considerations indicate a possibility for generalisations in our study but only with regard to low-risk nulliparae since this was the inclusion criterion of the respondents.

The method of discrete-choice experiment appeared to be an adequate research technique to investigate the preferences of low-risk pregnant women and their partners, because it allowed us to take into account the combined effect of multiple choice-determinants on the decision-making process. The results of this discrete-choice experiment can be confirmed by previous Dutch studies towards preferences of obstetric care ${ }^{3-8,29}$. However, the validation of the attributes is not guaranteed in this study. It is unknown whether the attributes selected for the study and attribute levels cover all important aspects of obstetric care for women and their partners. Other qualitative research methods can be used to identify other attributes relevant to the decision-making process ${ }^{21,44}$. Yet, concerns can be raised due to the inclusion of purely hypothetical profiles in the discrete-choice experiment. Although, the results of our discrete-choice experiment appeared consistent with prior expectations and previous research results, this issue requires further investigation.

The results of this discrete-choice experiment have implications for health care providers, insurance institutions and public decision makers. The results can be used to set priorities for health policy because respondents are required to make trade-offs between the attributes and the attribute levels. It is a task of policy makers and health care professionals to improve the obstetric care for pregnant women. This can be achieved by taking women's preferences with regard to childbirth into account, but also the preferences of their partners. Women whose preferences of childbirth were met, are more satisfied than those whose preferences were not met ${ }^{37,45,46}$. Furthermore, partners of pregnant women have to be taken seriously by health care professionals and they have to be involved in the decision-making process. 


\section{Chapter 4}

\section{References}

1 Central Bureau of Statistics, 2009.

2 Stichting Perinatale Registratie Nederland. Perinatale Zorg in Nederland 2006. Utrecht: Stichting Perinatale Registratie Nederland, 2008.

3 Van der Hulst LAM, van Teijlingen ER, Bonsel GJ, Eskes M, Bleker OP. Does a pregnant's woman intended place of birth influence her attitudes toward and occurrence of obstetric interventions? Birth 2004; 31: 28-33.

4 Anthony S, Buitendijk SE, Offerhaus PM, Dommelen P, van der Pal-de Bruin KM. Maternal factors and the probability of a planned home birth. Br J Obstet Gynaecol 2005; 112: 748-53.

5 Kind $\mathrm{E}$. Thuis of in het ziekenhuis? Welke reden zijn voor de cliënt bepalend voor de keuze? Tijdschrift voor Verloskundigen 2000; 25: 110-15.

6 Kleiverda G, Steen AM, Andersen I, Treffers PE, Everaerd W. Place of delivery in the Netherlands: maternal motives and background variables related to preference for home or hospital confinement. Eur J Obstet Gynecol Reprod Biol 1990; 39: 139-16.

7 Manshanden JCP, De keuze van de nulliparae; wanneer, waarom? Tijdschrift voor Verloskundigen 1997; 22: 34-40.

8 Wiegers T, Van der Zee J, Kerssens J, Keirse M. Home birth or short-stay hospital birth in a lowrisk population in the Netherlands. Soc Sci Med 1998; 46: 1505-11.

9 Bloom JR. The relationship of social support and health. Soc Sci Med 1990; 30: 635-7.

10 Nuckolls KB, Kaplan HB, Cassel J. Psychosocial assets, life crisis and the prognosis of pregnancy. Am J Epidemiol 1972; 95: 431-41.

11 Rodriguez A, Bohlin G, Lindmark G. Symptoms across pregnancy Gynecol Scand 2001; 80: 21323.

12 Saurel-Cubizolles MJ, Romito P, Ancel PY, Lelong N. Unemployment and psychological distress one year after childbirth in France. J Epidemiol Community Health 2000; 54: 185-91.

13 Gjerdingen DK, Froberg DG, Fontaine P. The effects of social support on women's health during pregnancy, labor and delivery, and the postpartum period. Fam Med 1991; 23: 370-5.

14 Webster J, Linnane JW, Dibley LM, Pritchard M. Improving antenatal recognition of women at risk for postnatal depression. Aust N Z J Obstet Gynaecol 2000; 40: 409-12.

15 Tarkka MT, Paunonen M. Social support and its impact on mothers' experiences of childbirth. J Adv Nurs 1996; 23: 70-5.

16 Ip WY. Relationships between partner's support during labour and maternal outcomes. J Clin Nurs 2000; 9: 265-72.

17 Berghs G, Spanjaard E. De normale zwangerschap: Bevalling en beleid. Nijmegen: Universiteit van Nijmegen, 1988.

18 Mottram L, First-time expectant fathers and their influence on decision making regarding choice for place of birth. Midwifery Digest. 2008; 18: 582-89.

19 Capogna G, Camorcia M, Stirparo S. Expectant fathers' experience during labor with or without epidural analgesia. Int J Obst Anest 2007; 16: 110-15.

20 Waldenström U, Hildingsson I, Rubertsson C, Rådestad I. A negative birth experience: prevalence and risk factors in a national sample. Birth 2004; 31: 17-27.

21 Hundley V, Ryan M, Graham W. Assessing women's preferences for intrapartum care. Birth 2001; 28: $254: 63$.

22 Longworth L, Ratcliffe J, Boulton M. Investigating women's preferences for intrapartum care: home versus hospital births. Health Soc Care Comm 2001; 9: 404-13.

23 Ryan M, Farrar S. Using conjoint analysis to elicit preferences for health care. BMJ 2000; 320: 1530-33.

24 Ryan M, Hughes J. Using conjoint analysis to assess women's preferences for miscarriage management. Health Econ 1997; 6: 261-73.

25 Ratcliffe J, Van Haselen R, Buxton M, Hardy K, Colehan J, Partridge M. Assessing patients' preferences for characteristics associated with homeopathic and conventional treatment of asthma: a conjoint analysis study. Thorax 2002; 57: 503-8. 


\section{Differences in preferences for obstetric care}

26 Ryan M. Using conjoint analysis to take account of patient preferences and go beyond health outcomes: an application to in vitro fertilization. Soc Sci Med 1999; 48: 535-546.

27 Ryan M, Gerard K. Using discrete choice experiments to value health care programmes: current practice and future research reflections. Appl Health Econ Health Policy 2003; 2: 1-10.

28 Permain D, Swanson J, Kroes E, Bradley M. Stated Preference Techniques. A Guide to Practice. The Hague, the Netherlands: Steer, Davis, Gleave and Hague Consulting Group, 1991.

29 Pavlova M, Hendrix M, Nouwens E, Nijhuis J, van Merode G. The choice of obstetric care by lowrisk pregnant women in the Netherlands: Implications for policy and management. Health Policy 2009; 93: 27-34.

30 Hundley V, Ryan M. Are women's expectations and preferences for intrapartum care affected by the model of care on offer? BJOG 2004; 111: 550-60.

31 Ryan M, Gerard K. Using discrete choice experiments to value health care programmes: current practice and future research reflections. Appl Health Econ Health Policy 2003; 2: 1-10.

32 Lancsar E, Louviere J. Conducting discrete choice experiments to inform healthcare decision making: a user's guide. PharmacoEconomics 2008; 26: 661-77.

33 Gamble J, Creedy DK, Teakle B. Women's expectations of maternity services: A community-based survey. Women and Birth. 2007; 20: 115-20.

34 Goodman P, Mackey MC, Tavakoli AS. Factors related to childbirth satisfaction. J Adv Nurs. 2004; 46: 212-9.

35 Hodnett ED. Pain and women's satisfaction with the experience of childbirth: a systematic review. Am J Obstet Gyn 2002; 186: 160-72.

36 Draper J. Whose welfare in the labour room? A discussion of the increasing trend of fathers' birth attendance. Midwifery 1997; 13: 132-8.

37 Eriksson C, Westman G, Hamberg K. Content of Childbirth-Related Fear in Swedish Women and Men-Analysis of an Open-Ended Question. J Midwifery Womens Health 2006; 51: 112-8.

38 Somers-Smith MJ. A place for the father? Expectations and experiences of support during childbirth. Midwifery 1999; 15: 101-8.

39 Greenhalgh R, Slade P, Spiby H. Fathers' coping style, antenatal preparation, and experiences of labor and the postpartum. Birth 2000; 27: 177-84.

40 Nichols MR. Paternal perspectives of the childbirth experience. Mat Child Nurs J 1993; 21: 99-108.

41 Hallgren A, Kihlgren M, Forslin L, Norberg A. Swedish fathers' involvement in and experiences of childbirth preparation and childbirth. Midwifery 1999; 15: 6-15.

42 Vehvilainen-Julkunen K. Liukkonen A. Fathers' experiences of childbirth. Midwifery 1998; 14: 10-7.

43 Nolan M. Caring for fathers in antenatal classes. Modern Midwife 1994; 4: 25-8.

44 Ryan M, Mclntosch E, Shackley P. Methodological issues in the application of conjoint analysis in health care. Health Econ 1998; 7: 373-8.

45 Christiaens W, Bracke P. Assessment of social psychological determinants of satisfaction with childbirth in a cross-national perspective. BMC Pregnancy Childbirth 2007; 7: 26.

46 Green JM. Expectations and experiences of pain in labor: Findings from a large prospective study. Birth 1993; 20: 65-72. 



\section{Chapter 5 \\ Operative deliveries in low-risk pregnancies in the Netherlands: primary versus secondary care}

M.S Maassen, M.J.C. Hendrix, H.C. van Vugt, S. Veersema, F. Smits and J.G. Nijhuis

BIRTH 2008; 35: 277-82 


\section{Chapter 5}

\section{Abstract}

Background In The Netherlands, 35 percent of births take place in "primary care" to women considered at low risk and during labour, approximately 30 percent are referred to "secondary care." High-risk women and some low-risk women deliver in secondary care. This study sought to compare planned place of birth and incidence of operative delivery among women at low risk of complications at the time of onset of labour.

Methods A retrospective analysis was conducted of data about births in The Netherlands during 2003 that were recorded routinely in the Netherlands Perinatal Registry. Mode of delivery was analyzed for women classified as low risk at labour onset according to their planned place of birth (intention-to-treat analysis). The primary outcome was the rate of operative deliveries (vacuum or forceps extraction or caesarean section).

Results Women at low risk who planned to give birth, and therefore laboured and delivered in secondary care, had a significantly higher rate of operative deliveries than women who began labour in primary care where they intended to give birth $(18 \%[3,558 / 19,850]$ vs $9 \%[7,803 / 87,187])$ (OR $2.25,95 \% \mathrm{Cl} 2.00-2.52)$. For caesarean section, the rates were 12 percent $(2,419 / 19,850)$ versus 3 percent $(2,990 / 87,817)$ (OR $3.97,95 \% \mathrm{Cl} 3.15-5.01)$, irrespective of parity.

Conclusions The rate of operative deliveries was significantly lower for low-risk pregnant women who gave birth in a primary care setting compared with similar women who planned birth in secondary care. As with any retrospective analysis, it was not possible to eliminate bias, such as possible differences between primary and secondary care in assignment of risk status. In addition, known risk factors for interventions, technologies such as induction of labour and foetal monitoring, are only available in secondary care. These findings clearly demonstrate the need for a prospective study to examine the relationship between planned place of birth and mode of delivery and neonatal and maternal outcomes. 


\section{Operative deliveries in low-risk pregnancies}

\section{Introduction}

In contrast to most other Western countries, planned home birth is common in The Netherlands, where approximately 23 percent of births take place at home. In addition, approximately 10 percent occur in the context of a short stay in a hospital under the care of a midwife or general practitioner ${ }^{1,2}$. Most planned home births are supervised by independent midwives, although for approximately 5 percent of births in primary care that take place in rural regions where no midwives are available, the general practitioner can be responsible for care ${ }^{3}$. Midwives provide independent care for women with uncomplicated pregnancies and most women visit their midwife for antenatal care. In the case of an uncomplicated pregnancy with midwife-attended care, women can choose to have either a home birth or a hospital birth under the responsibility and care of their midwife. In the latter situation, the women and their babies are usually discharged home within a few hours of birth for postpartum care.

As soon as the midwife suspects or diagnoses a risk factor or a complication during pregnancy or birth, the woman is referred to an obstetrician in secondary care. The selection procedure to assess risk is based on the Obstetric Vademecum ("Verloskundig Vademecum"), which is a protocol-based list of items developed by midwives, general practitioners, and obstetricians to distinguish between low- and high-risk pregnancies ${ }^{4}$. If operative delivery (vacuum and forceps extractions and caesarean section) is required, a woman must be transferred to the care of an obstetrician in secondary care. Women with high-risk pregnancies, such as twins, or pregnancies complicated by pre-existing maternal pathology always receive care from an obstetrician in the hospital. Data about all Dutch births are registered in the Netherlands Perinatal Registry, which contains information based on data from two professional registers: the National Perinatal Database for Primary Care (LVR-1), which is a register of midwife-assisted births, and the National Perinatal Database for Secondary Care (LVR-2), a register of obstetrician-assisted births. Independent midwives and obstetricians routinely record details about pregnancy, labour, birth, and the puerperium and maternal demographic information in these registers. In the case of a referral during pregnancy or delivery, both the midwife and the obstetrician will record information on the same pregnancy. These two databases are linked annually and aggregated to form the Netherlands Perinatal Registry. Previous research in 2003 in The Netherlands had shown that approximately 30 percent of all women who began labour in primary care transferred to secondary care before birth ${ }^{1}$. Primiparous women are known to have a higher risk of referral than multiparous women ${ }^{5-9}$, and 53 percent of the primiparaes and 19 percent of all multiparas who began care with a midwife were referred to secondary care ${ }^{1}$. Major indications for referral were lack of progress in labour, dystocia, foetal distress, and need for pain relief. Previous research carried out in developed countries suggested that a 


\section{Chapter 5}

difference in operative delivery rates might occur between deliveries starting at home and in a hospital. Ackermann-Liebrich et al found a significant difference in such rates between deliveries starting at home or in a hospital ${ }^{10}$. Women starting their delivery in a hospital underwent more caesarean sections and operative vaginal deliveries (vacuum or forceps extractions). Whether hospital deliveries took place under the care of a midwife or an obstetrician was unclear ${ }^{10}$. Janssen et al showed a higher incidence of operative deliveries in midwife-assisted and obstetrician-assisted hospital births compared with home births ${ }^{7}$.

Wiegers et al demonstrated a higher rate of vaginal operative deliveries in shortstay hospital deliveries under supervision of a midwife compared with planned home births in a Dutch population in $1996{ }^{6}$, but another Dutch study showed no significant difference between planned home births and short-stay hospital births in $2004^{8}$.

In 2005, Johnson and Daviss conducted a study about the outcomes of planned home births an hospital births with certified midwives ${ }^{9}$. More caesarean sections and vaginal operative deliveries took place in the hospital group, but the risk of undergoing an operative delivery was not equal in both groups because the women in the planned hospital birth group were a priori at higher risk of complications ${ }^{9}$. A pilot study conducted in the University Hospital of Maastricht compared women in primary and secondary care who were at low risk at the time they began labour and showed no statistical difference in operative delivery rates between midwife-assisted deliveries and low-risk obstetrician-assisted deliveries (J.G. Nijhuis and F. Smits, 1998, unpublished paper). The evidence base for planned place of birth and operative delivery rates was of limited use, for example, because of the considerable differences in maternity care systems among locations in which the studies were carried out. In addition, only the unpublished pilot study compared women in primary and secondary care who were considered to be at low risk of complications at the time that they began labour. The study reported here therefore sought to compare planned place of birth and incidence of operative delivery among women at low risk of complications at the time of onset of labour.

\section{Methods}

\section{Study Design}

This study was a retrospective analysis of data that were routinely recorded in the Netherlands Perinatal Registry about births in 2003. The rate of operative deliveries (vacuum or forceps extraction or unplanned/emergency caesarean section) was our primary outcome. 


\section{Operative deliveries in low-risk pregnancies}

Women who were classified as being at low risk at the time of labour onset and for whom data had been recorded about their planned place of birth were included. Data about the 5 percent of births supervised by general practitioners in rural areas were not included since they are not registered in the Netherlands Perinatal Registry ${ }^{3}$. All women with any risk factor indicated in the list below and all women referred from midwife to obstetrician during pregnancy due to complications during pregnancy were excluded from this analysis.

The risk factors used to exclude women from this analysis include the following:

1. Medical history: Neurological disorders/surgery, respiratory tract disorders, vitium cordis, varices, thromboembolism, chronic hypertension, other circulatory tract disorders, digestive tract disorders, recurrent urinary tract infections, other urinary tract disorders, orthopedic disorders/surgery, psychiatric disorders, diabetes mellitus, other endocrinological disorders, dermatological disorders, systemic disorders, use of drugs, and human immunodeficiency virus.

2. Gynecological history: Congenital uterine anomalies, uterus myomatosus, adnexal anomaly, and/or endometriosis with treatment, cervical surgery, and pelvic floor surgery.

3. Obstetric history: Narrowing of pelvic outlet, previous molar pregnancy or choriocarcinoma, previous cesarean section, previous anal sphincter injury, previous postpartum haemorrhage $>1,000 \mathrm{~mL}$ with blood transfusion, previous manual removal of placenta, previous gestational diabetes with use of insulin, and previous serious preeclampsia.

4. Complications during present pregnancy: Admission during pregnancy, congenital (viral) infections, pyelonephritis, PAP smear>IIla, epilepsy with treatment, tocolysis, antepartum haemorrhage in first or second trimester, polyhydramnios, blood group incompatibility, placenta previa, placental abruption, intrauterine growth restriction with admission, gestational diabetes with treatment, hyperemesis gravidarum with admission, and (pre-) eclampsia.

\section{Data Analysis}

Data were analyzed by planned rather than actual place of birth (intention to treat) and by parity. Statistical significance was assessed using chi-square test. Results are presented using odds ratios and $95 \%$ confidence intervals.

\section{Results}

Of the 191,609 births in The Netherlands in 2003, 107,667 were births to women considered at low risk, of whom 38 percent were primiparous and 62 percent were multiparous. For women with singleton births $(n=184,025), 48$ percent started their delivery in primary care and 10 percent were low risk and began labour in secondary care. All other women (42\%) were considered to be at high risk at the onset of labour. Figure 1 describes intended and actual place of birth of the women included in this study. It shows that $87,817(82 \%)$ of women began their delivery in primary care under the care of a midwife and $19,850(18 \%)$ started their delivery at low risk in secondary care under the care of an obstetrician. 


\section{Chapter 5}

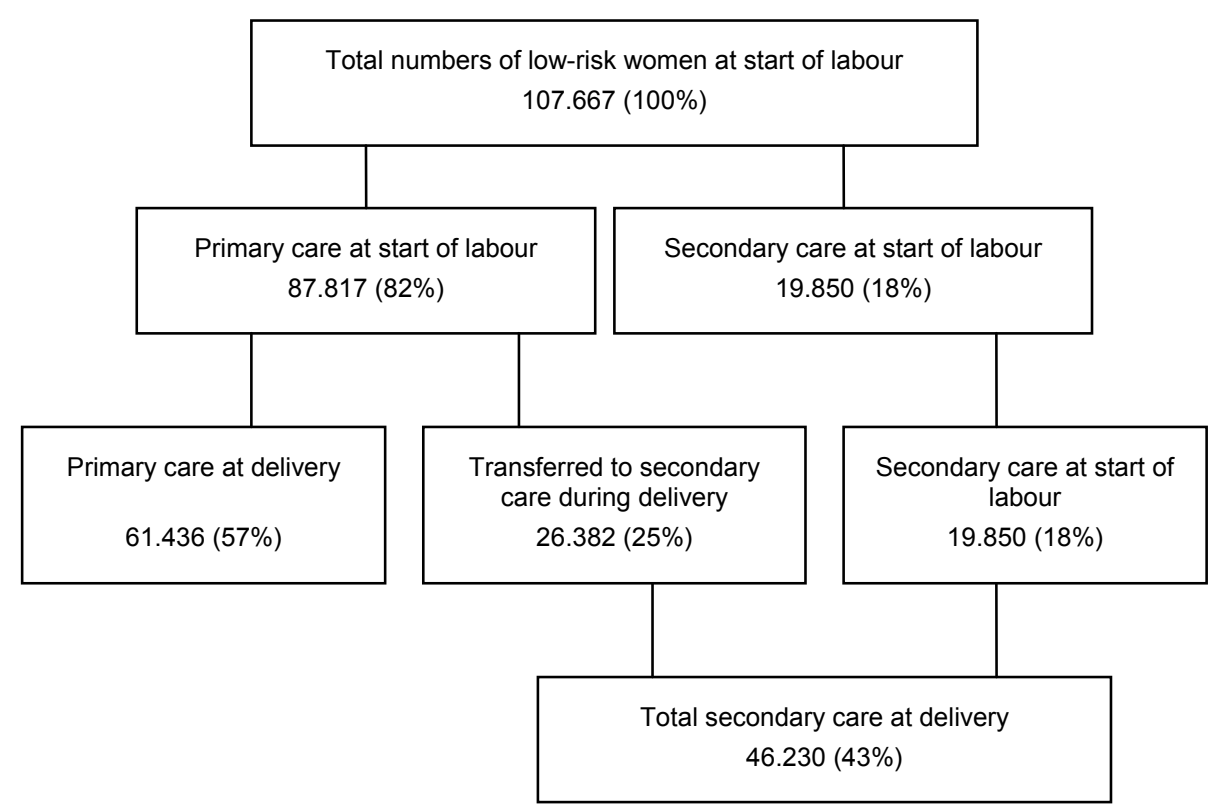

Figure 1: Intended and actual place of birth among low-risk women in The Netherlands in 2003.

The operative vaginal delivery rate was significantly lower in the primary care group compared with the secondary care group (8.9 vs $17.9 \%, \mathrm{p}<0.001$, OR $2.25,95 \% \mathrm{Cl} 2.00-2.52)$, as was the incidence of caesarean section (3.4 vs $12.2 \%, p<0.001$, OR $3.97,95 \% \mathrm{Cl} 3.15-5.01$ ) (Table 1). The spontaneous vaginal delivery rate was significantly lower in the secondary care group than in the primary care group (70 vs $88 \%, \mathrm{p}<0.001$, OR $0.32,95 \% \mathrm{Cl} 0.31-0.34$ ). Of primiparas who started labour in primary care, 75 percent had a spontaneous delivery compared with 54 percent in the secondary care group $(p<0.001$, OR $0.39,95 \%$ $\mathrm{Cl} 0.36-0.41)$. The caesarean section rate in the secondary care group was significantly higher than that in the primary care group (16 vs $6.3 \%,<0.001$, OR $2.85,95 \% \mathrm{Cl} 2.26-3.59)$. Of multiparas who started delivery in primary care, 95 percent had a spontaneous delivery compared with 81 percent in the secondary care $(p<0.001$, OR $0.21,95 \% \mathrm{Cl} 0.20-0.22)$. 


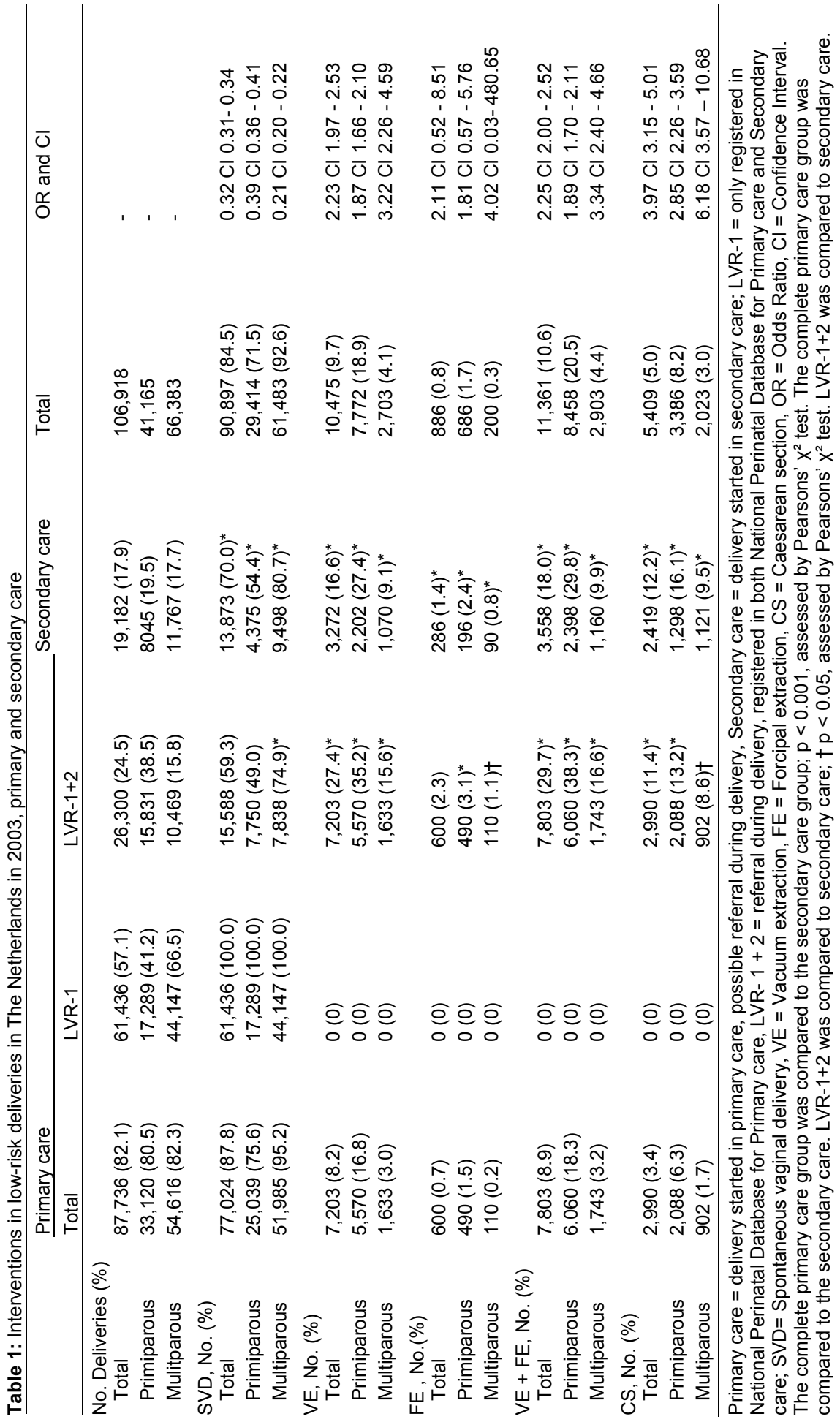




\section{Chapter 5}

\section{Discussion}

This study focused on the rate of operative deliveries among women at low risk and who were planning birth in a primary care setting compared with women at low risk in secondary care. We did not look at other perinatal outcomes and did not examine whether or not a higher or lower rate of operative deliveries leads to a better outcome. Analysis of this national data set demonstrated that women at low risk at the beginning of labour who deliver in secondary care were twice as likely to have an operative vaginal delivery and four times as likely to have a caesarean section compared with women who began labour and gave birth in primary care. The fact that more multiparas than primiparas had a spontaneous vaginal delivery may be largely explained by the higher risk that primiparas have of an operative delivery.

This study did not support the findings of the pilot study (J.G. Nijhuis and F. Smits, 1998, unpublished paper). The fact that the pilot was carried out in a single centre and the number of women who were eligible to be included was relatively small may have meant that the results reflected local differences in intervention rates. Previous studies have shown that local policies and different interpretations of indications for operative delivery appeared to greatly influence the rate of these interventions ${ }^{11,12}$, as demonstrated by Heres et al who showed regional variations in caesarean section rate of 6 to 23 percent ${ }^{12}$. Compared with our primary care group, a small study $(n=603)$ carried out in The Netherlands that examined operative delivery rates showed higher intervention rates of 11 percent caesarean section and 15 percent operative vaginal deliveries for midwife-supervised short-stay hospital births ${ }^{8}$. In our study, the higher rate of operative deliveries seen among women who started their delivery in secondary care is probably associated with a range of factors. For example, liberal use of foetal monitoring (cardiotocography) in secondary care increases intervention rates. A Cochrane review published in 2003, based on 12 studies conducted from 1976 to 2001, demonstrated a significant increase in caesarean sections and instrumental vaginal deliveries when cardiotocography was used compared with using only intermittent auscultation (relative risk 2.31 and 1.29, respectively, for low risk deliveries) ${ }^{13}$. This finding was confirmed in our study. It is possible that use of induction of labour may have been associated with the higher rate of operative deliveries in the secondary care group compared with the primary care group. Previous research ${ }^{14}$ has demonstrated that induction of labour for nulliparous women with low-risk pregnancies is associated with an increased risk of cesarean sections compared with spontaneous onset of labour. Induction of labour is only possible in secondary care not in primary care. However, since we did not have data about induction of labour, we were unable to control for this factor in this analysis. It is possible that bias was introduced in the recording of risk factors according to where a woman was planning to give birth. This bias could have 
operated so that those intending to labour and birth in primary care may have had risk factors more carefully identified than those who were intending to birth in secondary care and who would therefore have easier access to obstetric intervention. Another explanation for the difference in rates of operative delivery according to planned place of birth could be that obstetricians have a lower threshold for intervention or that the process of referral deters midwives from transferring women at "mild" risk who would be subject to intervention if they were in secondary care.

\section{Conclusions}

This study showed clearly that low-risk pregnant women were at significantly lower risk of an operative delivery if they began labour supervised by a midwife in a primary care setting. A large prospective study is now needed to examine the relationship between the rate of operative deliveries and perinatal outcomes. We are currently conducting such a study. 


\section{Chapter 5}

\section{References}

1 Stichting Perinatale Registratie Nederland. Bilthoven: Zuidam Uithof Drukkerijen, 2003.

2 Anthony S, Amelink-Verburg MP, Jacobusse GW, Pal van der-Bruin de KM. De thuisbevalling in Nederland 1995-2002, rapportage over de jaren 2001-2002. Bilthoven, Leiden: SPRN/TNO, 2005.

3 Anthony S. The Dutch perinatal and neonatal registers, applications in perinatal epidemiology. Leiden: De Bink, 2005.

4 College voor Zorgverzekeringen Diemen 2003. Verloskundig Vademecum 2003. Apeldoorn: VDAgroep, 2003.

5 Berghs G, Spanjaards E, Driessen L, et al. Neonatal neurological outcome after low-risk pregnancies. Eur J Obstet Gynecol 1995; 62: 167-71.

6 Wiegers TA, Keirse MJ, Zee van der J, Berghs GA. Outcome of planned home and planned hospital births in low risk pregnancies: Prospective study in midwifery practices in the Netherlands. BMJ 1996; 313: 1309-13.

7 Janssen PA, Lee SK, Ryan E, et al. Outcomes of planned home births versus planned hospital births after regulation of midwifery in British Columbia. Can Med Assoc J 2002; 166: 315-23.

8 Hulst van der LA, van Teijlingen ER, Bonsel GJ, et al. Does a pregnant woman's intended place of birth influence her attitudes toward and occurrence of obstetric interventions? Birth 2004; 31: 2833.

9 Johnson KC, Daviss BA. Outcomes of planned home births with certified professional midwives: Large prospective study in North America. BMJ 2005; 330: 1416.

10 Ackermann-Liebrich U, Voegeli T, Gunter-Witt K, et al. Home versus hospital deliveries: Follow up study of matched pairs for procedures and outcome. BMJ 1996; 313: 1313-8.

11 Elferink-Stinkens PM, Van Hemel OJ, Brand R. Differences in obstetrical intervention rates between Dutch hospitals. Eur J Obstet Gynecol 1994; 53: 165-73.

12 Heres MH, Pel M, Elferink-Stinkens PM, et al. The Dutch obstetric intervention study-Variations in practice patterns. Int J Gynaecol Obstet 1995; 50: 145-50.

13 Alfirevic Z, DevaneD, GyteGML. Continuous cardiotocography (CTG) as a form of electronic fetal monitoring (EFM) for fetal assessment during labor. Cochrane Database Syst Rev 2006;(3):CD006066. doi: 10.1002/14651858.CD006066.

14 Vrouenraets FPJM, Roumen FJME, Dehing CJG, et al. Bishop score and risk of cesarean delivery after induction of labor in nulliparous women. Obstet Gynecol 2005; 105: 690-7. 


\section{Chapter 6 \\ Differences in referrals in low-risk pregnancies in the Netherlands: home birth versus home-like hospital birth}

M.J.C. Hendrix, L.J.M. Smits, M.J. Nieuwenhuijze, J.L. Severens and J.G. Nijhuis 


\section{Chapter 6}

\section{Abstract}

Background In the Netherlands, low-risk pregnant women have the opportunity to choose for a home birth or a home-like hospital birth. However, evidence into the effect of planned place of birth on referrals to secondary care and interventions during delivery, controlled for other factors, is lacking. The objective of this study is to assess the differences in referral rates, intrapartum interventions and outcome of low-risk nulliparae with the intention to give birth at home and low-risk nulliparae with the intention to give birth in a home-like hospital setting.

Methods A prospective non-randomised study, using a questionnaire to measure the socio-demographic variables of 449 low-risk nulliparae starting their pregnancy under midwife and the medical reports of labour.

Results Low-risk nulliparous women with the intention to give birth at home have a considerably lower chance to be referred to secondary care during labour than women who prefer to give birth in a home-like hospital birth setting $(52.2 \%$ vs $66.1 \%, \mathrm{p}<0.05)$. No differences were found in urgent referral rates $(3.3 \%$ vs $3.3 \%$ ). Women who preferred a home-like hospital birth had more unplanned caesarean sections. No differences were found between both groups regarding neonatal outcomes.

Conclusions While the neonatal outcome is equal, planned home birth is associated with less referrals to the obstetrician and less unplanned caesarean sections compared to planned home-like birth. 


\section{Differences in referrals in low-risk pregnancies}

\section{Introduction}

In the Netherlands, planned home births are much more common than in other Western countries. In the year 2006, $29 \%$ of all Dutch births took place at home and another $10 \%$ in a home-like hospital environment ${ }^{1}$. However, of all nulliparas, $19 \%$ gave birth at home ${ }^{2}$. Low-risk pregnant women stay in the care of an independent registered midwife and are free to choose where to give birth, either at home or in the hospital. In the latter situation the woman stays under the responsibility and care of their own midwife, called a home-like hospital birth in this respect. When medical complications (or an increased risk of complications) occur during pregnancy or delivery, the midwife refers the pregnant woman to secondary care for further assessment or treatment. The collaboration between midwives and obstetricians have been specified in the "Verloskundig Vademecum" (Obstetric Manual) ${ }^{3}$.

The number of women referred to secondary care has increased steadily during recent years ${ }^{4,5}$. In 2006 , approximately $30 \%$ of all women who began labour in primary care were transferred to secondary care before delivery ${ }^{1}$. Nulliparas are known to have a higher risk to be referred to the obstetrician during labour than multiparae ${ }^{6-10}$. In $2006,80 \%$ of all nulliparas started their obstetric care in primary care. During pregnancy, $46 \%$ of all nulliparas were referred to secondary care. Of the group nulliparas who started their delivery in primary care, $43 \%$ were referred to the obstetrician for secondary care in the year ${ }^{1}$. When complications occur during a home birth, the woman has to be transferred to the hospital. Previous research ${ }^{11}$ has shown that, 3 years after giving birth, $23 \%$ of these primiparae were "unhappy" or "very unhappy" with their delivery. In contrast, 96\% of the women who had a home delivery were very satisfied after 3 years. Rijnders et al ${ }^{11}$ also showed that a referral to the hospital is an important risk factor for a negative recall of the birth experience.

The recent Dutch referral rates are based on retrospective data. But so far evidence into the effect of planned place of birth on referrals and interventions, controlled for other factors, is lacking. A recent study of Amelink et al ${ }^{12}$ made a categorisation of the types of referrals that take place during labour and immediately postpartum, and the corresponding neonatal outcomes. This categorisation provides a framework for the further evaluation of referral rates. Indications for referral were categorised into three groups: no referral, urgent referral and referral without urgency. Of all women who started labour in primary care, $3.6 \%$ had an urgent referral and in $28.3 \%$ the reason for referral was not so urgent. The study was based on data from the perinatal database 2001-2003 ${ }^{13}$. Limitation of this retrospective study was that the database gives no information about the severity of the complications that led to the referral or the time line of the complications. This may have led to overestimation or underestimation of the number of cases in the different categorisations. Another limitation of the lacking information about 


\section{Chapter 6}

the time lines is that it is not possible to draw firm conclusions about the effectiveness of the Dutch system of risk selection in relation to neonatal outcomes.

The objective of this study is to prospectively investigate the differences in referral rates between women who prefer to give birth at home, and women who want to give birth in a home-like hospital setting. Besides, differences in intervention rates between both groups are evaluated. Therefore we carried out an observational study, controlling for a range of possible confounding factors, including socio-demographic, and psychological characteristics as well as pregnancyrelated factors.

\section{Methods}

Of all midwifery practices, 150 practices from across the Netherlands were randomly selected from the Dutch Midwifery Association Registration. These midwifery practices were invited to participate in this study. Finally, 100 practices agreed to participate in the study. These midwives were involved in the consecutive recruitment of the study population. Women with a first ongoing pregnancy (nulliparas), and their partners, were eligible to participate in the cohort study. At the moment of inclusion (8-10 weeks pregnancy) they were under the supervision of their midwife. At intake, all women had a low-risk pregnancy (no medical complications or risk factors) and they had to understand the Dutch language sufficiently to read and fill out the questionnaires. The eligible pregnant women and their partners received the study information at the first prenatal visit, and were asked for informed consent to participation. Recruitment was carried out from March 2007 to August 2007. Ethical approval was obtained by the Medical Ethical Committee of the Maastricht University Medical Centre (registration no. 04234).

\section{Data collection}

Clinical data were collected using the medical records of the delivery of all respondents. Socio-demographic data were collected by a self-administered postal questionnaire, filled out by the respondents at 16 weeks of gestational age. The referral indications during labour were categorised according to the classification proposed by Amelink et al ${ }^{12}$. Category 0 comprises all women who were under care of a midwife at the start of labour and who gave birth under exclusive care of a midwife. Category 1 was defined as an urgent referral during labour that cannot be treated at the primary care level and requires immediate diagnostics or treatment in secondary care level (i.e. foetal distress). Category 2 is for referrals during labour which require expedient diagnostics or treatment at the secondary care level, but not immediately (i.e. failure in progress during first stage of labour). 


\section{Differences in referrals in low-risk pregnancies}

\section{Data analysis}

Data were analysed on the basis of "intention-to-treat", i.c. on the intention to give birth either at home or in the hospital based home-like birth setting and therefore independent of the actual place of delivery. Referral indications during birth according to the different categories, interventions during birth (planned and unplanned caesarean section, vacuum extraction, forceps extraction, fundus expression and pain relief treatment) and neonatal outcomes (1 minute Apgar score, 5 minute Apgar score and umbilical artery $\mathrm{Ph}$ ) of planned home birth and planned home-like hospital birth were compared.

Statistical differences between study groups were assessed using $X^{2}$-test for categorical variables and the independent t-test for continuous variables. For the definition of (major) depression, a cut-off point of $>14$ on the Edinburgh Postnatal Depression Scale (EPDS) was used ${ }^{14}$. For the Cambridge Worry Scale (CWS), with responses expressed on a 6-point scale, mean scores were calculated ${ }^{15}$.

For dichotomous outcomes, the odds ratios (OR) and their $95 \%$ confidence intervals $(\mathrm{Cl})$ were calculated. Potential confounders, including age, body mass index, distance to the hospital, smoking, use of alcohol, way of getting pregnant, education level, Cambridge Worry Scale, Edinburgh Postnatal Depression Scale and first pregnancy were selected a priori. These potential confounders were jointly adjusted for in a logistic regression analysis.

When the fraction of missing values in the socio-demographic variables was 0.10 or higher, Missing Value Analysis (MVA) was used to impute the missing values. MVA was used for the following variables (fraction of missing values): smoking (0.54), use of alcohol (0.54), use of folic acid (0.54), way of getting pregnant (0.27), other diseases (0.29), Cambridge Worry Scale (0.23) and Edinburgh Postnatal Depression Scale (0.27),

All analyses were conducted with the statistical software package SPSS 15.0 (SPSS, Chicago, IL, USA).

\section{Results}

Of the 529 women who gave informed consent, 80 women were excluded because they failed to fill out the first questionnaire. As shown in figure 1, 449 women gave informed consent and completed the baseline questionnaire at 15 weeks pregnancy. Of all women, $31(7 \%)$ were lost to follow-up. Therefore, this study comprised 418 cases. Of these women, 241 women (58\%) preferred a home birth (home group) and 177 women (42\%) preferred a home-like hospital birth (home-like group). During pregnancy, $25.3 \%(n=61)$ of the home group and $31.6 \%(n=56)$ of the home-like group were referred to secondary care $(p=0.155)$. Thus, 301 women (72\%) started their delivery with their midwife. The percentage of referral during labour was $52.2 \%(n=94)$ in the home group and $66.1 \%(n=80)$ 


\section{Chapter 6}

in the home-like group ( $p=0.017$; see fig. 1). Finally, 127 women were not referred and gave birth under supervision of their midwife: $32.8 \%(n=79)$ of all women with the intention to give birth at home gave actually birth at home and $13.6 \%(n=24)$ of all women in the home-like group gave actually birth in a homelike hospital setting $(p=0.000)$.

No differences were observed between the two groups with respect to sociodemographic and psychological variables. Table 1 shows the characteristics of all women who started antenatal care in primary care $(n=418)$ and the characteristics of the study population starting labour in primary care $(n=301)$.

Urgent referral rate (category 1) was similar among the two groups (3.3\% vs. $3.3 \% \mathrm{p}>0.05$, OR $0.99,95 \% \mathrm{Cl} 0.27-3.59$ ). The main reason for an urgent referral was fetal distress. Women in the home-like group had a higher risk to be referred to secondary care without urgency (category 2) than women in the home group (62.8\% vs. $48.9 \%, p<0.05$, OR $1.77,95 \%$ Cl 1.10-2.83) (table 2 ).

Table 3 shows the results of the intervention rate for the total study population $(n=418)$. Women in the home-like group had an almost 2 times higher risk to give birth by an unplanned caesarean section than women in the home group $(p<0.05)$. Table 4 shows that there are no statistically significant differences in intervention rates for women in primary care at the start of their delivery between the home and the home-like group. With regard to neonatal outcomes (1 minute Apgar score, 5 minutes Apgar score and umbilical artery $\mathrm{pH}$ ), no statistically significant differences between the two groups were observed either. There were no differences between crude and adjusted ORs. 
Differences in referrals in low-risk pregnancies

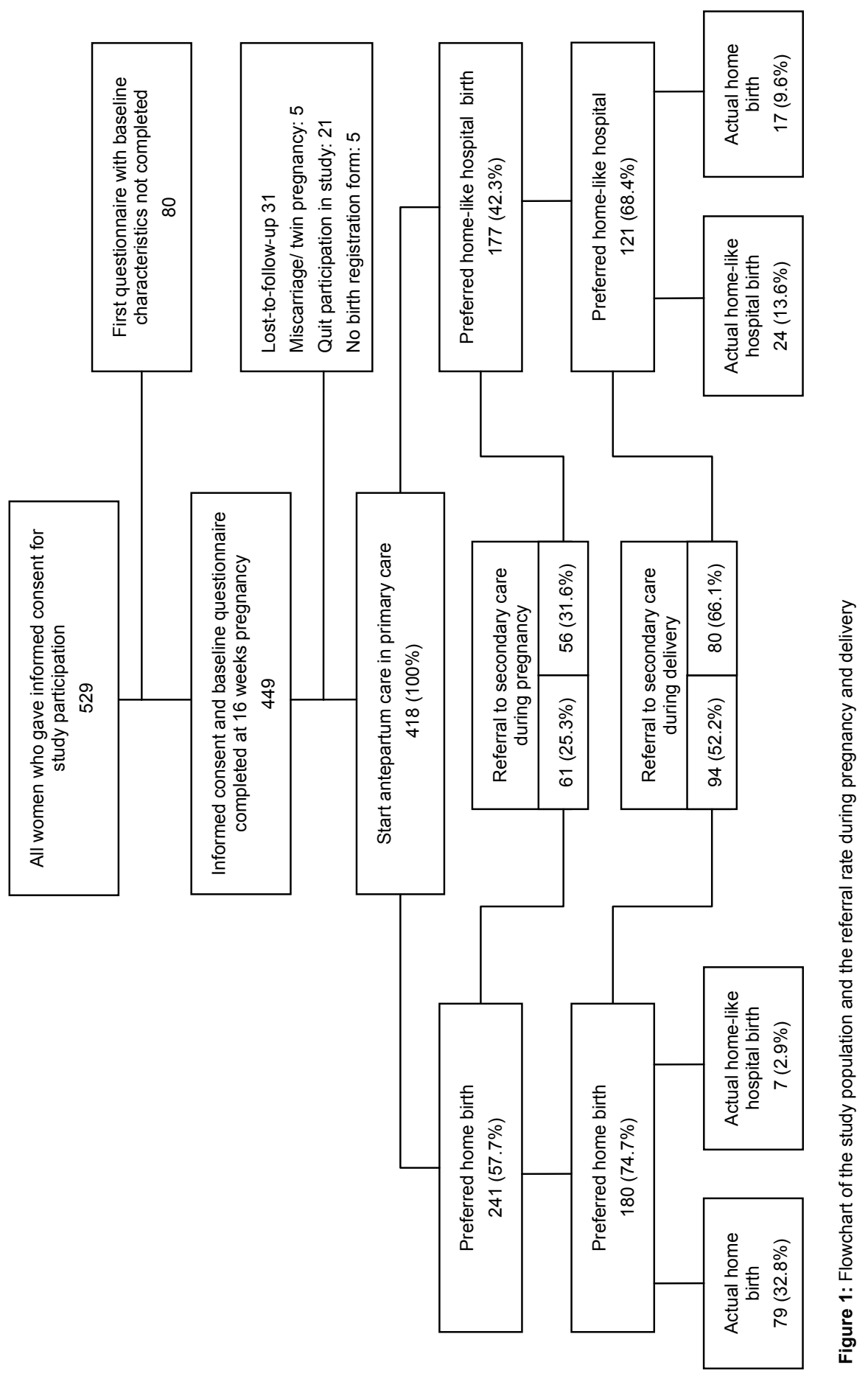




\section{Chapter 6}

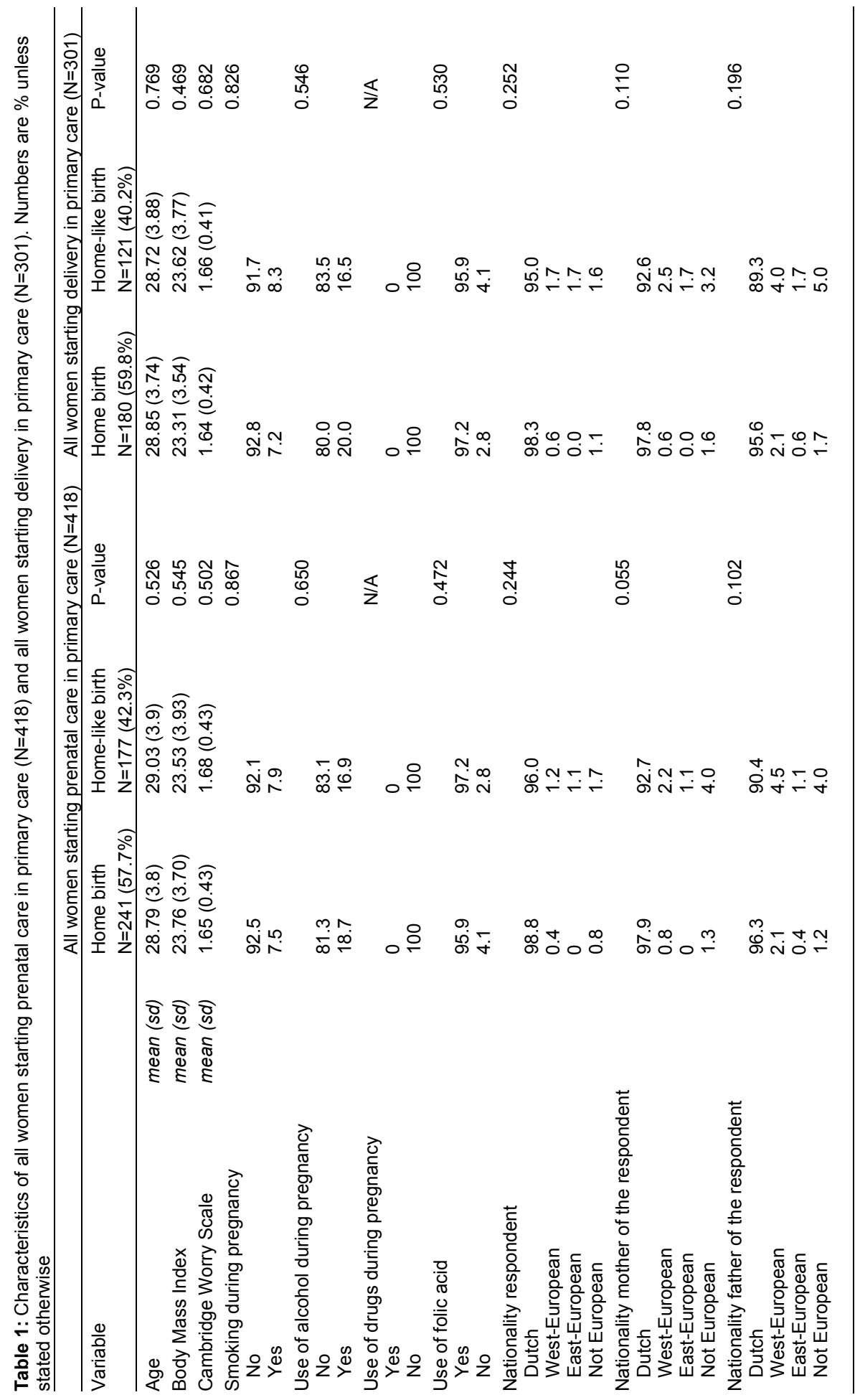


Differences in referrals in low-risk pregnancies

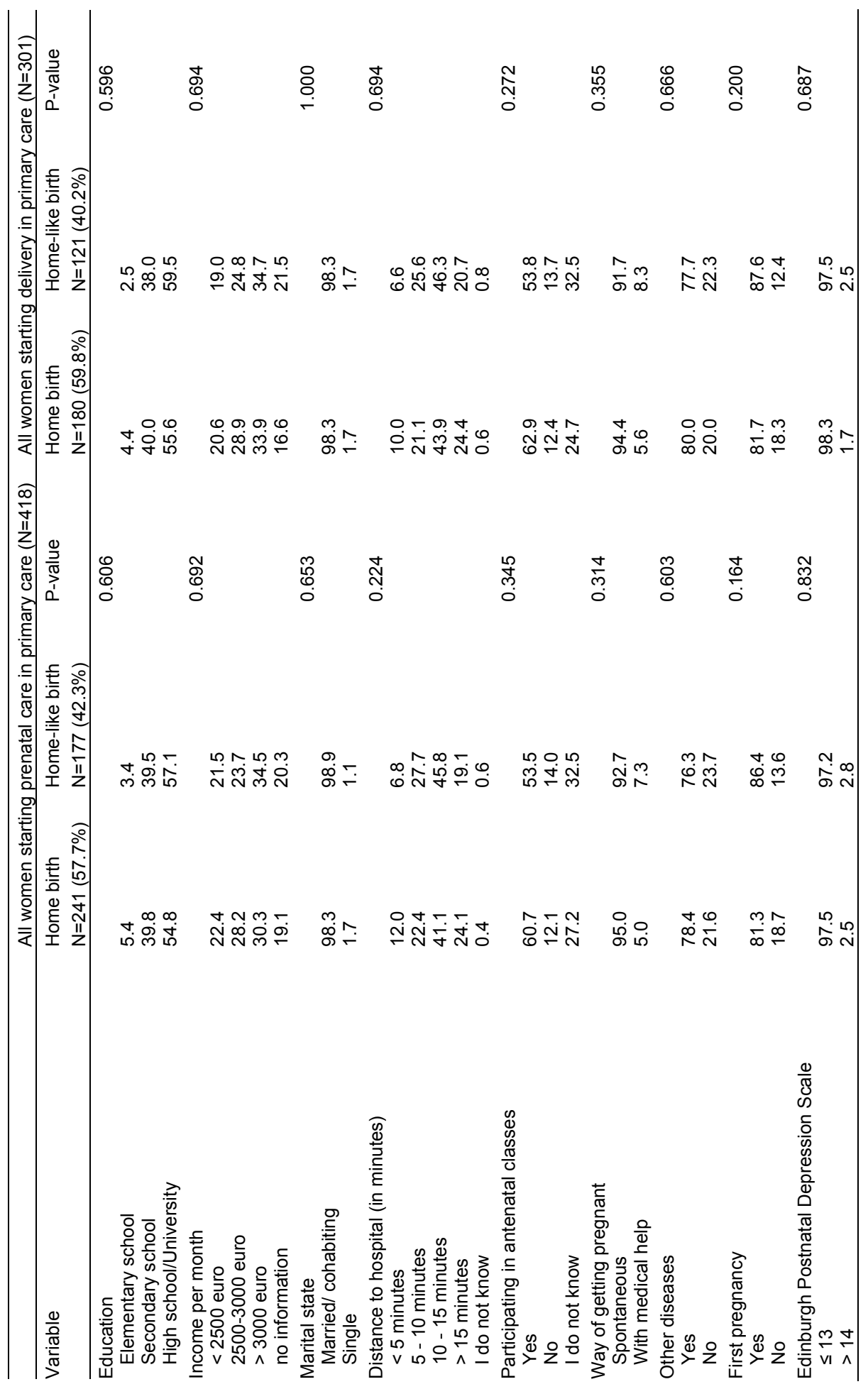




\section{Chapter 6}
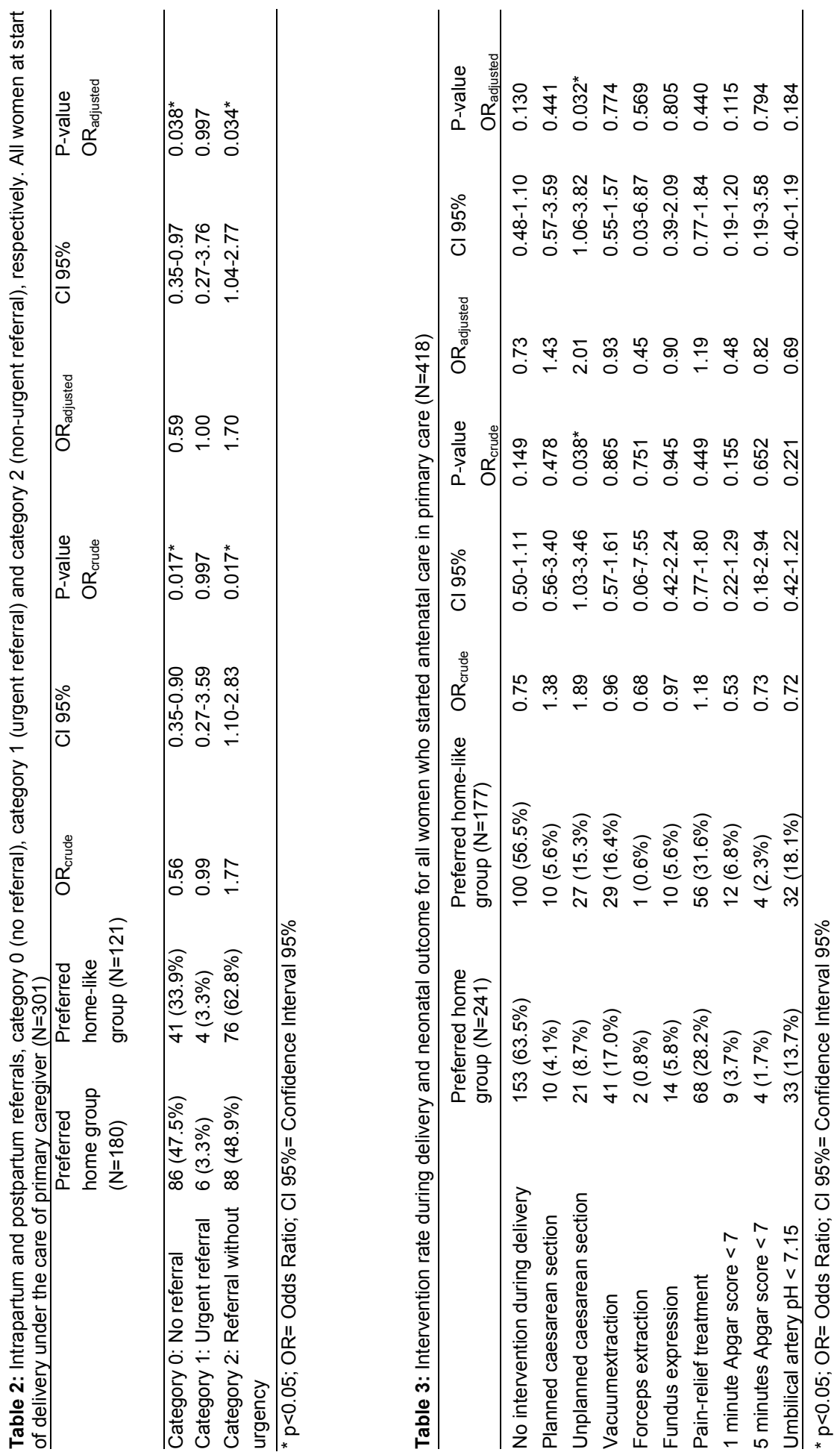


\section{Differences in referrals in low-risk pregnancies}

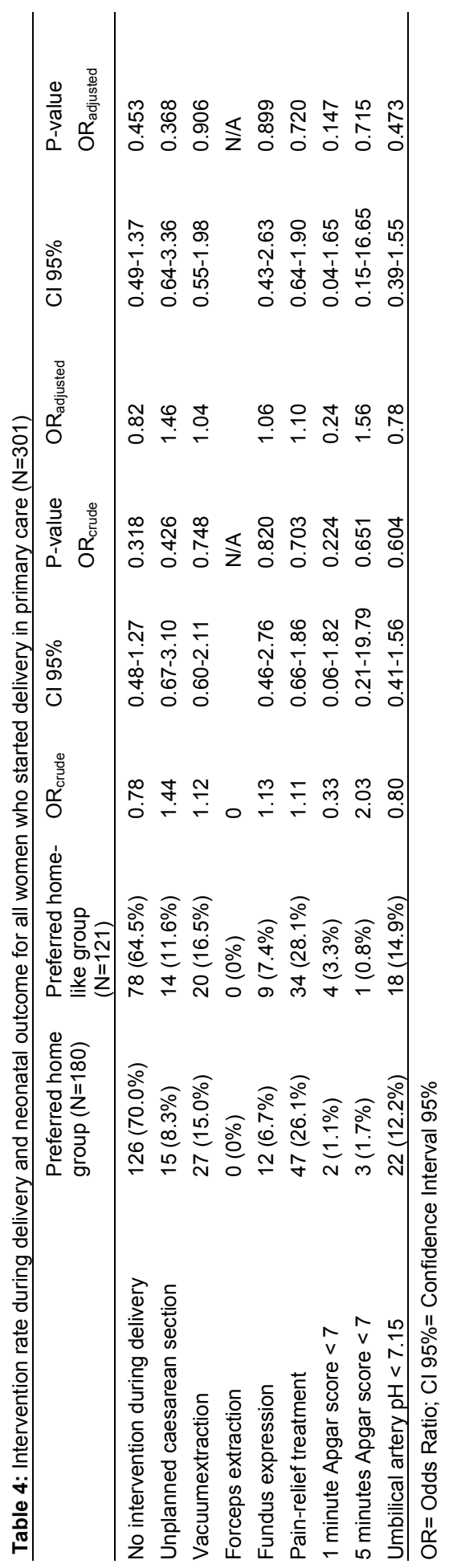




\section{Chapter 6}

\section{Discussion}

This study gives insight into differences in referral rates and intervention rates between women with the intention to give birth at home or in a home-like hospital birth setting in The Netherlands.

During pregnancy, women in the home group tended to have a lower chance of being referred to secondary care than women in the home like group. However, the difference was not statistically significant.

During labour, women in the home group had a considerably lower chance $(52.2 \%$ vs. $66.1 \%)$ to be referred to the obstetrician than women in the home-like group. This concerned referrals without urgency (category 2) only. The urgent referral rate was the same for both groups. On one hand, this can be explained by the treatment of the midwife. In case of a home-like hospital birth the woman is already in the hospital and the threshold to consult the obstetrician may be lower. On the other hand, these differences can be due to self-selection of the women. Women who prefer a home-like hospital birth know or feel that they have a higher risk of being referred to the obstetrician and choose for a home-like hospital birth. However, regarding the socio-demographic and psychological characteristics, there were no important differences between the groups, and also after controlling for these factors, results did not essentially change. Still, further research is needed to examine the differences between both groups regarding the decision-making process for the obstetric care. Aspects like self-esteem and sense of control of the pregnant woman, information and support of the partner, caregivers and family might influence this decision-making process.

Recently, Rijnders et al ${ }^{11}$ showed that a referral to secondary care is an important risk factor for a negative recall of the birth experience. It is unclear whether midwives inform pregnant women about the high referral chance during labour and the consequences for medical interventions. Especially for nulliparas it seems to be important to provide adequate information about the place of birth and possible risks. In that case, low-risk pregnant women and their partners can make well- thought out decisions. Given the results in this study, starting the delivery at home should give less negative recalls of the birth experience. However, it would be interesting to investigate the birth experiences of low-risk nulliparae taking into account preferred and actual place of birth, referrals to the obstetrician and interventions.

The results with respect to referral to an obstetrician during labour corroborate those of previous research 7,9,16,17. Those studies also found a higher percentage of referrals among women opting for a home-like hospital birth. Amelink et al ${ }^{12}$, who used the same classification for the referrals during labour, also found that women who planned a home birth had a significantly lower risk of being referred to secondary care than women opting for a home-like hospital birth. Unlike our study, the percentage of urgent referrals was also larger in the intended home- 


\section{Differences in referrals in low-risk pregnancies}

like hospital group than in the intended home birth group. However, their study population consisted of both nulliparous en multiparous women ${ }^{12}$.

Despite the differences in referral rates during labour, there are no differences in intervention rates for women in primary care at the start of their delivery between the home and home-like group. This finding is in agreement with a recent Dutch study ${ }^{9}$. Other previous studies showed that women with a low-risk pregnancy who are under supervision of an obstetrician have a higher chance for medical interventions during delivery than women who are under supervision of a midwife ${ }^{10,18}$. These findings underline the advantages of the primary care in a selected population when 'normal birth' is concerned.

Of all women who started antenatal care in primary care and opted for a home birth had a significant lower chance to receive an unplanned caesarean section without any neonatal consequence. Looking at all women who started labour in primary care, there were no significant differences between both groups. This indicates that the Dutch system of risk selection by the midwives works well.

Because home-like hospital births are known with higher referral rates to the obstetrician during delivery, it can be expected that a home-like hospital birth is associated with higher societal costs. However, a recent study has shown that the costs of home births and home-like hospital births are the same ${ }^{19}$.

Some limitations in this study need to be considered. It is important to underline that the results described in this study are based on the Dutch obstetric system where home births are more common than in other high income countries. Referral rates may not be generalizable to these other countries.

An important limitation relates to the method of data collection. This study is a multicenter prospective observational study. The initial idea was to perform a randomised controlled trial, in which the place of birth was decided for the women by means of randomisation. However, this approach appeared not to be feasible, as Dutch pregnant women did not accept randomisation for the place of birth, as we have published elsewhere ${ }^{20}$. Therefore, possible residual confounding by indication cannot be completely excluded in our study and may have influenced the results. However, all women had the same possibilities to choose their place of birth which may have diminished the potential for confounding by indication. We also adjusted in the analysis for confounding factors.

The percentage women with another origin than the Dutch origin is very small in our study population (1.2\% in the home group and $4.0 \%$ in the home-like group). In $2007,17.2 \%$ of all nulliparae had a non-Dutch origin ${ }^{21}$. This can be due to the chosen inclusion criterion that eligible women had to understand the Dutch language. To avoid selection bias, it is important to improve migrant participation in health care studies.

Perinatal mortality is an important outcome for the quality of care, and the Netherlands are known as a country with one of the highest perinatal mortality rates in Europe ${ }^{22,23}$. In our study, the study population was too small to take the perinatal 


\section{Chapter 6}

mortality rate as an outcome between planned home births and planned homelike births. Our neonatal outcomes gave no indication in that direction. A recent large Dutch study showed that planning a home birth does not increase the risk of perinatal mortality ${ }^{24}$.

Finally, some data in the socio-demographic and psychological characteristics were missing. Because this study concerned a non-randomised study, it was very important to analyse the differences in socio-demographic variables between both groups. Leaving out important risk factors could lack face validity and may lead to poor estimates. The standard approach - complete case analysis - is to exclude patients with missing data. This analysis can lead to selection bias if the profile of the excluded patients is different from the included patients ${ }^{25}$. Multiple imputation has become a widely accepted methodology for dealing with missing data ${ }^{26-28}$. Previous studies have shown that models developed using data sets in which missing data have been imputed perform more favourably than models developed using only patient records with complete data ${ }^{29,30}$. Multiple imputation has also been shown to produce less biased frequency distribution for risk factors with missing data compared with distributions based solely on complete data ${ }^{31}$.

\section{Conclusion}

The results of this study indicate that a planned home birth is associated with less referrals to the obstetrician and less unplanned caesarean sections while the neonatal outcome is equal in comparison to a planned home-like hospital birth. Women who actually start their delivery at home have a lower chance to be referred to the obstetrician than women who start their delivery in a home-like hospital setting. In these groups we found no clear differences between the intervention rates during delivery and neonatal outcome. 


\section{Differences in referrals in low-risk pregnancies}

\section{References}

1 Stichting Perinatale Registratie Nederland. Perinatale Zorg in Nederland 2006. Utrecht: Stichting Perinatale Registratie Nederland, 2008.

2 Stichting Perinatale Registratie Nederland. Bilthoven: Zuidam Uithof Drukkerijen, 2003.

3 Commissie Verloskunde van het CVZ. Verloskundig Vademecum 2003. Diemen: College voor Zorgverzekeringen, 2003.

4 Anthony S, Amelink-Verburg MP, Jacobusse GW, Pal van der-Bruin de KM. De thuisbevalling in Nederland 1995-2002, rapportage over de jaren 2001-2002. Bilthoven, Leiden: SPRN/TNO, 2005.

5 Amelink-Verburg MP, Rijnders MB, Buitendijk SE. A trend analysis in referrals during pregnancy and labour in Dutch midwifery care 1988-2004. BJOG 2009; 116: 923-32.

6 Berghs G, Spanjaards E, Driessen L, Doesburg W, Eskes T. Neonatal neurological outcome after low-risk pregnancies. Eur J Obstet Gynecol 1995; 62:167-71.

7 Wiegers TA, Keirse MJ, Zee van der J, Berghs GA. Outcome of planned home and planned hospital births in low risk pregnancies: Prospective study in midwifery practices in the Netherlands. BMJ 1996; 313: 1309-13.

8 Janssen PA, Lee SK, Ryan E, Etches DJ, Farquharson DF, Peacock D, et al. Outcomes of planned home births versus planned hospital births after regulation of midwifery in British Columbia. Can Med Assoc J 2002; 166: 315-23.

9 Van der Hulst LAM, van Teijlingen ER, Bonsel GJ, Eskes M, Bleker OP. Does a pregnant's woman intended place of birth influence her attitudes toward and occurrence of obstetric interventions? Birth 2004; 31: 28-33.

10 Johnson KC, Daviss BA. Outcomes of planned home births with certified professional midwives: Large prospective study in North America. BMJ 2005; 330: 1416.

11 Rijnders M, Baston H, Schonbeck Y, van der Pal K, Prins, M, Green J, et al. Perinatal factors related to positive or negative recall of birth experience in women 3 years post partum in The Netherlands. Birth 2008; 35: 107- 16.

12 Hendrix M, Van Horck M, Moreta D, Nieman F, Nieuwenhuijze M, Severens J, et al. Why women do not accept randomisation for place of birth: feasibility of a RCT in the Netherlands. BJOG 2009; 116: $537-44$.

13 Amelink-Verburg MP, Verloove-Vanhorick SP, Hakkenberg RMA, Veldhuijzen IME, Bennebroek Gravenhorst J, Buitendijk SE. Evaluation of 280000 cases in Dutch midwifery practices: a descriptive study. BJOG 2008; 115: 570-8.

14 Stichting Perinatale Registratie Nederland. Perinatale Zorg in Nederland 2001. Utrecht: Stichting Perinatale Registratie Nederland, 2005.

15 Murray D, Cox J. Screening for depression during pregnancy with the Edinburgh Depression Scale (EPDS). J Reprod Infant Psychol 1990; 8: 99-107.

16 Green J, Kafetsios K, Statham H, Snowdon C. Factor structure, validity and reliability of the Cambridge Worry Scale in pregnant population. J Health Psychol 2003; 8: 753-64.

17 Damstra-Wijmenga S. Veilig bevallen. Een vergelijkende studie tussen de thuisbevalling en de klinische bevalling. Groningen: Universiteit van Groningen, 1982.

18 Kleiverda G, Steen A, Andersen I, Treffers P, Everaerd W. Place of delivery in The Netherlands: actual location of confinement. Eur J Obstet Gynecol Reprod Biol 1991; 39: 139-46.

19 Maassen M, Hendrix M, Van Vugt H, Veersema S, Smits F, Nijhuis J. Operative deliveries in lowrisk pregnancies in The Netherlands: primary versus secondary care. Birth 2008; 35: 277-82.

20 Hendrix M, Evers S, Basten M, Nijhuis J, Severens J. Cost analysis of the Dutch Obstetric system: low-risk nulliparous women preferring home or short-stay hospital birth - a prospective nonrandomised controlled study. BMC Health Services Research 2009; 9: 211.

21 Stichting Perinatale Registratie Nederland. Perinatale Zorg in Nederland 2007. Utrecht: Stichting Perinatale Registratie Nederland, 2009.

22 Buitendijk SE, Nijhuis JG. Hoge perinatale sterfte in Nederland in vergelijking tot de rest van Europa. Ned. Tijdschr. Geneeskd 2004; 148: 1855-60. 


\section{Chapter 6}

23 Mohangoo AD, Nijhuis JG, Buitendijk SE, Ravelli ACJ, Hukkelhoven CWPM, Rijninks-van Driel GC, et al. Hoge perinatale sterfte in Nederland vergeleken met andere Europese landen. Ned Tijdschr Geneeskd 2008; 152: 2718-27.

24 de Jonge A, van der Goes BY, Ravelli ACJ, Amelink-Verburg MP, Mol BW, Nijhuis JG, et al. Perinatal mortality and morbidity in a nationwide cohort of 529688 low-risk planned home and hospital births. BJOG 2009; DOI:10.1111/j.1471-0528.2009.02175.x.

25 Glance LG, Osler TM, Mukabel DB, Meredith W, Dick AW. Impact of statistical approaches for handling missing data on trauma center quality. Annals of surgery 2009; 249: 143-8.

26 Grobbee DE, Hoes AW. Clinical Epidemiology: Principles, Medhods, and Applications for Clinical Research. Sudbury: Jones and Bartlett Publishers, 2009.

27 Harel O, Zhou XH. Multiple imputation: review of theory, implementation and software. Stat Med 2007; 26: 3057-77.

28 Ambler G, Omar RZ, Royston P. A comparison of imputation techniques for handling missing predictor values in a risk model with a binary outcome. Stat Methods Med Res 2007; 16: 277-98.

29 Burd RS, Jang TS, Nair SS. Predicting hospital mortality among injured children using a national trauma database. J Trauma 2006; 60: 792-801.

30 Clark TG, Altman DG. Developing a prognostic model in the presence of missing data: an ovarian cancer case study. J Clin Epidemiol 2003; 56: 28-37.

31 Moore L, Lavoie A, LeSage N. Multiple imputation of the Glasgow coma score. J Trauma 2005; 59: $698-704$. 


\section{Chapter 7 \\ Cost analysis of the Dutch obstetric system: home birth compared to short-stay hospital birth - a prospective non- randomised controlled study}

M.J.C. Hendrix, S.M.A.A. Evers, M.C.M. Basten, M.J. Nieuwenhuijze, J.G. Nijhuis and J.L. Severens

BMC Health Services Research 2009; 9: 211 


\section{Chapter 7}

\section{Abstract}

Background In the Netherlands, pregnant women without medical complications can decide where they want to give birth, at home or in a short-stay hospital setting with a midwife. However, a decrease in the home birth rate during the last decennium may have raised the societal costs of giving birth. The objective of this study is to compare the societal costs of home births with those of births in a short-stay hospital setting.

Methods This study is a cost analysis based on the findings of a multicenter prospective non-randomised study comparing two groups of nulliparous women with different preferences for where to give birth, at home or in a short-stay hospital setting. Data were collected using cost diaries, questionnaires and birth registration forms. Analysis of the data is divided into a base case analysis and a sensitivity analysis.

Results In the group of home births, the total societal costs associated with giving birth at home were $€ 3,695$ (per birth), compared with $€ 3,950$ per birth in the group for short-stay hospital births. Statistically significant differences between both groups were found regarding the following cost categories 'Cost of contacts with health care professionals during delivery' (€138.38 vs. €87.94, -50 (2.5-97.5 percentile range $(P R)-76 ;-25), p<0.05)$, 'cost of maternity care at home' $(€ 1,551.69$ vs. $€ 1,240.69,-311$ (PR $-485 ;-150), p<0.05)$ and 'cost of hospitalisation mother' ( $€ 707.77$ vs. $€ 959.06,251$ (PR 69;433), $p<0.05$ ). The highest costs are for hospitalisation ( $41 \%$ of all costs). Because there is a relatively high amount of (partly) missing data, a sensitivity analysis was performed, in which all missing data were included in the analysis by means of general mean substitution. In the sensitivity analysis, the total costs associated with home birth are $€ 4,364$ per birth, and $€ 4,541$ per birth for short-stay hospital births.

Conclusion The total costs associated with pregnancy, delivery, and postpartum care are comparable for home birth and short-stay hospital birth. The most important differences in costs between the home birth group and the short-stay hospital birth group are associated with maternity care assistance, hospitalisation, and travelling costs. 


\section{Cost analysis}

\section{Introduction}

In comparison with other European countries, the organisation of the Dutch obstetric system is unique, with a high percentage of home births (about $29 \%$ of all pregnant women) and a low rate of medical interventions (the rate of Caesarean sections is about $15 \%)^{1-3}$. Traditionally, the Dutch system is characterised by extensive primary healthcare services, supported by secondary, more specialized care ${ }^{4}$. Overall, the home birth rate has decreased during the last ten years (from $35 \%$ of all births in $1997-2000$ to $29 \%$ in $2005-2008)^{2}$. For nulliparae, the home birth rate is much lower, namely $18 \%$ in $2006{ }^{5}$. There is a high referral rate during pregnancy $(45 \%$ of all nulliparae in primary care) and delivery ( $43 \%$ of all nulliparae who started delivery in primary care) ${ }^{6}$. Pregnant women without medical complications have the possibility to choose where to give birth - at home or in a short-stay hospital setting, supervised in either setting by a registered midwife or GP (primary care) ${ }^{1}$. When there are medical complications, the attending professional (the midwife or the GP) refers the pregnant woman to an obstetrician in the hospital (secondary care). In short-stay hospital settings, the women and their babies are generally discharged within a few hours after birth for postpartum home care. However, due to the limited ability of GPs to be available all the time, in comparison with midwives (because GPs have a broader work perspective), the percentage of Dutch GPs supervising births has decreased over the last years (from $11 \%$ in 2000 to $6 \%$ in 2002). This trend is ongoing, and further limits the possibility of GPs to obtain experience in maternity care ${ }^{7}$. In the Netherlands, maternity care is financed by health insurers. Women who give birth in a shortstay hospital setting pay an extra out-of-pocket charge for the rent of the maternity room in the hospital. When a woman has a medical indication to give birth in the hospital under supervision of the obstetrician, the out-of-pocket charge expires.

The Dutch obstetric system has received a great deal of attention in the literature ${ }^{8}$. However, the system has increasingly come under pressure since the national perinatal mortality rate (between 22 weeks of pregnancy and 7 days postpartum) was shown to be one of the highest in Europe (10\% in 2004) ${ }^{9-11}$. Furthermore, a continuing increase in the referral rate to secondary care, especially for nulliparae, might raise the societal costs of giving birth. Because short-stay hospital births are known with higher referral rates to the obstetrician during delivery ${ }^{12-15}$, it can be expected that this is associated with higher societal costs. However, this information is still lacking and it becomes interesting to gain insight into the economic aspects of the different birth settings of the Dutch obstetric system.

Several studies have examined the economic implications of home births or short-stay hospital births in comparison with a hospital birth ${ }^{16-24}$. However, these studies were performed outside the Netherlands. Because of differences in relative and absolute price levels among jurisdictions, the unit cost prices are jurisdic- 


\section{Chapter 7}

tion specific and the results cannot be transferred to the typical Dutch system ${ }^{25}$. Furthermore, some of these studies had a very limited time frame, not looking at the costs from an early stage of pregnancy until a fixed period after delivery. These studies also did not calculate the societal costs of giving birth, meaning that all costs were taken into account disregarding who bears them, with a primary focus on health care costs. A cost analysis from a societal perspective gives insight in the costs of a treatment for the society. This means that not only the health care costs (i.e. costs of care givers, medication and hospitalisation) are included, but also the costs of patients (i.e. out-of-pocket costs, travel expenses), their family (i.e. informal care) and other non health care costs (i.e. productivity losses) ${ }^{26}$.

This study sets out to investigate the differences in costs from a societal perspective between low-risk nulliparae preferring to give birth at home and low-risk nulliparae preferring to give birth in a short-stay hospital setting.

\section{Methods}

Cost calculations were performed according to the Dutch manual for costing in health care, a methodological reference for performing costing studies in the Netherlands ${ }^{26,27}$. This manual introduces a six-step procedure for costing ${ }^{26,27}$. The first step involves determining the scope of the research, taking the perspective and the time horizon into account. The costing in this study was performed from a societal perspective, implying that all costs for society, including health care costs, patient and family costs are taken into account ${ }^{26}$. The time horizon for measuring costs related to pregnancy, birth, and postpartum care was set at 16 weeks of pregnancy until six weeks after delivery. This period was divided into the following four measurement periods: week $16^{+0}$ until $28^{+6}$ of pregnancy, week $29^{+0}$ until the end of pregnancy, delivery, and the first six weeks of the postnatal period.

The second step concerns the choice of the cost categories that are measured ${ }^{26,27}$. In this study we measured the health care sector costs and the non health care costs.

The third step of costing is to determine the resources that are used that lead to costs. Contacts with health care professionals, medication, maternity care assistance, medical interventions during delivery, pain control, and hospitalisation were identified as health care costs. Patient and family costs (i.e. informal care during pregnancy and postpartum period), transportation costs, and extra costs made by responders (i.e. costs for antenatal classes) were identified as non health care costs. In the fourth stage, the volumes of resources used are measured ${ }^{26-28}$. Volumes were determined using three sources: cost diaries, three questionnaires, the birth registration forms of midwife-assisted births (National Perina- 


\section{Cost analysis}

tal Database for Primary Care, LVR-1), and obstetrician-assisted births (National Perinatal Database for Secondary Care, LVR-2). Cost diaries completed by the respondents were used to determine the volumes of contacts with health care providers (e.g. midwife, GP, obstetrician) and the use of medication. The women were asked to fill in these diaries weekly. The first questionnaire was sent to each woman immediately after informed consent was given (gestational age 16 weeks). This questionnaire was used to collect the baseline information with regard to preferences for place of birth and demographic aspects. The second questionnaire, which was sent to each woman at the gestation stage of 32 weeks, was used to determine the extra costs incurred by the participants concerning their pregnancy (costs for materials and antenatal classes). The third questionnaire was sent to the participants six weeks after giving birth, and was used to collect data concerning the type of perinatal transportation and the time needed for transportation. The birth registration forms provided information with regard to the number of days of hospitalisation, pain medication during delivery, and the volume and type of diagnostic and therapeutic interventions. Although information regarding hospital admissions and the use of interventions was also obtained from the cost diaries, for this study data from the birth registration forms were used in order to strengthen the validity of the research, since it was expected that the data registered in these forms is more reliable. The fifth step is the valuation of the resources used ${ }^{26-28}$. The unit prices of the resources used were obtained from the standard costs given in the Dutch manual for costing, where available ${ }^{26}$. These standard costs are average unit costs of standard resource items ${ }^{27}$. Other unit prices (i.e. the unit prices of midwives) were obtained from expert (financial) resources, such as the Dutch Health Authority (NZA) and the Royal Dutch Organization of Midwives (KNOV). The medications used by the participants were grouped and unit prices were obtained from the Dutch pharmacotherapeutic compass ${ }^{29}$. Unit prices are presented in Euros for the year 2008. Whenever necessary, unit prices were converted to this reference year (2008) by means of price index numbers for June $2008{ }^{30}$. Table 1 gives an overview of the unit prices used in this cost analysis.

The final stage of the cost analysis is calculating the unit costs for each respondent by multiplying the volumes by the unit prices of the resources used ${ }^{26-28}$. The data on the total costs were analyzed by using the statistical package SPSS 12.0 (SPSS, Chicago, IL, USA) and MS-Excel.

\section{Sample}

This cost analysis concerns a multi-centered prospective non-randomised controlled study. The individuals participating in the research are grouped according to their preferred place of delivery at home or in a short-stay hospital setting. 


\section{Chapter 7}

In the study the following inclusion criteria were applied: the woman is giving birth for the first time (nulliparae), there are no medical indications for secondary care, the woman has the possibility to choose the place of birth (social circumstances), and the woman is fluent in the Dutch language. Recruitment for the study took place on a national level; 100 practices with independent midwives from across the Netherlands were selected at random and participated in recruiting the respondents. The women were informed about the study during their first visit to the midwife (8-10 weeks of pregnancy), and were included in the study if they met the criteria and gave informed consent. Recruitment was carried out from March 2007 to August 2007. Ethical approval was obtained from the Medical Ethical Committee Maastricht (MEC 04-234).

\section{Statistical analysis}

The statistical analysis involves analysis of the data collected in the cost analysis. The database was first checked for any erroneous data, by determining the minimum and maximum of the data. The minimum was expected to be zero, which indicated that no contact took place, no medications were used, or no hospital admission was necessary. If the maximum showed extremely high amounts, the database was checked to find out the reason for these outliers. No cases were excluded because of outlying values.

\section{Base case analysis and sensitivity analysis}

The statistical analysis of the collected data is divided into two separate data analyses: a base case analysis and a sensitivity analysis. The data sources collected from the participants showed that not all respondents were complete in registering their data. The reason for performing these two types of analyses was to compare the data as it was received from the participants with the scenario that all participants filled in all sources completely. It is unclear whether women, who did not fully or partially complete the data sources, have more health care consumption.

The participants who fully or partly completed the cost diaries and questionnaires were included in the base case analysis. In this analysis some respondents did not complete all items (see table 2). 


\section{Cost analysis}

Table 1: Unit prices used in the cost analysis

\begin{tabular}{|c|c|c|c|}
\hline Component & Unit & Price $(€)^{*}$ & Data Sources \\
\hline Midwife & per hour & 35.11 & KNOV / TNO ${ }^{1}$ \\
\hline Midwife assistant & per hour & 31.60 & KNOV / TNO ${ }^{1}$ \\
\hline \multirow[t]{2}{*}{ GP } & per visit & 21,95 & Oostenbrink et al. (2004) ${ }^{2}$ \\
\hline & per telephone consultation & 10,97 & Oostenbrink et al. $(2004)^{2}$ \\
\hline GP assistant & per hour & 11.70 & $\begin{array}{l}\text { Collective labour agreement (GP } \\
\text { care) }\end{array}$ \\
\hline \multirow[t]{2}{*}{$\begin{array}{l}\text { Out-patient clinic obstetrics/ } \\
\text { obstetrician / paediatrician/ } \\
\text { assistant physician }\end{array}$} & per visit & 68.50 & Oostenbrink et al. $(2004)^{2}$ \\
\hline & per telephone consultation & 34.25 & Oostenbrink et al. $(2004)^{2}$ \\
\hline Nurse in hospital & per hour & 10.36 & Oostenbrink et al. $(2004)^{2}$ \\
\hline \multirow[t]{3}{*}{$\begin{array}{l}\text { Maternity care assistance at } \\
\text { home }\end{array}$} & per intake & 54.80 & $\mathrm{Nza}^{3}$ \\
\hline & per telephone contact & 18.30 & $\mathrm{Nza}^{3}$ \\
\hline & per hour & 39.40 & $\mathrm{Nza}^{3}$ \\
\hline \multirow[t]{2}{*}{ Ultrasound } & per visit & 34.38 & CTG codes $(\mathrm{CVZ})^{4}$ \\
\hline & per hour (telephone) & 10.36 & CTG codes $(\mathrm{CVZ})^{4}$ \\
\hline Physiotherapist & per visit & 24.72 & Oostenbrink et al. $(2004)^{2}$ \\
\hline \multirow[t]{2}{*}{ Alternative treatment } & per visit & 46.67 & Websites alternative healers \\
\hline & per telephone consultation & 15.00 & Websites alternative healers \\
\hline \multirow[t]{2}{*}{ Medical specialist } & per visit & 68.50 & Oostenbrink et al. $(2004)^{2}$ \\
\hline & per telephone consultation & 34.25 & Oostenbrink et al. $(2004)^{2}$ \\
\hline \multirow[t]{2}{*}{ Lactation aid } & per visit & 64.00 & $\mathrm{NVL}^{5}$ \\
\hline & per telephone consultation & 10.00 & $\mathrm{NVL}^{5}$ \\
\hline Dietician & per 15 minutes & 14.20 & $\mathrm{Nza}^{3}$ \\
\hline Physician child health centre & per hour & 29.34 & $\begin{array}{l}\text { Collective labour agreement (home } \\
\text { care) }\end{array}$ \\
\hline Nurse child health centre & per hour & 23.84 & $\begin{array}{l}\text { Collective labour agreement (home } \\
\text { care) }\end{array}$ \\
\hline Help from family and friends & per hour & 9.02 & Oostenbrink et al. $(2004)^{2}$ \\
\hline Vacuum extraction & per subject & 431.22 & CTG codes $(\mathrm{CVZ})^{4}$ \\
\hline Caesarean section (planned) & per subject & 634.47 & CTG codes $(\mathrm{CVZ})^{4}$ \\
\hline Caesarean section (unplanned) & per subject & 586.03 & CTG codes (CVZ) ${ }^{4}$ \\
\hline Fundus expression & per subject & 431.22 & CTG codes $(\mathrm{CVZ})^{4}$ \\
\hline Forceps & per subject & 431.22 & CTG codes $(\mathrm{CVZ})^{4}$ \\
\hline Episiotomy & per subject & 361.79 & CTG codes (CVZ) ${ }^{4}$ \\
\hline Rupture (suture) & per subject & 361,79 & CTG codes $(\mathrm{CVZ})^{4}$ \\
\hline Hospital day (mother and child) & per day & 390.33 & Oostenbrink et al. (2004) ${ }^{2}$ \\
\hline
\end{tabular}

${ }^{1}$ KNOV: Koninklijke Nederlandse Organisatie van Verloskundigen (Royal Dutch Organization of Midwives); ${ }^{2}$ Oostenbrink et al. (2004) [18]. Dutch Manual for Costing: Methods and Standard Costs for Economic Evaluations in Health Care; ${ }^{3}$ Nza: Nederlandse Zorgautoriteit (Dutch Healthcare Authority); ${ }^{4}$ CTG: College Tarieven Gezondheidszorg (National Health Tariffs Authority); ${ }^{5}$ NVL: Nederlandse Vereniging van Lactatiekundigen (Dutch Organization of Lactation professionals); * All prices are converted to reference year 2008 by means of price index numbers of June 2008 


\section{Chapter 7}

Table 2: Response rates of data sources

\begin{tabular}{lll}
\hline Data source & $\begin{array}{l}\text { Response rate } \\
(\mathrm{n}=449)\end{array}$ & $\begin{array}{l}\text { Number of items imputed in } \\
\text { base case analysis (\%) }\end{array}$ \\
\hline Cost diary week 16 - 28 & $361(80.4 \%)$ & $68(0.0004)$ \\
Cost diary week 29 - 42 & $325(72.4 \%)$ & $49(0.0003)$ \\
Cost diary delivery & $307(68.4 \%)$ & $31(0.002)$ \\
Cost diary week 1 - 6 after delivery & $309(68.8 \%)$ & $192(0.001)$ \\
Questionnaire 2 & $344(76.6 \%)$ & $0(0)$ \\
Questionnaire 3 & $319(71.0 \%)$ & $0(0)$ \\
Birth registration forms & $418(93.1 \%)$ & $0(0)$ \\
Overall response rate complete cases & $253(56.3 \%)$ & \\
\hline
\end{tabular}

The missing items were imputed using general mean substitution, in which the mean of the whole group of responders was taken as a value for the missing data. Besides these missing items within cost diaries and questionnaires, there were also some missing cases, like participants who did not respond at all to a particular part of the data sources; consequently these data were completely missing. In the sensitivity analysis, the data of these missing reports were imputed using general mean substitution, and included in the analysis, to examine the impact of the uncertainty of these missing data on costs resulting from the base case cost analysis. The missing data of respondents were imputed only when a participant had completed the first questionnaire. Women with a missing baseline measurement were excluded.

\section{Bootstrap resample method}

The base case and sensitivity analyses are performed according to the intentionto-treat principle (delivery at home or in a short-stay hospital setting), including data from all participants. To investigate whether the data are distributed normally, histograms were plotted in SPSS, with a normal distribution curve included. It was concluded that the data are not distributed normally, indicating that the data are skewed. Despite the usual skewness in the distribution of costs, arithmetic means are generally considered to be the most appropriate measures to describe cost data ${ }^{31,32}$. Therefore, arithmetic means will be presented. However, because the cost data are skewed, non-parametric bootstrapping will be used to test for statistical differences in costs between the group intending to give birth at home and the group intending to give birth in a short-stay hospital setting. Non-parametric bootstrapping is a method based on random sampling, with replacement based on the participants' individual data ${ }^{33}$. Estimates (such as mean, standard deviation and confidence interval) are extracted from a non-parametric data set (no underlying distribution is assumed in the data set), to provide an approximation of the accuracy of the statistical estimates ${ }^{34}$, in order to represent 


\section{Cost analysis}

the uncertainty in the costs and to test whether there are significant differences between the costs of both groups ${ }^{35}$. The non-parametric bootstrap resample method is applied with 1000 replications in this study. The bootstrap replications will be used to calculate $95 \%$ confidence intervals around the costs, based on the $2.5^{\text {th }}$ and $97.5^{\text {th }}$ percentiles.

In addition, the mean costs for the actual place of birth were calculated. This statistical analysis was based on three groups (home birth, short-stay hospital birth and hospital birth).

\section{Results}

\section{Participants}

Of the 529 women who gave informed consent to participate in the study, 80 women were excluded because they failed to fill in the first enquiry. Therefore, the study analysed 449 cases. Table 2 summarises the response rate of the different data sources. The response rates differ from $68.4 \%$ for the cost diaries to $93.1 \%$ for the birth registration forms. The overall response rate for the complete cases is $56.3 \%$; these are the women who returned all separate data sources. The response rates represent the women who filled in the cost diaries and questionnaire, either completely or partially. The birth registration forms were received from the midwives of the participating women.

Of all women, 31 women $(7 \%)$ quit participation during follow-up, see figure 1 . Of the 418 women from whom a birth registration form was received, $241(57.7 \%)$ intended to give birth at home and 177 (42.3\%) intended to give birth in a shortstay hospital setting. Of the intended home births $32.8 \%$ succeeded, $2.9 \%$ delivered in a short-stay hospital setting and $64.3 \%$ in the hospital. Of the women who intended to give birth in a short-stay hospital setting $13.6 \%$ succeeded, $9.6 \%$ delivered a child at home and $76.8 \%$ were referred for a hospital delivery under the supervision of an obstetrician. Table 3 shows the base-line characteristics of the socio-demographic factors, giving information with regard to nationality, family income and education. Clearly there are no significant differences between the two groups (Table 3). 


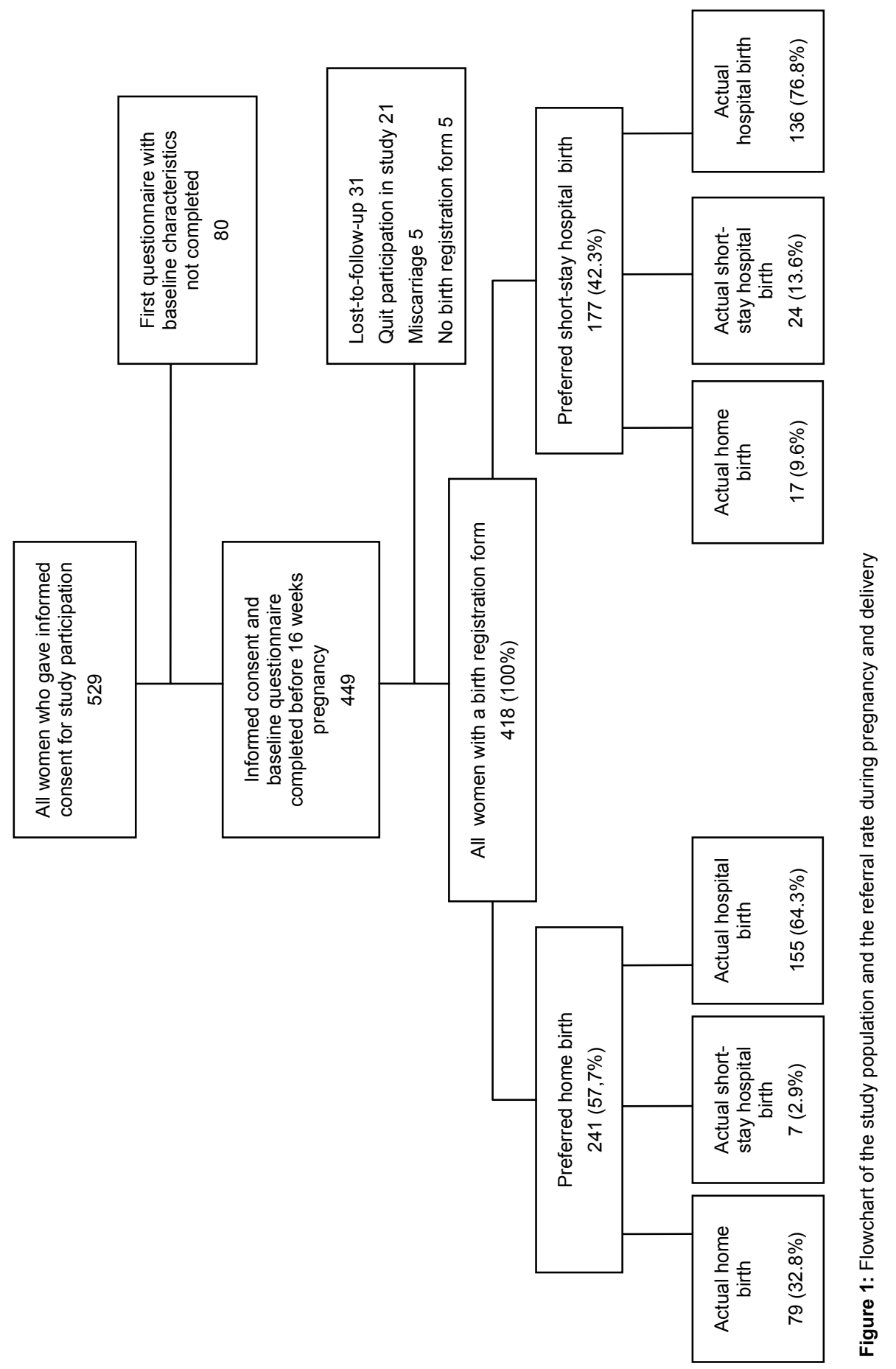


Table 3: Characteristics of all women questionnaire $1(n=449)$. Numbers are $\%$ unless stated otherwise

\begin{tabular}{|c|c|c|c|c|}
\hline Variable & & \multirow{2}{*}{$\begin{array}{l}\text { Home birth } \\
\mathrm{N}=255(56.8 \%)\end{array}$} & \multirow{2}{*}{$\begin{array}{l}\text { Short-stay } \\
\text { hospital birth } \\
\mathrm{N}=194(43.2 \%) \\
29.06(3.90)\end{array}$} & \multirow{2}{*}{$\begin{array}{l}\text { P-value* } \\
0.39\end{array}$} \\
\hline Age in years & Mean $(S D)$ & & & \\
\hline Body Mass Index & Mean $(S D)$ & $23.79(3.74)$ & $23.51(3.84)$ & 0.43 \\
\hline $\begin{array}{l}\text { Gestation age questionnaire } 1 \text { in } \\
\text { weeks }\end{array}$ & Mean $(S D)$ & $16.2(4.1)$ & $15.6(3.7)$ & 0.11 \\
\hline Cambridge Worry Scale** & Mean (SD) & $1.67(0.44)$ & $1.69(0.43)$ & 0.678 \\
\hline $\begin{array}{l}\text { Nationality respondent } \\
\text { Dutch } \\
\text { West-European } \\
\text { East-European } \\
\text { Not European }\end{array}$ & & $\begin{array}{l}98.4 \\
0.4 \\
0 \\
1.2\end{array}$ & $\begin{array}{l}96.0 \\
1.5 \\
1.0 \\
1.5\end{array}$ & 0.235 \\
\hline $\begin{array}{l}\text { Nationality mother of the respond } \\
\text { Dutch } \\
\text { West-European } \\
\text { East-European } \\
\text { Not European }\end{array}$ & & $\begin{array}{l}97.2 \\
1.2 \\
0 \\
1.6\end{array}$ & $\begin{array}{l}92.3 \\
2.6 \\
1.0 \\
4.1\end{array}$ & 0.057 \\
\hline $\begin{array}{l}\text { Nationality father of the responder } \\
\text { Dutch } \\
\text { West-European } \\
\text { East-European } \\
\text { Not European }\end{array}$ & & $\begin{array}{l}95.6 \\
2.0 \\
0.4 \\
2.0\end{array}$ & $\begin{array}{l}90.8 \\
4.1 \\
1.0 \\
4.1\end{array}$ & 0.230 \\
\hline $\begin{array}{l}\text { Education } \\
\text { Elementary school } \\
\text { Secondary school } \\
\text { High school/University }\end{array}$ & & $\begin{array}{l}5.9 \\
40.0 \\
54.1\end{array}$ & $\begin{array}{l}5.2 \\
38.7 \\
56.1\end{array}$ & 0.901 \\
\hline $\begin{array}{l}\text { Income per month } \\
<2500 \text { euro } \\
2500-3000 \text { euro } \\
>3000 \text { euro } \\
\text { no information }\end{array}$ & & $\begin{array}{l}24.0 \\
27.5 \\
29.8 \\
18.7\end{array}$ & $\begin{array}{l}21.7 \\
22.7 \\
34.5 \\
21.1\end{array}$ & 0.870 \\
\hline $\begin{array}{l}\text { Marital state } \\
\text { Married/ cohabiting } \\
\text { Single }\end{array}$ & & $\begin{array}{l}98.4 \\
1.6\end{array}$ & $\begin{array}{l}99.0 \\
1.0\end{array}$ & 0.703 \\
\hline $\begin{array}{l}\text { Distance to hospital } \\
<5 \text { minutes } \\
5-10 \text { minutes } \\
10-15 \text { minutes } \\
>15 \text { minutes } \\
\text { I do not know }\end{array}$ & & $\begin{array}{l}12.2 \\
23.1 \\
40.0 \\
24.3 \\
0.4\end{array}$ & $\begin{array}{l}6.7 \\
28.9 \\
44.8 \\
19.1 \\
0.5\end{array}$ & 0.136 \\
\hline $\begin{array}{l}\text { Participating in antenatal classes } \\
\text { Yes } \\
\text { No } \\
\text { I do not know }\end{array}$ & & $\begin{array}{l}60.9 \\
12.6 \\
26.5\end{array}$ & $\begin{array}{l}52.1 \\
14.4 \\
33.5\end{array}$ & 0.171 \\
\hline $\begin{array}{l}\text { First pregnancy } \\
\text { Yes } \\
\text { No }\end{array}$ & & $\begin{array}{l}81.6 \\
18.4\end{array}$ & $\begin{array}{l}85.1 \\
14.9\end{array}$ & 0.375 \\
\hline $\begin{array}{l}\text { Comorbidity } \\
\text { Yes } \\
\text { No }\end{array}$ & & $\begin{array}{l}15.8 \\
84.2 \\
\end{array}$ & $\begin{array}{l}22.2 \\
77.8\end{array}$ & 0.189 \\
\hline
\end{tabular}

* $p$-value $<0.05=$ significant 


\section{Chapter 7}

\section{Results of the cost analysis}

The number of volumes of resource use per period (week 16-28, week 29-42, delivery and post-partum period) are summarised in Table 4.

The costs associated with these volumes that resulted from the costs analysis in the base case analysis are summarised in Table 5 . Table 5 shows the differences between both groups, both for the bootstrapped mean costs and the mean costs. As can be seen in the table, the mean costs are comparable to the bootstrapped mean costs. The total bootstrapped mean costs over the whole period followed (from 16 weeks of pregnancy until six weeks after delivery) amounted to $€ 3,695$ for women who intended to give birth at home and $€ 3,950$ for women who intended to give birth in a short-stay hospital setting. When focusing on the costs of the different periods, there are no statistically significant differences between both groups. The costs of pregnancy and delivery are (slightly) higher in the home birth group, while the costs associated with postpartum period are higher in the short-stay hospital birth group.

When looking at the different cost categories, the costs for contacts with healthcare professionals are statistically significantly higher in the home birth group (€138.38 vs. €87.94, -50 (2.5-97.5 percentile range (PR) -76;-25), $p<0.05$ ). There are also statistically significant differences between both groups regarding 'costs of maternity care assistance at home' (€1,551.69 vs. €1,240.69, -311 (PR -485;$150), p<0.05)$ and 'costs of hospitalisation mother' ( $€ 707.77$ vs. $€ 959.06,251$ (PR $69 ; 433), p<0.05)$.

Furthermore, as is shown in Table 5 , the mean costs of hospitalisation in the base case analysis of the home birth group are higher in the period 'week 16-28' than in the short-stay hospital birth group, while in the short-stay hospital birth group these costs are statistically significantly higher in the post-partum period than in the home birth group.

The expenses incurred for transportation to the hospital when the delivery started are higher for the women who intended to give birth at home $(55 \%$ higher than the costs made by women who intended to give birth in a short-stay hospital setting). 
Cost analysis

Table 4: Quantities of resource use per period

\begin{tabular}{|c|c|c|c|c|c|c|c|c|c|}
\hline \multirow[t]{3}{*}{ Component } & \multirow[t]{3}{*}{ Unit } & \multicolumn{2}{|c|}{ Week 16-28 } & \multicolumn{2}{|c|}{ Week 29-42 } & \multicolumn{2}{|c|}{ Delivery } & \multicolumn{2}{|c|}{ Post-partum } \\
\hline & & & SSHB & & SSHB & & SSHB & & SSHB \\
\hline & & $\mathrm{N}=204$ & $\mathrm{~N}=157$ & $\mathrm{~N}=189$ & $\mathrm{~N}=142$ & $\mathrm{~N}=246$ & $\mathrm{~N}=180$ & $\mathrm{~N}=246$ & $\mathrm{~N}=179$ \\
\hline Midwife & $\begin{array}{l}\text { visit/ } \\
\text { telephone }\end{array}$ & 832 & 606 & 1281 & 919 & 382 & 251 & 629 & 382 \\
\hline Midwife assistant & $\begin{array}{l}\text { visit/ } \\
\text { telephone }\end{array}$ & 36 & 28 & 27 & 6 & 0 & 0 & 0 & 0 \\
\hline \multirow[t]{2}{*}{ GP } & visit & 56 & 40 & 23 & 23 & 0 & 1 & 91 & 64 \\
\hline & telephone & 8 & 9 & 4 & 2 & 0 & 0 & 16 & 15 \\
\hline GP assistant & $\begin{array}{l}\text { visit/ } \\
\text { telephone }\end{array}$ & 51 & 34 & 33 & 13 & 0 & 0 & 19 & 15 \\
\hline \multirow{2}{*}{$\begin{array}{l}\text { Out-patient clinic } \\
\text { obstetrics/ obste- } \\
\text { trician/ paediatri- } \\
\text { cian/ assistant }\end{array}$} & visit & 4 & 2 & 198 & 185 & 55 & 41 & 28 & 30 \\
\hline & telephone & 112 & 122 & 9 & 5 & 4 & 8 & 6 & 4 \\
\hline Nurse in hospital & $\begin{array}{l}\text { visit/ } \\
\text { telephone }\end{array}$ & 26 & 25 & 35 & 48 & 8 & 13 & 0 & 0 \\
\hline \multirow{3}{*}{$\begin{array}{l}\text { Maternity care } \\
\text { assistance at } \\
\text { home }\end{array}$} & intake & 4 & 4 & 42 & 31 & 0 & 0 & NA & NA \\
\hline & telephone & 4 & 1 & 8 & 4 & 0 & 0 & 0 & 0 \\
\hline & visit & 3 & 2 & 1 & 4 & 57 & 12 & 237 & 169 \\
\hline \multirow[t]{2}{*}{ Ultrasound } & visit & 85 & 86 & 5 & 11 & 0 & 0 & 0 & 0 \\
\hline & telephone & 0 & 1 & 33 & 24 & 0 & 0 & 0 & 0 \\
\hline Physiotherapist & visit & 27 & 36 & 7 & 1 & 0 & 0 & 7 & 0 \\
\hline \multirow{2}{*}{$\begin{array}{l}\text { Alternative treat- } \\
\text { ment }\end{array}$} & visit & 0 & 1 & 2 & 0 & 0 & 0 & 2 & 5 \\
\hline & telephone & 0 & 1 & 2 & 1 & 0 & 0 & 0 & 0 \\
\hline \multirow[t]{2}{*}{ Medical specialist } & visit & 12 & 3 & 1 & 0 & 0 & 0 & 1 & 1 \\
\hline & telephone & 3 & 2 & 2 & 2 & 0 & 0 & 0 & 0 \\
\hline \multirow[t]{2}{*}{ Lactation aid } & visit & 0 & 0 & 0 & 0 & 0 & 0 & 9 & 5 \\
\hline & telephone & 0 & 0 & 0 & 0 & 0 & 0 & 9 & 2 \\
\hline $\begin{array}{l}\text { Physician child } \\
\text { health centre }\end{array}$ & $\begin{array}{l}\text { visit/ } \\
\text { telephone }\end{array}$ & 0 & 0 & 0 & 0 & 0 & 0 & 86 & 55 \\
\hline $\begin{array}{l}\text { Nurse child health } \\
\text { centre }\end{array}$ & $\begin{array}{l}\text { visit/ } \\
\text { telephone }\end{array}$ & 0 & 0 & 0 & 0 & 0 & 0 & 267 & 192 \\
\hline $\begin{array}{l}\text { Help from family } \\
\text { and friends }\end{array}$ & $\begin{array}{l}\text { visit/ } \\
\text { telephone }\end{array}$ & 0 & 0 & 0 & 0 & 0 & 0 & 47 & 47 \\
\hline Vacuum extraction & per unit & NA & NA & NA & NA & 43 & 29 & NA & NA \\
\hline $\begin{array}{l}\text { Caesarean section } \\
\text { (planned) }\end{array}$ & per unit & NA & NA & NA & NA & 10 & 10 & NA & NA \\
\hline $\begin{array}{l}\text { Caesarean section } \\
\text { (unplanned) }\end{array}$ & per unit & NA & NA & NA & NA & 21 & 27 & NA & NA \\
\hline Fundus expression & per unit & NA & NA & NA & NA & 14 & 11 & NA & NA \\
\hline Forceps & per unit & NA & NA & NA & NA & 2 & 1 & NA & NA \\
\hline Episiotomy & per unit & NA & NA & NA & NA & 122 & 75 & NA & NA \\
\hline Rupture & per unit & NA & NA & NA & NA & 82 & 66 & NA & NA \\
\hline $\begin{array}{l}\text { Hospital day } \\
\text { (mother and child) }\end{array}$ & per day & 7 & 0 & 83 & 47 & 33 & 21 & 840 & 854 \\
\hline
\end{tabular}




\section{Chapter 7}

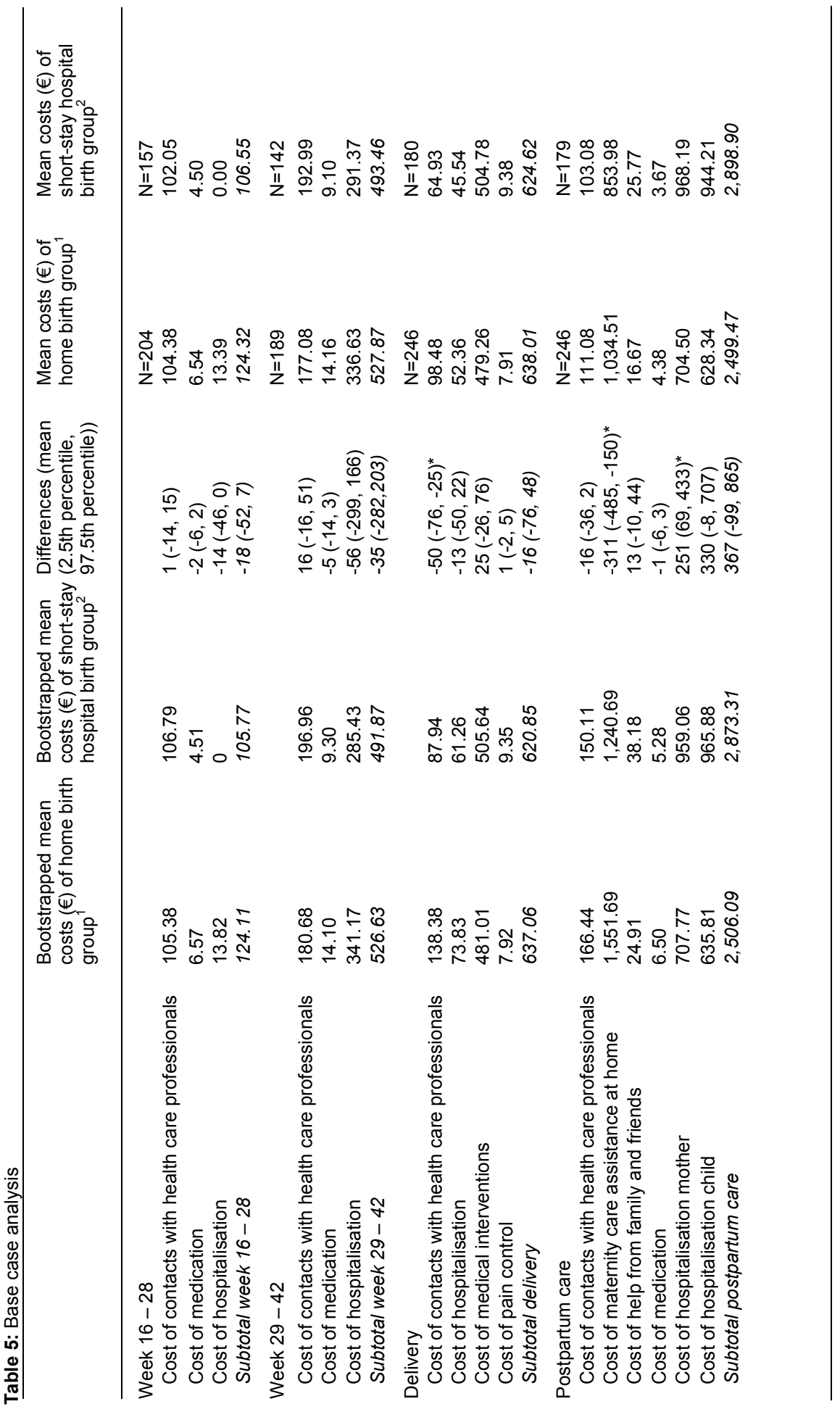




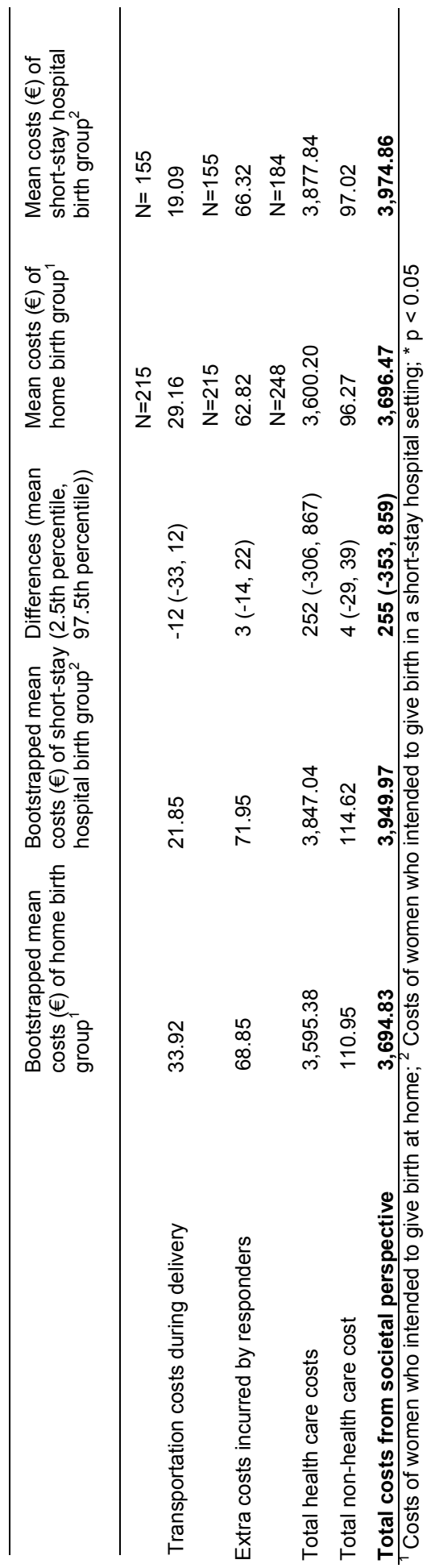




\section{Chapter 7}

The results of the sensitivity analysis are shown in Table 6. All 449 respondents are included in the sensitivity analysis, and the missing data are included by means of general mean substitution. When focusing on the differences between the home birth and the short-stay hospital birth group in terms of percentage, the results of the sensitivity analysis showed no divergence from the conclusions that were drawn from the results of the base case analysis. Although the (sub)total costs are higher than those of the base case analysis, the overall results remain the same, both for the bootstrapped mean costs as well as for the mean costs.

The total costs of giving birth resulting from the sensitivity analysis are $€ 4,364$ for the home birth group, and $€ 4,541$ for the short-stay hospital birth group. The total costs for the two groups are higher than in the base case analysis because all 449 respondents are included in the analysis, instead of eliminating those respondents whose data was incomplete. Furthermore, the results in the sensitivity analysis are equal to the results of the base case analysis.

The costs of hospitalisation constituted the largest portion of the total costs ( $40.7 \%$ in the sensitivity analysis), as shown in Table 7 . In addition, about $32 \%$ of all costs were spent on maternity care assistance at home. The costs of contacts with various health care professionals (i.e. midwives, GPs, obstetricians and other professionals) $14 \%$, respectively.

Table 8 shows the results of the analysis of the database with imputed values for all respondents $(n=449)$. These results are the mean costs for the actual place of birth. The costs for antenatal care are the lowest for women who gave birth at home. Looking at the costs "week 16-28", the differences between the three birth places are small. The costs for women who gave birth in the hospital are slightly higher ( $€ 123$ more), but the antenatal costs for "week 29-42" for the women who gave birth in the hospital are much higher than the costs for women who gave birth at home or in the short-stay hospital setting (respectively $€ 608, € 202$ and $€ 215)$. The costs during delivery and postpartum care are the lowest for the women who gave birth in a short-stay hospital setting. The costs for women who gave birth in the hospital under the supervision of an obstetrician are for each subtotal the highest. The hospital birth group has the highest total costs $(€ 5,208)$. Giving birth in a short-stay hospital birth setting is less costly than giving birth at home ( $€ 2,816$ vs. $€ 3,173)$. The results of the analysis based on the database with no imputed values showed no differences (data not shown). 


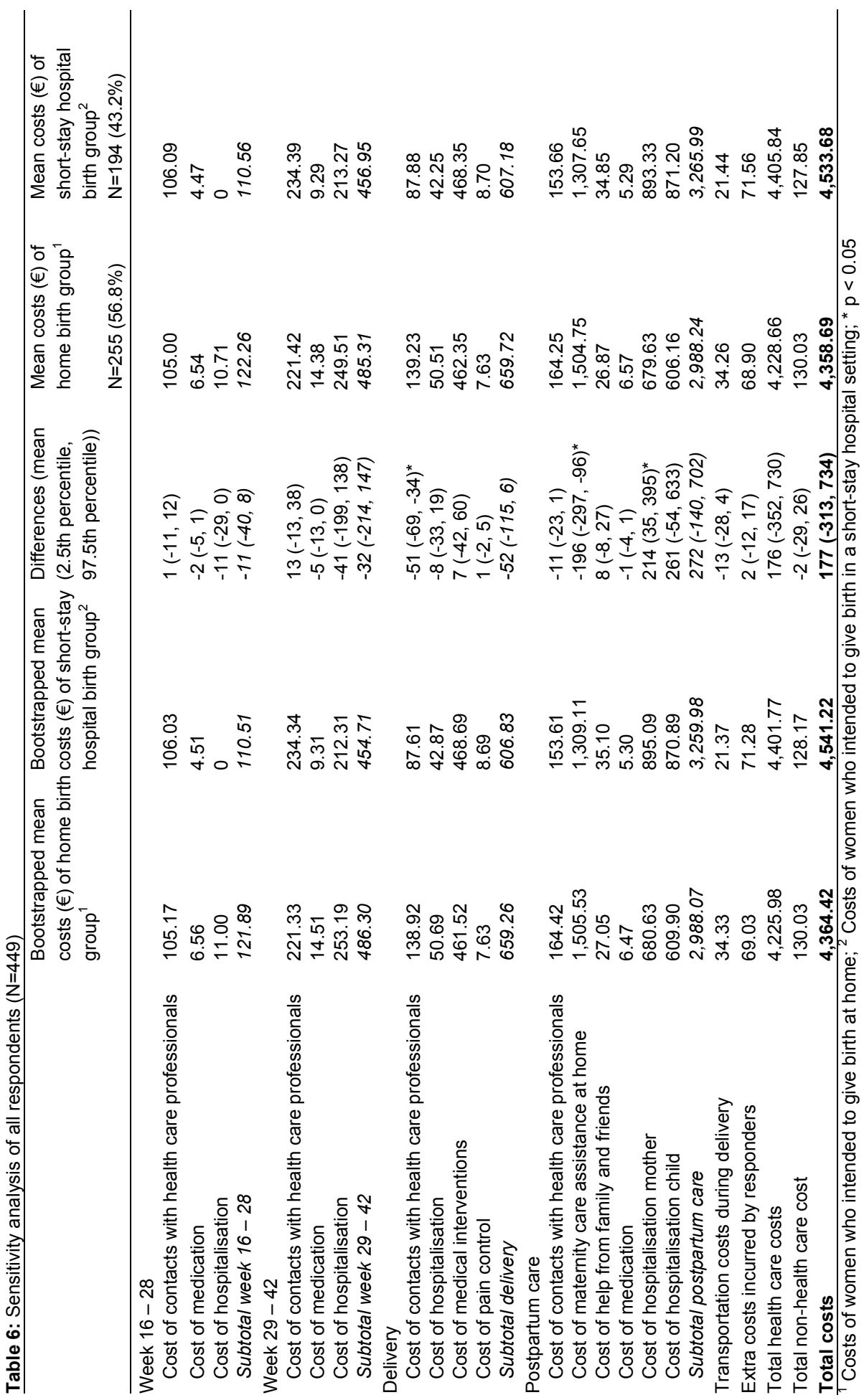




\section{Chapter 7}

Table 7: Total costs per cost category for the base case analysis and sensitivity analysis.

\begin{tabular}{ll}
\hline & $\begin{array}{l}\text { Total costs per cost category }(€) \\
\text { Sensitivity analysis }\end{array}$ \\
\hline Cost of hospitalisation & $3,616.57(40.7 \%)$ \\
Cost of maternity care assistance at home & $2,812.40(31.6 \%)$ \\
Cost of contacts with health care professionals & $1,211.92(13.6 \%)$ \\
Cost of medical intervention & $930.70(10.5 \%)$ \\
Extra costs incurred by responders & $140.46(1.6 \%)$ \\
Cost of informal care & $61.78(0.7 \%)$ \\
Cost of medication (incl. pain relief treatment delivery) & $62.87(0.7 \%)$ \\
Cost of transportation & $55.70(0.6 \%)$ \\
\hline
\end{tabular}

Table 8: Analysis actual place of birth $(n=418)$

\begin{tabular}{|c|c|c|c|}
\hline & $\begin{array}{l}\text { Mean costs }(€) \\
\text { home birth } \\
\text { group }{ }^{1} \\
N=96(23.0 \%)\end{array}$ & $\begin{array}{l}\text { f Mean costs }(€) \text { of } \\
\text { short-stay hospital } \\
\text { birth group }{ }^{2} \\
N=31(7.4 \%)\end{array}$ & $\begin{array}{l}\text { Mean costs }(€) \text { of } \\
\text { hospital birth } \\
\text { group }^{3} \\
\mathrm{~N}=291(69.6 \%)\end{array}$ \\
\hline Subtotal week 16 - 28 & 100.65 & 115.74 & 122.50 \\
\hline Subtotal week 29 - 42 & $202.07^{*}$ & $214.53^{*}$ & $607.96^{*}$ \\
\hline Subtotal delivery & $562.78^{*}$ & $491.07^{*}$ & $719.87^{*}$ \\
\hline Subtotal postpartum care & $2,227.26^{*}$ & $1,924.40^{*}$ & $3,649.62^{*}$ \\
\hline Total health care costs & $3,056.43^{*}$ & $2,711.47^{*}$ & $5,071.83^{*}$ \\
\hline Total non health care cost & 116.35 & 104.95 & 136.54 \\
\hline Total costs actual place of birth & $3,172.78^{*}$ & $2,816.42^{*}$ & $5,208.37^{*}$ \\
\hline
\end{tabular}

\section{Discussion}

This is the first article which reports on the first cost analysis into the costs of giving birth in the Netherlands of nulliparous women with different intentions where to give birth: at home or in a short-stay hospital setting. We expected that the costs of home births would be much lower than those of short-stay hospital deliveries. From the results however, it can be concluded that there is no difference in the total costs between the home birth group and the short-stay hospital group. In the home birth group, more costs were spent on maternity care assistance in the postpartum period. This conclusion is in line with the result that the costs of hospitalisation of the mother and child in the postpartum period are higher for the short-stay hospital birth group. In the Dutch obstetric system, 


\section{Cost analysis}

women who remain hospitalised after delivery receive fewer days of maternity care assistance at home and therefore receive less reimbursement for maternity care assistance at home. This leads to lower costs for maternity care assistance at home than for the home birth group.

Furthermore, the results of the cost analysis have shown that travelling expenses incurred during transportation to the hospital when the delivery started, are higher for women who intended to give birth at home. This may be due to fact these women did not plan to travel to the hospital and are often transferred to the hospital in a later phase of the delivery, when there is more urgency. When looking at the frequencies of using transportation other than the car, $1.2 \%$ of women from the home birth group makes use of a taxi and $4.7 \%$ is transported to the hospital by ambulance (for the short-stay hospital group $0.5 \%$ and $2.6 \%$ respectively). This indicates that women who intend to give birth at home make use of more expensive transportation more often, leading to higher costs.

The results of the cost analysis for the actual place of birth showed a large difference in antenatal costs in "week 29-42" between women who gave birth in secondary care and women who gave birth in primary care. This means that most of the complications during pregnancy arise in the last period of the pregnancy. All respondents were at low risk at the beginning of their pregnancy. When complications occur during pregnancy, their midwife (primary care) has to refer them to much more expensive secondary care. Comparing the results of the analysis of the actual place of birth with the results of the intention-to-treat analysis, a shift can be seen. In the intention-to-treat analysis the costs of a short-stay hospital birth are slightly (but not significantly) higher than the costs of a home birth. In the cost analysis of the actual place of birth, the costs for a short-stay hospital birth are slightly lower than the costs of a home birth. This indicates that the referral rate to secondary care is much higher in the short-stay hospital birth group than in the home birth group, because the expensive care by secondary caregivers will increase the total costs in the intention-to-treat analysis. Further research will be necessary to investigate the difference in referral rates in a short-stay hospital birth and a home birth.

Women who opt for a home birth or a short-stay hospital birth have a lower chance for an operative delivery (i.e. vacuumextraction, forcipal extraction and caesarean section) than women who choose for a hospital birth ${ }^{36}$, while Dutch studies also showed that the maternal and neonatal outcomes of home births and short-stay hospital births are equal to the outcomes of hospital births. This knowledge in combination with the results of this study underlines the advantages of the primary care for low-risk pregnant women when 'normal birth' is concerned.

The collaboration between midwives and obstetricians has to improve to give adequate information to pregnant women about the differences between home births and short-stay hospital births and the chance for a referral to the obstetri- 


\section{Chapter 7}

cian. Women can make optimal decisions about their place of birth what will probably lead to a positive birth experience.

\section{Comparison with other studies}

The reason for our cost analysis was to provide insight into the costs of giving birth in the Netherlands of nulliparous women with different intentions of where to give birth. A cost analysis from a societal perspective has not been performed in the Netherlands before. The outcomes of other studies that examined the economic implications of home births and short-stay hospital births (as opposed to maternity care in the hospital) in other countries could not be generalised to the Netherlands, because the Dutch obstetric system is different, with a high rate of home births and low rate of medical interventions ${ }^{16-22}$. Furthermore, the methodology applied in these other studies does not always correspond with the methodology used in our study. As was explained in the introduction, these studies did not follow the same period (16 weeks of pregnancy until six weeks after delivery) ${ }^{17}$ and costs were not calculated from a societal perspective ${ }^{16,17}$. Another difference is that this cost analysis is based on intention-to-treat, i.e. whether to give birth at home or in a short-stay hospital setting, while some of the other studies were based on the actual place of birth. Finally, the other studies compared home births and births in a short-stay hospital setting with hospital births ${ }^{16,17,20,22}$ but made no comparisons between home births and short-stay hospital births.

Ratcliffe ${ }^{18}$ concluded that the total mean health service costs were lowest for women intending to give birth at home, followed by giving birth in a short-stay hospital setting, and giving birth in the hospital. The low costs of home births reflected the low use of resources during birth by this group.

Anderson and Anderson ${ }^{19}$ compared home births with short-stay hospital births and hospital births. The outcomes of other studies in this field are reviewed. The charges of the different birth locations are determined, based on the intended location. The conclusion was that the average costs of uncomplicated vaginal births are less when delivery takes place at home, as opposed to a short-stay hospital setting or the hospital. Henderson and Petrou ${ }^{21}$ conducted a structured review of the economic implications of home births and short-stay hospital births and compared the resource use of these birth settings as opposed to hospital birth. Eleven studies were included in the review, with different methodologies, inclusion criteria and costs results (heterogeneous studies). It was concluded that although resource use is higher in the hospital, this does not always lead to higher costs for hospital births (because midwives have a different education grade and because hospitals are existing facilities).

Although the studies discussed here provide insight into the proportion of costs of different birth settings, the results are not comparable to our results, because we focused on the difference in costs between intended home births and short-stay 


\section{Cost analysis}

hospital births. Our study does not take the costs of planned delivery in the hospital into account.

\section{Limitations}

Some limitations in this study need to be considered. An important limitation relates to the method of data collection. This cost analysis concerned a multicenter prospective cohort study. The initial idea was to perform a randomized controlled trial, in which the place of birth was decided for the women by means of randomization. However, this approach appeared not to be feasible, as Dutch pregnant women do not accept randomization for the place of birth, as we have published elsewhere ${ }^{37}$. Therefore, possible residual confounding by indication cannot be completely excluded in our study and may explain the results. However, all women had the same possibilities to choose their place of birth, based on social circumstances, which may have diminished the potential for confounding by indication. The results of this study are representative for the Dutch women intending to give birth at home or in a short-stay hospital setting. One hundred midwives from across the Netherlands were selected at random and participated in the recruitment of the respondents. All women were asked to their preferred place of birth in an early stage of their pregnancy (around 16 weeks of gestation age). All women filled in this question and had, therefore, a choice for their place of birth. It is unknown whether this choice is realistic. In the second questionnaire (around 32 weeks of gestation age) the preferred place of birth was asked again. For this analysis we used the first choice for place of birth.

Another limitation concerns the perspective of the study. The aim of this study was to calculate the total costs of giving birth in the Netherlands from a societal perspective. However, the productivity losses of parents are not included in this study, because a difference in productivity losses between the home birth group and the short-stay hospital birth group was not expected. Besides the health care costs, this study also calculated the patient and family costs, which excluded the research from being studied from a health care perspective.

The health care costs included the costs of contacts with health care professionals, medication, maternity care assistance, medical interventions during delivery, pain control, and hospitalization. However, the cost of diagnostic tests such as ultrasounds and CTG monitoring were not separately included in this study. Instead, when women received such a diagnostic test, this test was included in the cost analysis as being an extra contact with the concerning health care provider, in which the time of the appointment was taken into consideration. Therefore, the cost of the diagnostic test itself is included in the calculation of unit costs of visits and it is not possible to present the difference in use of diagnostic tests between both groups. 


\section{Chapter 7}

The poor completion of the cost diaries that were used to calculate part of the cost volumes is also considered a limitation of our study. Of the diaries returned, a considerable number were answered only in part; not all weeks were completed. It appeared to be very time-consuming to complete the diaries. Therefore, the missing data were supplied by means of the other data, using general mean substitution.

In this research the comparison between different birth settings was reduced to an analysis of the costs. The effects of giving birth in the different birth settings were beyond the scope of this analysis. The consequences of giving birth at home, in a short-stay hospital setting, or in the hospital have been studied by several researchers in the past, and these studies indicated similar consequences regarding the different birth settings. A Dutch study concluded that planned home births are at least as good as planned hospital births for women delivering their first child without medical complications, indicating that the choice to give birth at home is a safe choice ${ }^{38}$. Similar studies performed outside the Netherlands concluded that there is no increased risk for low-risk women to give birth at home, and that home births result in fewer medical interventions ${ }^{39-43}$. Because the effects are similar within different birth settings, these consequences were not taken into account.

A final limitation concerns the comparison of our results with the conclusions of earlier studies. As was already explained, these studies differed in methodology and were mostly focused on a comparison between short-stay hospital births and hospital births. Furthermore, it is hard to compare a Dutch short-stay hospital setting with those countries, where they are called birth centres. The characteristics and basic idea of such birth settings may differ between countries.

\section{Conclusions}

The objective of this study was to give a view of the Dutch obstetric system from an economical perspective. This study provides insight into the societal costs of the two groups of women giving birth for the first time in the Netherlands with different intentions regarding place of giving birth. Because of the high rate of home births in the Netherlands, the obstetric system is currently a topic of debate. In summary, from the results of this cost analysis, it may be concluded that there is no difference in the total costs between low-risk nulliparae who prefer to give birth at home and low-risk nulliparae who prefer to give birth in a short-stay hospital setting. 


\section{Cost analysis}

\section{References}

1 Wiegers TA, Van Der Zee J, Keirse MJNC: Maternity Care in The Netherlands: The Changing Home Birth Rate. Birth 1998; 25: 190-7.

2 CBS. Minder thuisbevallingen. http://www.cbs.nl; 2009.

3 NVOG. Leeswijzer NVOG-indicatoren keizersnede. Utrecht: NVOG; 2004.

4 Wiegers TA, Van Der Zee J, Keirse MJNC: Variation in home-birth rates between midwifery practices in the Netherlands. Midwifery 2000; 16: 96-104.

5 Stichting Perinatale Registratie Nederland. Utrecht: 2006.

6 Stichting Perinatale Registratie Nederland. Perinatale Zorg in Nederland 2006. Utrecht: Stichting Perinatale Registratie Nederland; 2008.

7 Waelput AJM: Wat is verloskundige zorg? Nationaal Kompas Volksgezondheid. Bilthoven: Rijksinstituut voor Volksgezondheid en Milieu, RIVM; 2008.

8 Vries RG de: A pleasing birth: midwives and maternity care in the Netherlands. Philadelphia: Temple University Press; 2005.

9 Buitendijk SE, Nijhuis JG: Hoge perinatale sterfte in Nederland in vergelijking tot de rest van Europa. Ned Tijdschr Geneeskd 2004; 148: 1855-60.

10 Mohangoo AD, Nijhuis JG, Buitendijk SE, Ravelli ACJ, Hukkelhoven CWPM, Rijninks-van Driel GC, Tamminga P. Hoge perinatale sterfte in Nederland vergeleken met andere Europese landen: de Peristat-II-studie. Ned Tijdschr Geneeskd 2008; 152: 2718-27.

11 Achterberg PW: Met de besten vergelijkbaar? Internationale verschillen in sterfte rond de geboorte. Bilthoven: RIVM; 2005.

12 Wiegers TA, Keirse MJ, Zee van der J, Berghs GA: Outcome of planned home and planned hospital births in low risk pregnancies: Prospective study in midwifery practices in the Netherlands. BMJ 1996; 313: 1309-13.

13 Van der Hulst LAM, van Teijlingen ER, Bonsel GJ, Eskes M, Bleker OP: Does a pregnant's woman intended place of birth influence her attitudes toward and occurrence of obstetric interventions? Birth 2004; 31: 28-33.

14 Damstra-Wijmenga S: Veilig bevallen. Een vergelijkende studie tussen de thuisbevalling en de klinische bevalling. Groningen: Universiteit van Groningen; 1982.

15 Kleiverda G, Steen A, Andersen I, Treffers P, Everaerd W: Place of delivery in The Netherlands: actual location of confinement. Eur J Obstet Gynecol Reprod Biol 1991; 39: 139-46.

16 Stone PW, Zwanziger J, Hinton Walker P, Buenting J: Economic Analysis of Two Models of Maternity Care: A Freestanding Birth Center Compared to Traditional Care. Res Nurs Health 2000; 23 : 279-89.

17 Hundley VA, Donaldson C, Lang GD, Cruickshank FM, Glazener CMA, Milne JM, Mollison J: Costs of intrapartum care in a midwife-managed delivery unit and a consultant-led labour ward. Midwifery 1995; 11: 103-9.

18 Ratcliffe J: The economic implications of the Edgware birth center. In: Birth Centres: A Social Model for Maternity Care. Edited by Kirkham M. Oxford: Elsevier Health Sciences; 2003: 131-9.

19 Anderson RL, Anderson DA: The cost-effectiveness of home birth. J Nurse-Midwifery 1999; 44: 305.

20 Henderson J, Mugford M: An economic evaluation of home births. In Home Births: The Report of the 1994 Confidential Enquiry by the National Birthday Trust Fund. Edited by Chamberlain G, Wraight A, Crowley P. London: Parthenon; 1997: 191-212.

21 Henderson J, Petrou S: Economic Implications of Home Births and Birth Centers: A Structured Review. Birth 2008; 35: 136-46.

22 Spitzer MC: Birth centers. Economy, safety and empowerment. J Nurse-Midwifery 1995; 40: 371-5.

23 Gray AM, Steele R. The economics of specialist and general practitioner maternity units. Journal of the Royal College of General Practitioners 1981; 31: 586-92.

24 Stilwell JA. Relative costs of home and hospital confinement. BMJ 1979; 2: 257-9. 


\section{Chapter 7}

25 Drummond M, Barbieri M, Cook J, Glick HA, Lis J, Malik F, et al: Transferability of Economic Evaluation Across Jurisdictions: ISPOR Good Research Practices Task Force Report. Value in Health 2009; 12: 409-18.

26 Oostenbrink JB, Bouwmans CAM, Koopmanschap MA, Rutten FFH: Handleiding voor kostenonderzoek; methoden en standaard kostprijzen voor economische evaluaties in de gezondheidszorg. Amstelveen: College voor Zorgverzekeringen (CVZ); 2004.

27 Oostenbrink JB, Koopmanschap MA, Rutten FFH: Standardisation of Costs: The Dutch Manual for Costing in Economic Evaluations. Pharmacoeconomics 2002; 20: 443-54.

28 Drummond MF, Sculpher MJ, Torrance GW, O'Brien BJ, Stoddart GL: Methods for the Economic Evaluation of Health Care Programmes. New York: Oxford University Press; 2005.

29 Dutch Health Insurance Executive Board. Pharmacotherapeutic compass 2008. Amstelveen: Dutch Health Insurance Executive Board; 2008.

30 CBS. StatLine, www.statline.cbs.nl. Den Haag: Statistics Netherlands; 2008.

31 Barber JA, Thompson SG: Analysis of cost data in randomised controlled trials: An application of the non-parametric bootstrap. Stat Med 2000; 19: 3219-36.

32 Ramsey S, Willke R, Briggs A, Phil D, Brown R, Buxton M, et al: Good Research Practices for Cost-Effectiveness Analysis Alongside Clinical Trials: The ISPOR RCT-CEA Task Force Report. Value Health 2005; 8: 521-33.

33 Briggs $\mathrm{AH}$, Wonderling DE, Mooney CZ: Pulling cost-effectiveness analysis up by its bootstraps: a non-parametric approach to confidence interval estimation. Health Econ 1997; 6: 327-40.

34 Drummond MF, MacGuire A: Economic Evaluation in Health Care: Merging Theory with Practice. Oxford: Oxford University Press; 2001.

35 Berger ML, Bingefors K, Hedblom EC, Pahos CL, Torrance GW: Health care cost, quality and outcomes. ISPOR book of terms. Lawrenceville: International Society for Pharmacoeconomics and Outcomes Research; 2003.

36 Maassen M, Hendrix M, Van Vugt $\mathrm{H}$, Veersema S, Smits F, Nijhuis J: Operative deliveries in lowrisk pregnancies in The Netherlands: primary versus secondary care. Birth 2008; 35: 277-82.

37 Hendrix M, Van Horck M, Moreta D, Nieman F, Nieuwenhuijze M, Severens J:, et al: Why women do not accept randomisation for place of birth: feasibility of a RCT in the Netherlands. BJOG 2009; 116: 537-44.

38 Wiegers TA: Home or hospital birth: a prospective study of midwifery care in the Netherlands. Eur J Obstet Gynecol Reprod Biol 1998; 79: 139-41.

39 Ackermann-Liebrich U, Voegeli T, Gunter-Witt K, Kunz I, Zullig M, Schindler C, Maurer M: Home versus hospital deliveries: follow up study of matched pairs for procedures and outcome. BMJ 1996; 313: 1313-8.

40 Janssen PA, Lee SK, Ryan EL, Etchesv DJ, Farquharson DF, Peacock D, Klein MC: Outcomes of planned home births versus planned hospital births after regulation of midwifery in British Columbia. Can Med Assoc J 2002; 166: 315-23.

41 Olsen O: Meta-analysis of the safety of home birth. Birth 1997; 24: 4-13.

42 Hodnett ED, Downe S, Edwards N, Walsh D: (2005). Home-like versus conventional institutional settings for birth. Cochrane Database of Systematic Reviews 20051.

43 Albers LL, Katz VL: Birth setting for low-risk pregnancies: an analysis of the current literature. J Nurse-Midwifery 1991; 36: 215-20. 
Chapter 8

General discussion 


\section{Chapter 8}

\section{Main findings}

In the Netherlands, the decrease in the home birth rate ${ }^{1,2}$, high perinatal mortality ${ }^{3,4}$ and the increase in the referral and intervention rates during birth ${ }^{5-7}$ are subjects of ongoing debates among midwives, obstetricians and also policy makers. The aim of this thesis is to explore the main aspects of obstetric care for low-risk pregnant women in the Netherlands, in particular, regarding preferences, referral rates during birth, intervention rates and costs of obstetric care.

Low-risk pregnant nulliparae have strong preferences related to the place of birth and obstetric care during birth (chapter 3 ). These preferences are multidimensional and are influenced by factors such as obstetric care, socio-demographic factors and attitudes towards the place of birth. The type of birth setting, the possibility of receiving a pain-relief during birth and the place of birth were the most important determinants of the hypothetical choice of obstetric care for low-risk nulliaparae. Women who preferred a birth in the hospital found it less important to give birth in a home-like birth setting but it was more important for them not to be transferred to the hospital during birth. This complies with our preliminary expectations.

For both women and their partners, the possibility of influencing the decisionmaking process during birth is the most important determinant of their choice of obstetric care (chapter 4). For partners, the possibility of receiving pain-relief treatment during birth is more important than for women (as suggested by our study). For women, the home-like birth setting was more important than for partners.

Regarding the findings in this thesis we can conclude that primary care is the adequate place to start delivery for low-risk pregnant women. In primary care, women have a lower chance of operative deliveries during birth than in secondary care. This is in line with other (inter)national studies ${ }^{8-12}$.

Comparing home births and home-like hospital births, differences were found in referral rates without urgency. Women who opted for a home-like hospital birth had a higher chance of being referred to secondary care than women who opted for a home birth. These findings are not in line with our expectations: in case of medical problems during a home birth, the midwife will decide to refer the woman to the obstetrician in an earlier stage, because the woman has to be transferred to the hospital. However, during a home-like hospital birth the threshold for midwives to consult the obstetrician seems to be lower.

The results of our study showed no differences between both groups regarding intervention rates during birth, neonatal outcomes and costs of obstetric care. 


\section{General discussion}

\section{Generalizability of the results to multiparae}

The results presented in this thesis are applicable for low-risk nulliparae. It is not possible to generalize the results to multiparous women. Previous research showed that there are some important differences between nulliparae and multiparae. Due to obstetric histories (e.g. caesarean section, high blood pressure), less multiparae start their prenatal care in primary care. However, multiparous women who had an uncomplicated first delivery are known to have lower referral rates, both during pregnancy and delivery. The referral rates of multiparous women in 2006 and 2007 are presented in tables 1 and 2 (for comparison, see also tables 1 and 2 in chapter 1). In 2006, 86.2\% of all women who started their delivery in primary care gave actually birth in primary care. In 2007 this was $87.0 \%$, respectively.

Table 1: Referral rates from primary care to secondary care of multiparae in 2006.

\begin{tabular}{|c|c|c|c|}
\hline & $\begin{array}{l}\text { All multiparae } \\
\mathrm{N}=96.931(100 \%)\end{array}$ & $\begin{array}{l}\text { All multiparae who } \\
\text { started their prenatal } \\
\text { care in primary care }\end{array}$ & $\begin{array}{l}\text { All multiparae who } \\
\text { started their delivery } \\
\text { in primary care }\end{array}$ \\
\hline & & $\mathrm{N}=73.210(100 \%)$ & $\mathrm{N}=46.655(100 \%)$ \\
\hline Primary care & $73.210(75.5 \%)$ & $73.210(100 \%)$ & \\
\hline Secondary care & $23.721(24.5 \%)$ & & \\
\hline $\begin{array}{l}\text { Referral during pregnancy to } \\
\text { secondary care }\end{array}$ & $26.555(27.4 \%)$ & $26.555(36.3 \%)$ & \\
\hline Start birth in primary care & $46.655(48.1 \%)$ & $46.655(63.7 \%)$ & $46.655(100 \%)$ \\
\hline Start birth in secondary care & $50.276(51.9 \%)$ & & \\
\hline Referral during birth & $6.437(6.6 \%)$ & $6.437(8.8 \%)$ & $6.437(13.8 \%)$ \\
\hline Birth in primary care & $40.218(41.5 \%)$ & $40.218(54.9 \%)$ & $40.218(86.2 \%)$ \\
\hline Birth in secondary care & $56.713(58.5 \%)$ & & \\
\hline
\end{tabular}




\section{Chapter 8}

Table 2: Referral rates from primary care to secondary care of multiparae in 2007.

\begin{tabular}{|c|c|c|c|}
\hline & $\begin{array}{l}\text { All multiparae } \\
\mathrm{N}=94.484(100 \%)\end{array}$ & $\begin{array}{l}\text { All multiparae who } \\
\text { started their prenatal } \\
\text { care in primary care } \\
\mathrm{N}=71.929(100 \%)\end{array}$ & $\begin{array}{l}\text { All multiparae who } \\
\text { started their delivery } \\
\text { in primary care } \\
\mathrm{N}=46.655(100 \%)\end{array}$ \\
\hline Primary care & $71.929(76.1 \%)$ & $71.929(100 \%)$ & \\
\hline Secondary care & $22.555(23.9 \%)$ & & \\
\hline $\begin{array}{l}\text { Referral during pregnancy to } \\
\text { secondary care }\end{array}$ & $27.189(28.8 \%)$ & $27.189(37.8 \%)$ & \\
\hline Start birth in primary care & $44.740(47.4 \%)$ & $44.740(62.2 \%)$ & $44.740(100 \%)$ \\
\hline Start birth in secondary care & $49.744(52.6 \%)$ & & \\
\hline Referral during birth & $5.804(6.1 \%)$ & $5.804(8.1 \%)$ & $5.804(13.0 \%)$ \\
\hline Birth in primary care & $38.936(41.2 \%)$ & $38.936(54.1 \%)$ & $38.936(87.0 \%)$ \\
\hline Birth in secondary care & $55.548(58.8 \%)$ & & \\
\hline
\end{tabular}

There are also some differences between multiparae and nulliparae regarding satisfaction with their (place of) birth. Rijnders et al ${ }^{13}$ showed that multiparae had, three years after giving birth, less negative feelings toward their birth compared to nulliparae (11\% vs. $23 \%)$. Finally, multiparae are known with less interventions during birth than nulliparae ${ }^{8,10,14}$.

\section{Policy implications}

The findings in this study underline the advantages of primary care in a selected population when 'normal birth' is concerned. Obstetric care in the Netherlands has been organised adequately and midwives in primary care are well-educated and competent to handle risk factors during pregnancy and birth process.

This study shows that primary care leads to less interventions during birth and less costs ${ }^{14,15}$. Other Dutch studies showed home births are a safe option to give birth and lead to higher satisfaction with the obstetric care received ${ }^{13-16}$. However, referral rates are high, especially for nulliparae. Previous research showed that an increase in referral rates can lead to dissatisfaction in women ${ }^{13,17-19}$. It is wellknown that while the information given by caregivers is an important factor for satisfaction, it might also influence the choice of place of birth (chapter 3).

It is important to preserve the autonomy for women to choose their own place to give birth ${ }^{20}$. However, midwives and obstetricians have to give more information about the high referral rates during birth and the higher risk of interventions during a hospital birth. Also information about giving birth in the hospital and possibilities on pain-relief treatment must be provided by the caregivers. With this in- 


\section{General discussion}

formation, pregnant women can make informed choices for their place of birth and will be more satisfied with the obstetric care they receive.

The cooperation between midwives in primary care and obstetricians in secondary care must be improved. The aim of caregivers has to be to provide optimal quality of care. Nowadays, professionals in primary and secondary care do not frequently cooperate with each other to achieve the best quality of care. It is therefore recommended that a clinical practicum be added to primary care in the study curriculum for obstetricians.

Finally, women who prefer to give birth in a home-like hospital setting have to rent a maternity room in the hospital. For this rent, the woman has to pay a fee of about $€ 350.00$ out-of-pocket (if these costs are not covered by her health insurance). To promote the autonomy of women to choose their own place of birth, it is not consistent to use a financial incentive regarding the place where to give birth. To overcome this situation, on one hand it is possible to abolish the out-ofpocket payment for a home-like hospital birth, on the other hand, the out-ofpocket costs can be equally introduced for both a home birth and a hospital birth (secondary care).

\section{Implications for further research}

The initial idea of this study was to investigate the differences between home births and home-like hospital births by a randomised controlled trial. Low-risk pregnant women were randomised between a home birth and a home-like hospital birth. As mentioned in chapter 2, in contrast to the findings of the pilot study, after the recruitment of one hundred pregnant women in the prospective study, only one woman was willing to be randomised regarding the initial place of delivery. Autonomy in the choice of place of birth is the most important reason for refusal. Therefore, the study design had to be changed into a prospective observational study.

One of the objectives in the RCT was to investigate differences in costeffectiveness between home births and home-like hospital births, using a trial based full economic evaluation. This piggy back economic evaluation should have made a comparison of both societal costs and patient outcome of both alternatives. Trial-based economic evaluations are considered to be of high value in health care decision making ${ }^{21}$. However, because we had to change the study design, this objective could not be met. A model-based comparison between home births and home-like hospital births is an alternative to this original idea, however, this objective was beyond the scope of this thesis. Nevertheless, the current studies provide data that might make it possible to perform an economic evaluation based on a modelling approach, for which, there are other options. Drummond et al ${ }^{22}$ describe several techniques. The monetary units are similar 


\section{Chapter 8}

across most techniques; however, as the consequences of home versus homelike hospital birth differ, a cost-minimization analysis is not the way forward. This study gathered data about the satisfaction of women regarding place of birth and the obstetric care during delivery. Considering the fact that satisfaction varies between subjects, the outcome measure 'satisfaction' can be used as the effect parameter in an economic model, other than a cost-effectiveness or cost-utility analysis. A cost-consequence analysis may present a listing of all relevant outcome measures and costs of both treatment strategies (e.g. direct costs, indirect costs, clinical outcomes and satisfaction). In that case decision-makers can form their own view of relative importance of the different aspects ${ }^{23}$. This type of analysis provides the most comprehensive presentation of information describing the value of a healthcare intervention, and is also conceptually appealing, however, it does not make it possible to compare the efficiency of interventions over different areas within a health care system. For this purpose, a cost-benefit analysis in which the outcome is not expressed in terms of natural units, but using a monetary value, could be attractive. The data from our discrete-choice experiment can be used to estimate the willingness to pay (WTP) of pregnant women to receive the obstetric care that they prefer. Willingness to pay is a measure of the respondent's willingness to forego (or sacrifice) income in order to obtain certain benefits and could be used as the effect measure in a cost-benefit analysis. However, the method of discrete-choice experiment is still being developed and the validity of the WTP measures based on this method, are still being discussed in the literature. For current policy making, a cost-benefit analysis is therefore premature.

It would be interesting to investigate the satisfaction of this study population three years after giving birth. These results should be comparable with the results of the study of Rijnders et al ${ }^{13}$ and the international studies in Belgium and United Kingdom ${ }^{24,25}$. All of those studies, except the study of Rijnders et al, gave information about both the expectations and the experiences with the obstetric care.

A remarkable outcome observed in our study was the number of low-risk pregnant women who started their delivery in secondary care (about 10\%) ${ }^{14}$. This result implies that these pregnant women chose to be under the care of the obstetrician. It is unclear whether there are socio-demographic differences between women who are under supervision of the primary care giver and women who are under the supervision of the secondary care giver.

We have already begun a prospective observational study to investigate sociodemographic differences between women preferring the care of a midwife and women preferring the care of an obstetrician regarding interventions during birth, costs and satisfaction. 


\section{General discussion}

\section{References}

1 Anthony S, Amelink-Verburg MP, Jacobusse GW, van der Pal- de Bruin KM. De thuisbevalling in Nederland 1995-2002. Leiden: Stichting Perinatale Registratie Nederland en TNO Kwaliteit van Leven, 2005.

2 Centraal Bureau voor de Statistiek, 2009.

3 Buitendijk SE, Nijhuis JG. Hoge perinatale sterfte in Nederland in vergelijking tot de rest van Europa. Ned Tijdschr Geneeskd 2004; 148: 1855-60.

4 Mohangoo AD, Nijhuis JG, Buitendijk SE, Ravelli ACJ, Hukkelhoven CWPM, Rijninks-van Driel GC, Tamminga P. Hoge perinatale sterfte in Nederland vergeleken met andere Europese landen: de Peristat-II-studie. Ned Tijdschr Geneeskd 2008; 152: 2718-27.

5 Amelink-Verburg MP, Rijnders MEB, Buitendijk SE. A trend analysis in referrals during pregnancy and labour in Dutch midwifery care 1988-2004. BJOG 2009; 116: 923-32.

6 Hingstman L, Kenens RJ. Cijfers uit de registratie van verloskundige: peiling 2008. Utrecht: Nivel, 2009.

7 Stichting Perinatale Registratie Nederland. Perinatale Zorg in Nederland 2006. Utrecht: Stichting Perinatale Registratie Nederland, 2008.

8 Wiegers TA, Keirse MJ, Zee van der J, Berghs GA. Outcome of planned home and planned hospital births in low risk pregnancies: Prospective study in midwifery practices in the Netherlands. BMJ 1996; 313: 1309-13.

9 Janssen PA, Lee SK, Ryan E, et al. Outcomes of planned home births versus planned hospital births after regulation of midwifery in British Columbia. Can Med Assoc J 2002; 166: 315-23.

10 Van der Hulst LAM, van Teijlingen ER, Bonsel GJ, Eskes M, Bleker OP. Does a pregnant's woman intended place of birth influence her attitudes toward and occurrence of obstetric interventions? Birth 2004; 31: 28-33.

11 Johnson KC, Daviss BA. Outcomes of planned home births with certified professional midwives: Large prospective study in North America. BMJ 2005; 330: 1416.

12 Ackermann-Liebrich U, Voegeli T, Gunter-Witt K, et al. Home versus hospital deliveries: Follow up study of matched pairs for procedures and outcome. BMJ 1996; 313: 1313-8.

13 Rijnders M, Baston H, Schonbeck Y, van der Pal, K, Prins, M, Green J, Buitendijk S. Perinatal factors related to positive or negative recall of birth experience in women 3 years post partum in The Netherlands. Birth 2008; 35: 107-16.

14 Maassen M, Hendrix M, Van Vugt $\mathrm{H}$, Veersema S, Smits F, Nijhuis J. Operative deliveries in lowrisk pregnancies in The Netherlands: primary versus secondary care. Birth 2008; 35: 277-82.

15 Hendrix M, Evers S, Basten M, Nijhuis J, Severens J. Cost analysis of the Dutch Obstetric system: low-risk nulliparous women preferring home or short-stay hospital birth - a prospective nonrandomised controlled study. BMC Health Services Research 2009; 9: 211.

16 de Jonge A, van der Goes BY, Ravelli ACJ, Amelink-Verburg MP, Mol BW, Nijhuis JG, et al. Perinatal mortality and morbidity in a nationwide cohort of 529688 low-risk planned home and hospital births. BJOG 2009; DOI:10.1111/j.1471-0528.2009.02175.x.

17 Christiaens W, Gouwy A, Bracke P. Does a referral from home to hospital affect satisfaction with childbirth? A cross-national comparison. BMC Health Services Research 2007; 7: 109.

18 Wiegers TA, van der Zee J, Keirse MJ. Transfer from home to hospital: what is its effect on the experience of childbirth? Birth 1998; 25: 19-24.

19 Kleiverda G, Steen AM, Andersen I, Treffers PE, Everaerd W. Confinement in nulliparous women in the Netherlands: subjective experiences related to actual events and post-partum well-being. J Reprod Infant Psychol 1991; 9: 195-213.

20 Hendrix M, Van Horck M, Moreta D, Nieman F, Nieuwenhuijze M, Severens J, et al. Why women do not accept randomisation for place of birth: feasibility of a RCT in the Netherlands. BJOG 2009; 116: $537-44$.

21 Drummond M, McGuire A. Economic evaluation in health care. Merging theory with practice. New York: Oxford University Press; 2001. 


\section{Chapter 8}

22 Drummond M, Sculpher M, Torrance G, O'Brien B, Stoddart G. Methods for the economic evaluation of health care programmes. New York: Oxford University Press; 2005.

23 Mauskopf J, Paul J, Grant D, Stergachis A. The role of cots-consequence analysis in healthcare decision-making. Pharmacoeconomics 1998; 13: 277-88.

24 Christiaens W, Bracke P. Place of birth and satisfaction with childbirth in Belgium and Netherlands. Midwifery 2009; 25: e11-e19.

25 Baston H, Rijnders M, Green J, Buitendijk S. Looking back on birth three years later: Factors associated with a negative appraisal in England and in the Netherlands. J Reprod Infant Psychol 2008; 26: 323-39. 
Chapter 9

Summary 


\section{Chapter 9}

In contrast to most other high-income countries, the organization of the Dutch obstetric care is unique. In the Netherlands, low-risk pregnant women have the possibility of choosing between a home birth and a home-like hospital birth, supervised by their own primary caregiver, a midwife or a general practitioner. Annually, about $30 \%$ of all Dutch women who expecting a child give birth at home and another $10 \%$ in a home-like hospital environment. The remaining $60 \%$ give birth at a hospital under supervision of the obstetrician (secondary care). However, the organization of the Dutch obstetric care came under pressure because of several developments in the last decade, such as high perinatal mortality, negative perceptions of birth experiences with the obstetric care and high intervention and referral rates.

The overall aim of this thesis is to investigate the differences amongst low-risk pregnant women with regard to place of birth, as well as the effectiveness and efficiency of care.

In chapter 1, a review of the developments in obstetric care in the Netherlands is given and an introduction and description of the research aims is described.

In chapter 2, the results of a study regarding the reasons why women are not willing to participate in a randomized controlled trial (RCT) for the place of birth are described. A pilot study showed that $50 \%$ of low-risk nulliparae were willing to participate in a RCT for the place of birth. After conducting this RCT, only one woman was included for the RCT. A questionnaire gave insight in the reasons for refusing participation. The most important reason why women refused participation in the trial was that they had already chosen their place of birth before they were asked to participate at 12 weeks pregnancy. From their answers, it became clear that pregnant women strongly value their autonomy of choice. The decision not to participate in the trial was not influenced by the information given by the midwife and the additional written information. Factors that prevent randomisation for place of birth are difficult to influence. There is a need to explore why there is such certainty of view amongst women having their first child. Until we have an understanding of why women select information to make these choices and why women are reluctant to participate in trials that challenge choice, it may well be impossible to mount a trial of place of birth.

The discussions on home birth and obstetric care in the Netherlands often refer to the preferences of Dutch women for place of birth and attributes of obstetric care. In chapter 3, we investigated whether the choice of obstetric care by lowrisk pregnant women is due to preferences for a specific birth place (home or hospital) per se, or due to the specific combination of preferences for obstetric care, socio-demographic status and attitudes that jointly result in a given choice of obstetric care. For this research question, the discrete-choice experiment has 
been applied. The analysis suggests that there are strong preferences among some Dutch women for a home birth. Nevertheless, the absence of a medical pain-relief treatment might provide incentives for some women to opt for a birth in a hospital, especially at the end of their pregnancy. If the attractiveness of home birth should be preserved in the Netherlands, specific attention should be paid on the approach to pain during a home birth. Efforts could also be made in offering a domestic atmosphere during hospital births to improve hospital-based obstetric care in view of women's preferences.

In chapter 4, we used the discrete-choice experiment to explore the differences in preferences regarding obstetric care between low-risk nulliparea and their partners. 321 women and 212 partners filled in a questionnaire with seven discrete-choice questions. Possibility on influencing decision-making was, both for pregnant women and their partners, was the most important characteristic of the obstetric care. For women, a home-like birth setting was an important characteristic, while the partners found the possibility on pain-relief treatment during birth very important. The results of this study suggest that women and their partners have clearly defined preferences for obstetric care. There are some differences between women and the partners about the preferences. These findings are important where policy issues relating to aspects of maternity care service delivery are being considered.

In chapter 5, we compared planned place of birth and incidence of operative delivery among women at low risk of complications at the time of onset of labour. A retrospective analysis was conducted of data about births in The Netherlands during 2003 that were recorded routinely in the Netherlands Perinatal Registry $(n=107,667)$. Mode of delivery was analyzed for women classified as low risk at labour onset according to their planned place of birth (intention-to-treat analysis). The primary outcome was the rate of operative deliveries (vacuum or forceps extraction or caesarean section). Women at low risk who planned to give birth, and therefore laboured and delivered in secondary care, had a significantly higher rate of operative deliveries than women who began labour in primary care where they intended to give birth $(18 \%[3,558 / 19,850]$ vs $9 \%[7,803 / 87,187]$ (OR $2.25,95 \% \mathrm{Cl} 2.00-2.52)$. For caesarean section, the rates were 12 percent $(2,419 / 19,850)$ versus 3 percent $(2,990 / 87,817)$ (OR 3.97, 95\% Cl 3.15-5.01), irrespective of parity. The rate of operative deliveries was significantly lower for low-risk pregnant women who gave birth in a primary care setting compared with similar women who planned birth in secondary care. As with any retrospective analysis, it was not possible to eliminate bias, such as possible differences between primary and secondary care in assignment of risk status. In addition, known risk factors for interventions, technologies such as induction of labour and foetal monitoring, are only available in secondary care. These findings clearly 


\section{Chapter 9}

demonstrate the need for a prospective study to examine the relationship between planned place of birth and mode of delivery and neonatal and maternal outcomes.

Low-risk nulliparae are known with higher referral rates and intervention rates than low-risk multiparae. However, it is unclear whether there are differences between low-risk nulliparae opting for a home birth and low-risk nulliparae opting for a home-like hospital birth regarding referrals during delivery, intervention rates and neonatal outcomes. In chapter 6 , we describe the results of such a study. A questionnaire to measure the socio-demographic variables of 449 low-risk nulliparae and the medical reports of labour was used. Low-risk nulliparous women with the intention to give birth at home have a considerably lower chance to be referred to secondary care during labour than women who prefer to give birth in a home-like hospital birth setting $(52.2 \%$ vs $66.1 \%, p<0.05)$. No differences were found in urgent referral rates (3.3\% vs $3.3 \%)$. Women who preferred a home-like hospital birth had more unplanned caesarean sections $\left(8.7 \%\right.$ vs $15.3 \%\left(\mathrm{OR}_{\mathrm{adj}}\right.$ $2.01,95 \% \mathrm{Cl} 1.06-3.82)$. No differences were found between both groups regarding neonatal outcomes.

The objective of the study described in chapter 7, was to compare the societal costs of home births with those of births in a home-like hospital setting. This study was a cost analysis based on the findings of a multicenter prospective nonrandomised study comparing two groups of nulliparous women with different preferences for where to give birth, at home or in a home-like hospital setting. Data were collected using cost diaries, questionnaires and birth registration forms. Analysis of the data is divided into a base case analysis and a sensitivity analysis. In the group of home births, the total societal costs associated with giving birth at home were $€ 3,695$ (per birth), compared with $€ 3,950$ per birth in the group for home-like hospital births. Statistically significant differences between both groups were found regarding the following cost categories 'Cost of contacts with health care professionals during delivery' (€138.38 vs. $€ 87.94,-50$ (2.5-97.5 percentile range (PR) -76;-25), $\mathrm{p}<0.05)$, 'cost of maternity care at home' $(€ 1,551.69$ vs. $€ 1,240.69,-311$ (PR $-485 ;-150), p<0.05)$ and 'cost of hospitalisation mother' ( $€ 707.77$ vs. $€ 959.06,251$ (PR 69;433), p<0.05). The highest costs are for hospitalisation ( $41 \%$ of all costs). Because there is a relatively high amount of (partly) missing data, a sensitivity analysis was performed, in which all missing data were included in the analysis by means of general mean substitution. In the sensitivity analysis, the total costs associated with home birth are $€ 4,364$ per birth, and $€ 4,541$ per birth for home-like hospital births. The total costs associated with pregnancy, delivery, and postpartum care are comparable for home birth and home-like hospital birth. The most important differences in costs between the home birth group and the home-like hospital birth group are associated with maternity care assistance, hospitalisation, and travelling costs. 


\section{Chapter 10}

\section{Samenvatting}




\section{Chapter 10}

De organisatie van het Nederlands verloskundig systeem is, in vergelijking met andere ontwikkelde landen, uniek. In Nederland hebben zwangeren de mogelijkheid om te kiezen tussen een thuisbevalling en een poliklinische bevalling onder begeleiding van de eigen verloskundige of huisarts. Jaarlijks bevalt $30 \%$ van de Nederlandse vrouwen thuis en $10 \%$ bevalt poliklinisch in het ziekenhuis (eerste lijn). De overige $60 \%$ bevalt in het ziekenhuis onder begeleiding van de gynaecoloog (tweede of derde lijn). De laatste jaren is de organisatie van de verloskundige zorg onder druk komen te staan door verschillende ontwikkelingen, zoals hoge perinatale sterfte, negatieve ervaringen met de verloskundige zorg en hoge interventie- en verwijscijfers.

Het doel van dit proefschrift heeft betrekking op het onderzoeken van de verschillen tussen zwangeren met betrekking tot de plaats van bevalling en de effectiviteit en doelmatigheid van de zorg.

In hoofdstuk 1 wordt een overzicht gegeven van de ontwikkelingen in de verloskundige zorg in Nederland. Daarnaast worden de onderzoeksdoelen beschreven.

In hoofdstuk 2 worden de resultaten weergegeven van een onderzoek naar de redenen waarom zwangeren niet willen deelnemen aan een gerandomiseerde studie naar de plaats van bevallen. Een pilot-study liet zien dat $50 \%$ van de nulliparae bereid was om deel te nemen aan een RCT voor de plaats van bevallen. Nadat deze RCT was opgezet, bleek slechts één zwangere te willen deelnemen aan deze studie. Een vragenlijst gaf inzicht in de redenen voor het weigeren van deelname. De belangrijkste reden waarom vrouwen weigerden om mee te doen aan een RCT was dat zij al hadden gekozen waar ze wilden bevallen voordat zij gevraagd werden deel te nemen aan het onderzoek. Uit de resultaten bleek dat zwangeren autonomie hoog waarderen. De beslissing om niet deel te nemen aan de RCT werd niet beïnvloed door de schriftelijke en mondelinge informatie die door de verloskundige werd verstrekt. De redenen om niet te participeren zijn moeilijk te beïnvloeden en er is behoefte aan onderzoek waarom vrouwen al zo vroeg in de zwangerschap weten waar ze willen bevallen en waarom ze deze keuzes maken.

De discussies omtrent thuis bevallen en de verloskundige zorg verwijzen vaak naar de voorkeuren van vrouwen voor de plaats van bevallen en de kenmerken van de verloskundige zorg. In hoofdstuk 3 hebben we onderzocht in hoeverre de keuzes van zwangeren ten aanzien van verloskundige zorg een gevolg is van voorkeuren voor een specifieke plaats van bevallen (thuis of poliklinisch) of ten gevolge van een combinatie van voorkeuren, sociodemografische factoren en attitude die samen leiden tot een bepaalde keuze met betrekking tot de verloskundige zorg. Voor deze onderzoeksvraag gebruikten we de discrete-choice experiment. De analyse laat zien dat er sterke voorkeuren zijn bij Nederlandse 
vrouwen voor een thuisbevalling. Daarnaast is de afwezigheid van pijnbestrijding in de thuissituatie voor sommige vrouwen een reden om te kiezen voor een poliklinische bevalling. Dit is vooral het geval aan het einde van de zwangerschap.

Om de thuisbevalling in Nederland aantrekkelijk te houden voor zwangeren zal er aandacht geschonken kunnen worden aan de benadering van pijn in de thuissituatie. Winst is ook te halen uit het huiselijk inrichten van verloskamers zodat de poliklinische bevalling aansluit bij de wensen van de zwangeren.

In hoofdstuk 4 hebben we de discrete-choice experiment gebruikt om de verschillen in voorkeuren ten aanzien van de verloskundige zorg tussen zwangeren en hun partners te onderzoeken. 321 vrouwen en 212 partners hebben een vragenlijst ingevuld met zeven discrete-choice questions. De mogelijkheid om inspraak te hebben in het besluitvormingsproces was voor zowel de vrouwen als de partners het belangrijkste item van de verloskundige zorg. Voor de vrouwen was een huiselijke bevallingsomgeving een belangrijk item, terwijl de partners de mogelijkheid op pijnbestrijding belangrijk vonden. De resultaten laten zien dat vrouwen en hun partners hun voorkeuren duidelijk hebben gedefinieerd. Er zijn enkele verschillen tussen de vrouwen en hun partners die belangrijk zijn voor het beleid ten aanzien van de verloskundige zorg in Nederland.

In hoofdstuk 5 vergelijken we de geplande plaats van bevallen en de incidentie van kunstverlossingen tussen zwangeren zonder medische indicatie op het moment dat de bevalling begint. In een retrospectieve studie zijn de LVR-gegevens uit 2003 gebruikt ( $n=107.667$ ). De wijze van bevallen is geanalyseerd voor alle vrouwen die geen medische indicatie hadden aan het begin van de bevalling in vergelijking met de geplande plaats van bevallen (intention-to- treat analyse). De uitkomstmaat was het aantal kunstverlossingen (vacuüm en forcipale extractie en keizersneden). Vrouwen zonder medische indicatie die gepland hadden om in de tweede lijn te bevallen hadden een significant hogere kans op een kunstverlossing dan vrouwen die de bevalling in de eerste lijn zijn gestart $(18 \%$ $[3,558 / 19,850]$ vs $9 \% \quad[7,803 / 87,187]$ (OR 2.25, 95\% Cl 2.00-2.52). 12\% $(2,419 / 19,850)$ van de zwangeren in de tweede lijn beviel met een keizersnede en $3 \%$ van de zwangeren in de eerste lijn beviel met een keizersnede $(2,990 / 87,817$ ) (OR 3.97, 95\% Cl 3.15-5.01), onafhankelijk van de pariteit. Het aantal kunstverlossingen was significant lager voor zwangeren in de eerste lijn vergeleken met dezelfde zwangeren in de tweede lijn. Zoals met elke retrospectieve studie, was het niet mogelijk om bias te elimineren, zoals mogelijke verschillen tussen eerste lijn en tweede lijn ten aanzien van risico status van de onderzoekspopulatie. Toch zijn bekende factoren voor interventies, zoals inleiden van de bevalling en foetale bewaking alleen mogelijk in de tweede lijn. Deze resultaten laten zien dat een prospectief onderzoek naar de relatie tussen geplande 


\section{Chapter 10}

plaats van bevallen en de wijze van bevallen en neonatale en maternale uitkomsten noodzakelijk is.

Het is bekend dat nulliparae zonder medische indicatie een grotere kans hebben op een verwijzing en interventie tijdens de bevalling dan multiparae zonder medische indicatie. Toch is het onduidelijk in hoeverre er verschillen zijn in verwijzingen, interventies en neonatale uitkomsten tussen vrouwen die kiezen voor een thuisbevalling en vrouwen die kiezen voor een poliklinische bevalling. In hoofdstuk 6 beschrijven we de resultaten van een dergelijk onderzoek. Een vragenlijst om de sociodemografische variabelen te meten van 449 nulliparae zonder medische indicatie en hun medische verslaglegging van de bevalling zijn gebruikt. Zwangeren met de intentie om thuis te bevallen hebben significant minder kans op een verwijzing tijdens de bevalling dan vrouwen die voor een poliklinische bevalling kiezen $(52.2 \%$ vs $66.1 \%, p<0.05)$. Er zijn geen verschillen gevonden in urgente verwijscijfers (3.3\% vs 3.3\%). Vrouwen die de voorkeur hadden voor een poliklinische bevalling hadden meer ongeplande keizersneden $(8.7 \%$ vs $15.3 \%$ $\left(\mathrm{OR}_{\text {adj }} 2.01,95 \% \mathrm{Cl} 1.06-3.82\right)$. Tussen beide groepen zijn geen verschillen gevonden met betrekking tot neonatale uitkomsten.

Het doel van het onderzoek zoals beschreven in hoofdstuk 7 was het vergelijken van de maatschappelijke kosten van thuisbevallingen en poliklinische bevallingen. Dit onderzoek was een kostenanalyse en gebaseerd op de resultaten van een multicenter prospectief onderzoek. Twee groepen van nulliparae met verschillende voorkeuren ten aanzien van de plaats van bevallen (thuis en poliklinisch) werden met elkaar vergeleken. De gegevens werden verzameld met behulp van een kostendagboek, vragenlijsten en de registratieformulieren van de bevalling.

In de groep vrouwen die thuis wilden bevallen, waren de totale maatschappelijke kosten $€ 3.695$ (per bevalling), vergeleken met $€ 3.950$ per geboorte in de groep vrouwen die poliklinisch wilden bevallen. Tussen beide groepen werden statistisch significante verschillen gevonden ten aanzien van de volgende categorieën: 'Kosten van de contacten met professionals tijdens de bevalling' ( $€ 138,38$ vs. $€ 87,94,-50$ (2.5-97.5 percentile range (PR) -76;-25), $p<0.05)$, 'kosten van de kraamzorg thuis' $(€ 1.551,69$ vs. $€ 1.240,69,-311$ (PR $-485 ;-150), p<0.05)$ en 'kosten van de ziekenhuisopname van de moeder' (€707,77 vs. €959,06, 251 (PR 69;433), $p<0.05)$. Ziekenhuisopname leidt tot de hoogste kosten (41\% van alle kosten). Omdat het aantal ontbrekende waarden relatief groot was, is er een sensitiviteitsanalyse uitgevoerd, waarin alle ontbrekende waarden werden geimputeerd en meegenomen in de analyse. In de sensitiviteitsanalyse waren de totale kosten van een thuisbevalling $€ 4.364$ per geboorte, en $€ 4.541$ per poliklinische geboorte. De totale kosten ten aanzien van zwangerschap, bevalling en nazorg zijn vergelijkbaar voor beiden groepen (thuis en poliklinisch). De belangrijkste verschillen in kosten tussen thuisbevallingen en poliklinische bevallingen hebben betrekking op de kraamzorg, ziekenhuisopname en reiskosten. 


\section{Dankwoord}

Onderzoek doe je niet alleen!

Dit proefschrift is dan ook het resultaat van een samenwerking met velen, die ik wil bedanken voor hun inzet.

Ten eerste wil ik graag alle vrouwen en hun partners bedanken voor hun bereidheid om mee te doen aan dit onderzoek. Ook de verloskundigen die een enthousiaste bijdrage hebben geleverd aan de inclusie en het versturen van de partusverslagen, ben ik dankbaar voor hun medewerking.

Daarnaast zijn er ook een aantal mensen die ik graag met naam wil bedanken:

Prof. dr. J.G. Nijhuis, beste Jan, in oktober 2002 spraken we voor de eerste keer over een gerandomiseerde studie naar de plaats van bevallen. Ik was meteen enthousiast, niet realiserende wat een lange hobbelige weg er te gaan was. Nadat we eindelijk de subsidie hadden gekregen, konden we in 2005 starten met het onderzoek. Je wist me altijd te inspireren en aan te zetten om verder te gaan, ook toen bleek dat het randomiseren van de zwangere vrouwen niet ging lukken. Ik ben blij met het vertrouwen dat je in mij had en de kans die je mij hebt geboden dit onderzoek te doen. Jouw goede ideeën, betrokkenheid, snelle controles en interesse hebben een grote en positieve invloed gehad op mij en op dit proefschrift.

Prof. dr. J.L. Severens, beste Hans, je werd al in een vroeg stadium bij dit onderzoek betrokken. Geen slechte keuze, want ieder gesprek met jou was van grote waarde. HTA was voor mij een onbekend terrein, maar door jouw begeleiding en je HTA-lessen heb ik het mij behoorlijk eigen gemaakt. Heel hartelijk dank voor de 'doelmatige' samenwerking.

Dr. M.I. Pavlova, beste Milena, je hebt mij wegwijs gemaakt in de conjoint analysis en de discrete- choice experiment. Geen makkelijke methodiek, maar je was iedere keer weer bereid om mij te helpen en samen verder te werken aan de analyses. Veel dank hiervoor.

De leescommissie, bestaande uit Prof. dr. J.F.M. Metsemakers, Prof. dr. S.E. Buitendijk, Prof. dr. G.G.M. Essed, Prof. dr. W. Groot en Dr. A. de Jonge, wil ik heel hartelijk danken dat zij de moeite hebben genomen om mijn proefschrift te beoordelen. 


\section{Dankwoord}

Marianne Nieuwenhuijze en Naomi Satijn, door jullie bijdrage aan de projectgroep creëerden we draagvlak in de eerste lijn. Zeer belangrijk voor het uiteindelijke resultaat! Ik ben jullie dan ook dankbaar voor jullie enthousiaste medewerking en jullie praktische ideeën en tips.

Voor de toekomst hoop ik dat we nog veel onderzoek in de eerste lijn van de grond krijgen.

Marlies Rijnders, bij de overstap van de RCT naar een cohortstudie heb je me geholpen bij de landelijke uitzet van het onderzoek. Door jouw ervaringen met de Greater Expectations studie, heb je een belangrijke bijdrage kunnen leveren aan de vragenlijsten. Hartelijk dank voor de fijne samenwerking en hopelijk lukt het jou ook om je proefschrift snel af te ronden.

Fred Nieman, Luc Smits, Silvia Evers, Bas Veersema, Frans Smits en Frits van Merode, dank voor jullie bijdragen aan de verschillende hoofdstukken. Jullie hebben ieder, met een eigen expertise, een belangrijke bijdrage geleverd aan de analyse van de data.

Fred, dankzij jou weet ik nu hoe ik vragenlijsten moet ontwikkelen en analyseren. Ook toen we wilden onderzoeken waarom de zwangeren niet wilden mee doen aan de RCT stond je meteen klaar om mee te denken bij de ontwikkeling van een vragenlijst en de aanpassingen van het artikel.

Luc, jij hebt mij wegwijs gemaakt in de logistische regressie-analyse en het imputeren van missing data. Mijn eerste bezoek aan jou kan ik mij nog goed herinneren. Ik wist niet waar en hoe ik moest beginnen, maar we zijn er samen uitgekomen en ik heb er veel van geleerd.

De toenmalige studenten, Elvira Nouwens, Marloes Maassen, Marleen van Vugt, Marieke van Horck, Daphne Moreta, Priscilla Mantingh, Marianne Delescen, Anne de Leij, Emy Vankan, Marloes Basten en Robijn Wagenmakers, wil ik ontzettend bedanken voor hun bijdrage aan dit onderzoek. Zonder jullie was het nooit gelukt om alle gegevens verzameld en ingevoerd te krijgen.

Veerle, Raph, Maria en Natasja, dank voor de gezellige tijd. Koffie drinken en samen eten... het zorgde voor de nodige afleiding. En... ik kan nog steeds niet kiezen wie er beter bevalt...

Mijn vrienden wil ik danken voor hun vriendschap, de interesse in mijn werk en onderzoek, maar bovenal voor de broodnodige ontspanning, zoals etentjes, uitgaan, sporten en weekendjes weg.

Natuurlijk wil ik graag mijn (schoon)familie bedanken en dan met name mijn ouders. Pap, mam, bedankt voor jullie vertrouwen en onvoorwaardelijke steun. 


\section{Dankwoord}

Mijn kleine meisje Boo, het hoogtepunt van de afgelopen vijf jaar was jouw geboorte. Ik geniet intens van jou en de manier waarop je opgroeit en je je ontwikkelt. Vanaf nu ligt de laptop in de kast als ik vrij ben, dus alle tijd voor jou om leuke dingen te doen en de wereld te ontdekken.

Liefste Bart, ik ben ontzettend blij dat jij op mijn pad bent gekomen. Het is zo fijn om te weten dat er altijd iemand voor je is, iemand die achter je staat en je volledig steunt in de keuzes die je maakt. Samen met jou voel ik mij compleet! Je bent echt mijn maatje. Zonder jouw steun was dit proefschrift er niet gekomen. Ondanks dat het niet jouw 'ding' is, heb je iedere keer weer mijn artikelen gelezen. Ontzettend veel dank voor alles wat je me tot nu toe hebt gegeven en ik verheug me op de toekomst, samen met jou!

Marijke 



\section{Curriculum Vitae}

Marijke Hendrix werd, na een voorspoedige thuisbevalling, op 2 oktober 1979 in Born geboren. In 1996 nam zij haar HAVO-diploma aan het Bisschoppelijk College te Sittard (huidige Trevianum) in ontvangst. Zij startte in september van dat jaar de studie HBO-Verpleegkunde aan de Hogeschool Zuyd in Sittard (later Heerlen).

$\mathrm{Na}$ een stage aan de Universidad Vall d'Hebron in Barcelona studeerde zij in juni 2000 af, waarna zij verder ging studeren aan de Universiteit Maastricht. Zij studeerde Gezondheidswetenschappen met als differentiatie Zorgwetenschappen. $\mathrm{Na} 2$ jaar, in september 2002, behaalde zij haar doctoraalexamen.

Haar carrière begon zij bij de afdeling Gynaecologie in het academisch ziekenhuis Maastricht als coördinator Transmuraal Zorgcentrum Voortplanting. De ontwikkelingen binnen de verloskunde bleken de aanzet voor het promotieonderzoek 'Wat bevalt beter: thuis of (poli)klinisch?'. In september 2005 startte zij met dit promotieonderzoek, waarvan het resultaat hier voor u ligt.

In maart 2010 vervolgde zij haar carrière als docent-onderzoeker aan de Academie Verloskunde Maastricht.

\section{List of publications}

1. Maassen M, Hendrix M, Van Vugt H, Veersema S, Smits F, Nijhuis J. Operative deliveries in low-risk pregnancies in The Netherlands: primary versus secondary care. Birth 2008;35:277-282.

2. Hendrix M, Van Horck M, Moreta D, Nieman F, Nieuwenhuijze M, Severens $\mathrm{J}$, et al. Why women do not accept randomisation for place of birth: feasibility of a RCT in the Netherlands. BJOG 2009;116(4):537-44.

3. Pavlova M, Hendrix M, Nouwens E, Nijhuis J, van Merode G. The choice of obstetric care by low-risk pregnant women in the Netherlands: Implications for policy and management. Health Policy 2009;93:27-34.

4. Hendrix M, Evers S, Basten M, Nijhuis J, Severens J. Cost analysis of the Dutch obstetric system: low-risk nulliparous women preferring home or shortstay hospital birth - a prospective non-randomised controlled study. BMC Health Services Research 2009;9:211. 
